\title{
JULIANA ROdRIGUES PINTO
}

\section{Morbidade de crianças com baixo peso ao nascer} durante o primeiro ano de vida na cidade de

\author{
Sobral, Ceará
}

Dissertação apresentada à Faculdade de Medicina da Universidade de São Paulo para obtenção do título de Mestre em Ciências

Programa de: Pediatria

Orientadora:Prof ${ }^{a}$. Dr ${ }^{\mathrm{a}}$. Edna Maria de Albuquerque Diniz

\section{SÃO PAULO}

2010 
Dados Internacionais de Catalogação na Publicação (CIP)

Preparada pela Biblioteca da

Faculdade de Medicina da Universidade de São Paulo

Creprodução autorizada pelo autor

Pinto, Juliana Rodrigues

Morbidade de crianças com baixo peso ao nascer durante o primeiro ano de vida na cidade de Sobral, Ceará / Juliana Rodrigues Pinto. -- São Paulo, 2010.

Dissertação(mestrado)--Faculdade de Medicina da Universidade de São Paulo.

Programa de Pediatria.

Orientadora: Edna Maria de Albuquerque Diniz.

Descritores: 1.Recém-nascido de baixo peso 2.Morbidade 3.Hospitalização 4.Aleitamento materno 5.Prematuro

USP/FM/DBD-320/10 


\title{
DEDICATÓRIA
}

\author{
Aos meus pais, \\ pelo amor e segurança, exemplo de caráter, perseverança, \\ e esforço que fizeram ao me proporcionar \\ educação e uma formação acadêmica.
}

Ao meu irmão,

espelho em minha identidade, ensinou-me a amar e a repartir, por todas as vezes que confiou em mim.

Ao meu marido, companheiro de todas as horas, apoio nos momentos mais difíceis.

E aos meus filhos Enzo e Lucas, amor sem limites, além da barreira espaço-tempo. 


\section{AGRADECIMENTOS}

À Prof ${ }^{\mathrm{a}}$. Dr ${ }^{\mathrm{a}}$. Edna Maria Albuquerque Diniz, pela confiança e por me honrar com seus conhecimentos acadêmicos e pessoais, meu mais sincero reconhecimento e agradecimento.

Ao Dr. Alexandre Ferraro, por resgatar em mim ensinamentos há muito esquecidos.

Aos agentes comunitários de saúde e enfermeiros da equipe do Programa de Saúde da Família de Sobral, sem os quais este trabalho não teria se concretizado.

À diretoria do Hospital Dr. Estevam Pontes e da Santa Casa de Misericórdia de Sobral, por aprovarem a realização da pesquisa.

Aos auxiliares de enfermagem da Maternidade e do Berçário da Santa Casa de Misericórdia de Sobral, pela disponibilidade com que continuamente me atenderam.

Aos amigos Andrea, Fábio, Michele, Hiroki, Renata e Carlos, por vivenciarem comigo este trabalho e por me brindarem com observações sempre relevantes.

À Adriana, Airana, Hayssa, pelo carinho que dedicaram aos meus filhos durante todo o desenvolvimento da pesquisa. 
"A coisa mais indispensável a um homem é reconhecer o uso que deve fazer do seu próprio conhecimento."

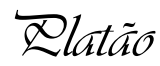


Esta tese está de acordo com as seguintes normas, em vigor no momento desta publicação:

Referências: adaptado de International Committee of Medical Journals Editors (Vancouver)

Universidade de São Paulo. Faculdade de Medicina. Serviço de Biblioteca e Documentação. Guia de apresentação de dissertações, teses e monografias. Elaborado por Anneliese Carneiro da Cunha, Maria Julia de A. L. Freddi, Maria F. Crestana, Marinalva de Souza Aragão, Suely Campos Cardoso, Valéria Vilhena. $2^{\mathrm{a}}$ ed. São Paulo: Serviço de Biblioteca e Documentação; 2005.

Abreviaturas dos títulos dos periódicos de acordo com List of Journals Indexed in Index Medicus. 


\section{SUMÁRIO}

Lista de abreviaturas e siglas

Lista de tabelas

Lista de figuras

Lista de gráficos

Resumo

Summary

1 INTRODUÇÃO

1.1 Caracterização do problema: a importância de estudar crianças com baixo peso ao nascer.

1.2 Determinantes do baixo peso ao nascer...........................................

1.3 Baixo peso ao nascer como fator de risco ...................................... 10

1.4 Justificativa do estudo.......................................................... 14

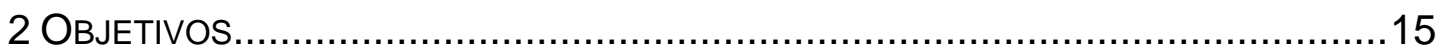

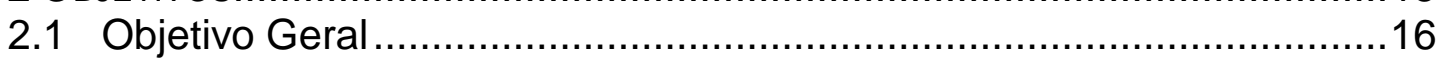

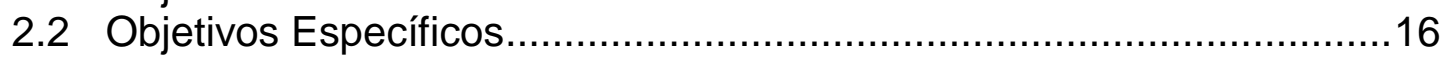

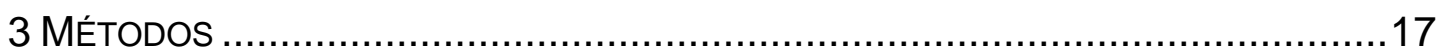

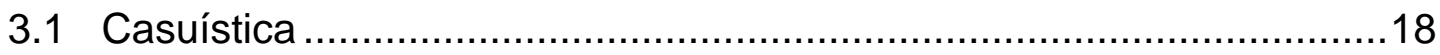

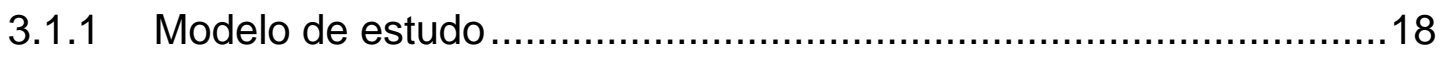

3.1.2 Sobral: o local do estudo ..................................................... 18

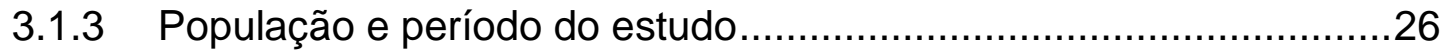

3.1.4 Critérios de inclusão ...............................................................27

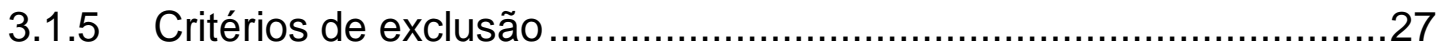

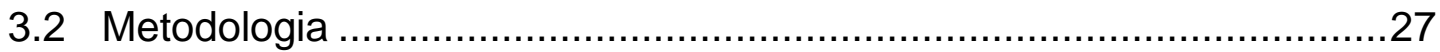

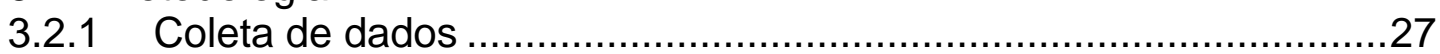

3.2.2 Variáveis de estudo ............................................................28

3.2.2.1 Variáveis de exposição ....................................................28

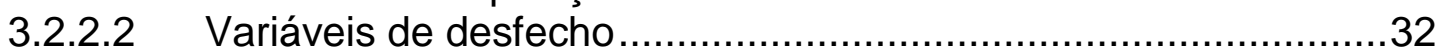

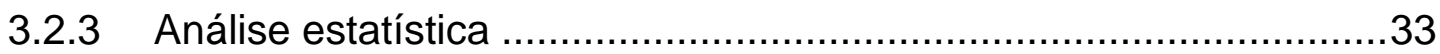

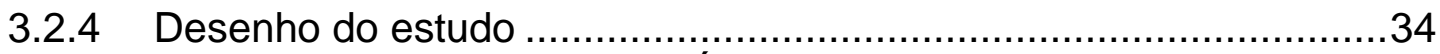

3.2.5 Aprovação em Comissão de Ética .............................................. 35

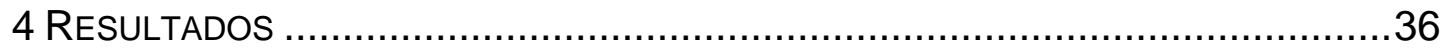

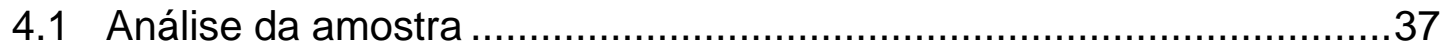

4.1.1 Características maternas....................................................... 37

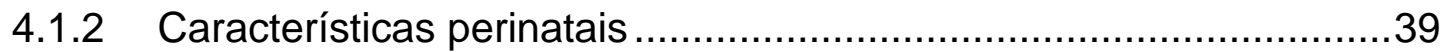

4.2 Evolução ponderoestatural ........................................................ 41

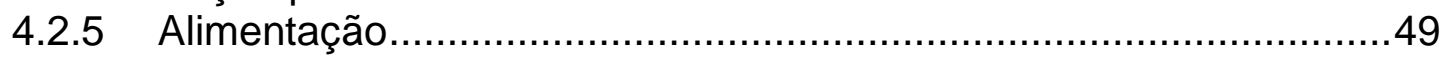

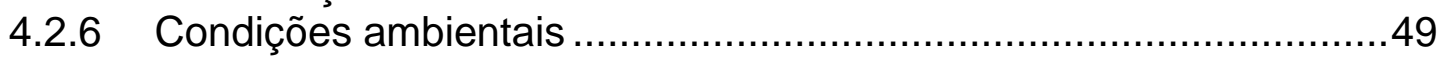


4.2.7 Condições mórbidas................................................................50

4.2.7.1 Consultas com patologias durante o acompanhamento do PSF no primeiro ano de vida..................................................50

4.2.7.2 Consultas e internações hospitalares …………………...........51

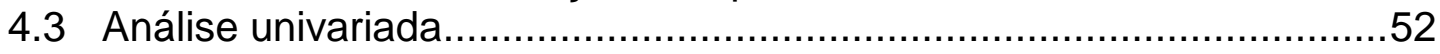

4.3.1 Relação entre consultas por doença no PSF e variáveis de exposição

4.3.2 Relação entre consultas em emergência hospitalar e variáveis de exposição.

4.3.3 Relação entre internações hospitalares e variáveis de exposição

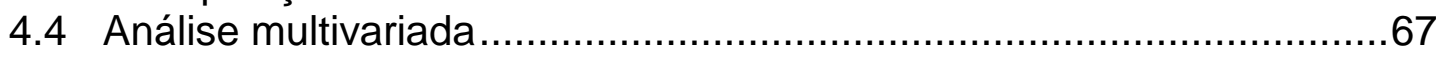

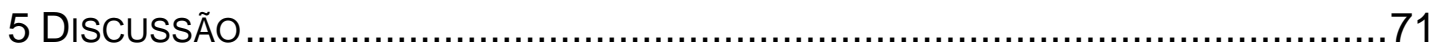

5.1 Características maternas das crianças com BPN acompanhadas pelo PSF da cidade de Sobral, CE.............................73

5.2 Características perinatais das crianças com BPN acompanhadas pelo PSF da cidade de Sobral, CE............................75

5.3 A evolução ponderoestatural das crianças com BPN acompanhadas pelo PSF da cidade de Sobral, CE.

5.4 Condições ambientais e econômicas das crianças com BPN acompanhadas pelo PSF da cidade de Sobral, CE

5.5 Morbidades das crianças com BPN acompanhadas pelo PSF da cidade de Sobral, CE.

5.6 Relações das variáveis de exposição estudadas e o número de consultas por patologia das crianças com BPN no PSF da cidade de Sobral, CE.

5.7 Relações das variáveis de exposição estudadas e a presença de consultas em emergência pediátrica das crianças com BPN da cidade de Sobral, CE.

5.8 Relações das variáveis de exposição estudadas e a presença de internação no período neonatal nas crianças com BPN da cidade de Sobral, CE

5.9 Relações das variáveis de exposição estudadas e a presença de internação após o período neonatal nas crianças com BPN da cidade de Sobral, CE.

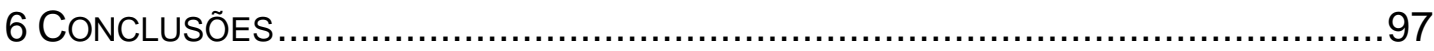

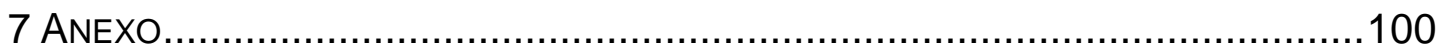

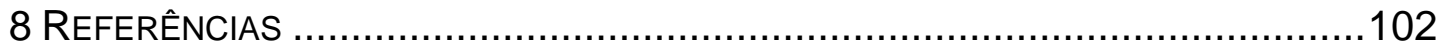




\section{LISTA DE ABREVIATURAS E SIGLAS}

$\begin{array}{ll}\text { AA } & \text { - Aleitamento artificial } \\ \text { ACS } & \text { - Agente Comunitário de Saúde } \\ \text { AIDPI } & \text { - Atenção Integrada as Doenças Prevalentes da Infância } \\ \text { AIG } & \text { - Adequado para idade gestacional } \\ \text { AM } & \text { - Aleitamento Materno } \\ \text { AME } & \text { - Aleitamento Materno Exclusivo } \\ \text { BP } & \text { - Baixo Peso } \\ \text { BPN } & \text { - Baixo Peso ao Nascer } \\ \text { CMI } & \text { - Coeficiente de Mortalidade Infantil } \\ \text { DNV } & \text { - Declaração de nascido vivo } \\ \text { DV } & \text { - Desvio-Padrão } \\ \text { GECA } & \text { - Gastroenterocolite Aguda } \\ \text { GIG } & \text { - Grande para idade gestacional } \\ \text { IBGE } & \text { - Instituto Brasileiro de Geografia e Estatística } \\ \text { IC } & \text { - Intervalo de confiança } \\ \text { IG } & \text { - Idade Gestacional } \\ \text { IGC } & \text { - Idade Gestacional Corrigida } \\ \text { IRA } & \text { - Infecções Respiratórias Agudas } \\ \text { IVAS } & \text { - Infecções de Vias Aéreas Superiores } \\ \text { MS } & \text { - Ministério da Saúde } \\ \text { OD } & \text { - Odds Ratio } \\ \text { OMS } & \text { - Organização Mundial de Saúde } \\ \text { ONU } & \text { - Organizações das Nações Unidas } \\ \text { PIG } & \text { - Pequeno para idade gestacional } \\ \text { - Programa de Saúde da Família } \\ \text { - Retardo de crescimento intrauterino } \\ \text { REém-nascido } \\ \text { RE }\end{array}$




$\begin{array}{ll}\text { RNBP } & \text { - Recém-nascido de Baixo Peso } \\ \text { RNPT } & \text { - Recém-nascido Pré-termo } \\ \text { RNT } & \text { - Recém-nascido a Termo } \\ \text { SCMS } & \text { - Santa Casa de Misericórdia de Sobral } \\ \text { SINASC } & \text { - Sistema de Informações de Nascidos Vivos } \\ \text { SM } & \text { - Salário mínimo } \\ \text { UTI } & \text { - Unidade de terapia intensiva }\end{array}$




\section{LISTA DE TABELAS}

Tabela 1 - Variáveis maternas da população de crianças com BPN e da amostra de estudo - Sobral, CE - 2005 a 2007

Tabela 2 - Variáveis perinatais da população de crianças com BPN e da amostra de estudo - Sobral, CE - 2005 a 2007

Tabela 3 - Médias de peso, comprimento e perímetro cefálico e respectivos DP durante as consultas de puericultura no primeiro ano de vida. Sobral, CE - 2005 a 2007.

Tabela 4 - Alimentação referida durante as consultas de puericultura das crianças com BPN - Sobral, CE - 2005 a 2007

Tabela 5 - Condições ambientais e econômicas das crianças com BPN por ocasião da primeira consulta de puericultura Sobral, CE - 2005 a 2007 50

Tabela 6 - Distribuição percentual das consultas por doença em PSF e variáveis maternas das crianças com BPN estudadas durante o primeiro ano de vida - Sobral, CE - 2005 a 2007

Tabela 7 - Distribuição percentual das consultas por doença em PSF e variáveis perinatais das crianças com BPN estudadas durante o primeiro ano de vida - Sobral, CE - 2005 a 2007

Tabela 8 - Distribuição percentual das consultas por doença em PSF e variáveis ambientais e econômicas das crianças com BPN estudadas durante o primeiro ano de vida Sobral, CE - 2005 a 2007

Tabela 9 - Distribuição percentual das consultas por doença em PSF e a evolução ponderoestatural e alimentação até os 4 meses das crianças com BPN estudadas durante o primeiro ano de vida - Sobral, CE - 2005 a 2007.

Tabela 10 - Distribuição percentual das consultas em emergência hospitalar e características maternas das crianças com BPN estudadas durante o primeiro ano de vida Sobral, CE - 2005 a 2007 
Tabela 11 - Distribuição percentual das consultas em emergência hospitalar e características perinatais das crianças com BPN estudadas durante o primeiro ano de vida Sobral, CE - 2005 a 2007

Tabela 12 - Distribuição percentual das consultas em emergência hospitalar e características ambientais e econômicas das crianças com BPN estudadas durante o primeiro ano de vida - Sobral, CE - 2005 a 2007

Tabela 13 - Distribuição percentual das consultas em emergência hospitalar e a evolução ponderoestatural e alimentação aos quatro meses das crianças com BPN estudadas durante o primeiro ano de vida - Sobral, CE - 2005 a 2007

Tabela 14 - Distribuição percentual das características maternas e presença de internação neonatal das crianças com BPN estudadas durante o primeiro ano de vida Sobral, CE - 2005 a 2007

Tabela 15 - Distribuição percentual das características perinatais e a presença de internação neonatal das crianças com BPN estudadas durante o primeiro ano de vida Sobral, CE - 2005 a 2007

Tabela 16 - Distribuição percentual das características ambientais e econômicas e a presença de internação neonatal das crianças com BPN estudadas durante o primeiro ano de vida - Sobral, CE - 2005 a 2007

Tabela 17 - Distribuição percentual das características maternas e a presença de internação após o período neonatal das crianças com BPN estudadas durante o primeiro ano de vida - Sobral, CE - 2005 a 2007

Tabela 18 - Distribuição percentual das características perinatais e a presença de internação após o período neonatal das crianças com BPN estudadas durante o primeiro ano de vida - Sobral, CE - 2005 a 2007

Tabela 19 - Distribuição percentual das características ambientais e econômicas e a presença de internação após o período neonatal das crianças com BPN estudadas durante 0 primeiro ano de vida - Sobral, CE - 2005 a 2007 66

Tabela 20 - Distribuição percentual da evolução ponderoestatural e alimentação aos 4 meses de idade e internação após o período neonatal das crianças com BPN estudadas durante o primeiro ano de vida - Sobral, CE - 2005 a 2007 
Tabela 21 - Análise multivariada entre consultas por doença em PSF e as variáveis características maternas, perinatais, evolução ponderoestatural durante o primeiro ano de vida das crianças com BPN estudadas - Sobral, CE 2005 a 2007

Tabela 22 - Análise multivariada entre consulta em emergência pediátrica e as variáveis características perinatais, condições ambientais e alimentação durante o primeiro ano de vida das crianças com BPN estudadas - Sobral, CE - 2005 a 2007

Tabela 23 - Análise multivariada entre internação neonatal e as variáveis características maternas, perinatais, condições ambientais e econômicas durante o primeiro ano de vida das crianças com BPN estudadas - Sobral, CE - 2005 a 2007

Tabela 24 - Análise multivariada entre internação após o período neonatal e as variáveis características maternas, perinatais, alimentação e evolução ponderoestatural durante o primeiro ano de vida das crianças com BPN estudadas - Sobral, CE - 2005 a 2007 


\section{LISTA DE FIGURAS}

Figura 1 - A cidade de Sobral dentro do Estado do Ceara..........................19

Figura 2 - Município de Sobral - Sede e Distritos ........................................20

Figura 3 - Cobertura populacional pelo Agente Comunitário de Saúde do PSF na cidade de Sobral, CE - 2002 a 2009 .............21

Figura 4 - Fluxograma da população de crianças nascidas vivas com BPN segundo o SINASC às vivas até um ano de idade com prontuário hospitalar e de PSF 


\section{LISTA DE GRÁFICOS}

Gráfico 1 - Evolução da média de peso das crianças do sexo feminino e de BPN, pela idade gestacional, estudadas durante o primeiro ano de vida - Sobral, CE - 2005 a 2007

Gráfico 2 - Evolução da média de peso das crianças do sexo masculino e de BPN, pela idade gestacional, estudadas durante o primeiro ano de vida - Sobral, CE - 2005 a 2007

Gráfico 3 - Evolução da média do comprimento das crianças do sexo feminino e de BPN, pela idade gestacional, estudadas durante o primeiro ano de vida - Sobral, CE 2005 a 2007

Gráfico 4 - Evolução da média de peso do comprimento do sexo masculino e de BPN, pela idade gestacional, estudadas durante o primeiro ano de vida - Sobral, CE - 2005 a 2007

Gráfico 5 - Evolução da média do perímetro cefálico das crianças do sexo feminino e de BPN, pela idade gestacional, estudadas durante o primeiro ano de vida - Sobral, CE 2005 a 2007

Gráfico 6 - Evolução da média do perímetro cefálico das crianças do sexo masculino e de BPN, pela idade gestacional, estudadas durante o primeiro ano de vida - Sobral, CE 2005 a 2007

Gráfico 7 - Distribuição das consultas em PSF segundo a patologia das crianças com BPN durante o primeiro ano de vida. Sobral, CE - 2005 a 2007

Gráfico 8 - Distribuição do número de dias de internação de acordo com o diagnóstico por ocasião da alta hospitalar das crianças de BPN durante o primeiro ano de vida - Sobral, CE - 2005 a 2007 


\section{RESUMO}

Pinto JR. Morbidade de crianças com baixo peso ao nascer durante 0 primeiro ano de vida na cidade de Sobral, Ceará [dissertação]. São Paulo: Faculdade de Medicina, Universidade de São Paulo; 2010.

INTRODUÇÃO: O baixo peso ao nascer representa fator de risco importante para a morbidade e mortalidade neonatal e infantil, sendo acompanhado por prematuridade, retardo de crescimento intra-uterino, ou ambos os fatores. OBJETIVO: Estudar as características maternas, perinatais, ambientais, econômicas, evolução ponderoestatural e alimentação das crianças nascidas com baixo peso e sua interação no aumento da morbidade durante o primeiro ano de vida. MÉTODOS: Estudo de coorte retrospectivo realizado na cidade de Sobral, Ceará, no período de três anos (2005 a 2007) onde foram incluídas 261 crianças nascidas com baixo peso (BP) e acompanhadas pelo Programa de Saúde da Família. Foi utilizado a Base de Dados do Sistema de Informações de Nascidos Vivos e revisão de prontuários hospitalares e ambulatoriais destas crianças para coleta de dados, quantificação e causa das consultas e internações. Para análise das variáveis foram realizadas distribuições de freqüência, Odds Ratio (OR), respectivos intervalos de confiança (95\%) e significância estatística das associações. A análise final de associação utilizou modelo de regressão multivariado para avaliar os fatores de risco relacionados com o aumento da morbidade. RESULTADOS: Entre as 261 crianças estudadas, a média da idade materna foi de 24 anos, sendo que $29,12 \%$ das mães eram adolescentes. Cerca de $41,76 \%$ das mães eram solteiras e $31,42 \%$ casadas ou com união estável, e $24,14 \%$ eram sem escolaridade. Quanto às características perinatais, $52,11 \%$ das crianças nasceram de parto vaginal, $52,49 \%$ pré-termos; $55,56 \%$ eram do sexo feminino, $98,08 \%$ das crianças obtiveram Apgar de 5 minutos maior que 6 . O peso médio de nascimento foi de $2140 \mathrm{~g}$, sendo que $72,03 \%$ das crianças nasceram com peso entre 2000 e $2500 \mathrm{~g}$. Houve incremento do escore-z de peso até os quatro meses de idade cronológica para crianças nascidas a termo e idade gestacional corrigida para os pré-termo em cerca de $87 \%$ das crianças e $45 \%$ do escore$z$ do comprimento. $O$ índice de aleitamento materno exclusivo foi de $26,05 \%$ e $8,43 \%$ até os 4 e 6 meses de idade respectivamente. Observou-se que $13,97 \%$ das crianças residiam em casa de taipa, $36,49 \%$ dos domicílios utilizavam fogão a lenha e $36,11 \%$ viviam com renda familiar inferior a um salário mínimo. Quanto a morbidade, as 261 crianças nascidas com baixo peso realizaram 1103 consultas por motivo de doença no Programa de Saúde de Família, tendo como causa principal infecções respiratórias 
agudas. Ocorreram 469 consultas ocorreram em emergência pediátrica e 156 internações hospitalares, principalmente no período neonatal. Foram identificados como fatores de risco para maior morbidade: a) Interrupção do aleitamento materno exclusivo antes dos quatro meses o qual esteve associado a presença de consulta em emergência (OR 3,$07 ; p<0,001) ; b$ ) Idade gestacional e peso de nascimento baixos, com maior probabilidade de internação no período neonatal (OR 6,26; $p<0,001)$; c) Prematuridade e a ausência de recuperação de peso até os 4 meses estiveram associados a internação por pneumonia, diarréia aguda e outros motivos (OR 5,15 e 0,65; $p=0,036$ e 0,013 , respectivamente). As demais variáveis não tiveram relação com a morbidade estudada. CONCLUSÃO: A prematuridade, a interrupção do aleitamento materno exclusivo antes dos quatro meses e a ausência do incremento de peso estiveram associadas a maior morbidade nas crianças de baixo peso ao nascer. Nesta população atendida pelo PSF, as características maternas, ambientais e econômicas não estiveram associadas à maior morbidade.

Palavras-chave: Recém nascido de baixo peso. Morbidade. Internação. Aleitamento Materno. Prematuridade. 


\section{SUMMARY}

Pinto JR. Morbidity of children with low birth weight during the first year of life in the city of Sobral, Ceará [dissertation]. São Paulo: Faculdade de Medicina, Universidade de São Paulo; 2010.

BACKGROUND: Low birth weight represents an important risk factor for neonatal and infant morbidity and mortality, accompanied by prematurity, intrauterine growth restriction, or both. OBJECTIVE: To study maternal, perinatal, environmental, economic characteristics, growth and feeding of children with low birth weight and their interaction in the increased morbidity during the first year of life. METHODS: A retrospective cohort study conducted in the city of Sobral, Ceará, in the period of three years (20052007) which included 261 children with low birth weight (LBW) and followed by the Family Health Program. We used the database of the "Sistema de Informação de Nascidos Vivos" (SINASC) and review data collection of hospital and ambulatory records of these children, quantification and causes of emergency room visits and hospitalizations. For analysis of the variables, were used frequency distributions, odds ratio (OR), confidence intervals $(95 \%)$ and statistical significance of associations. The final analysis of association used logistic regression analysis to assess the risk factors associated with increased morbidity. RESULTS: Among 261 children studied, the average maternal age was 24 years, and $29.12 \%$ of mothers were teenagers. Approximately $41.76 \%$ were single mothers and $31.42 \%$ were married or with a stable union, and $24.14 \%$ were uneducated. Regarding perinatal characteristics, $52.11 \%$ were born vaginally, $52.49 \%$ were preterm, $55.56 \%$ were female and $98.08 \%$ of the children had Apgar 5 minutes greater than 6 . The average birth weight was $2140 \mathrm{~g}$, and $72.03 \%$ of children born weighing between 2000 and $2500 \mathrm{~g}$. There was catch up in weight to four months of chronological age for children born at term and corrected gestational age for preterm at around $87 \%$ and $45 \%$ in height. The rate of exclusive breastfeeding was $26.05 \%$ and $8.43 \%$ to 4 and 6 months of age respectively. It was observed that $13.97 \%$ of children lived in wattle and daub house, $36.49 \%$ of households used wood stoves, and $36.11 \%$ lived with less than one minimum wage. As for morbidity, the 261 children born with low birth weight were 1103 visits due to illness in the Family Health Program, with the main cause was acute respiratory infections. There were 469 emergency visits and 156 pediatric emergency hospital admissions, especially in the neonatal period. Were identified as risk factors for increased morbidity: a) interruption of exclusive breastfeeding before 4 months which was associated with the presence of emergency consultation (OR 3.07, p 
$<0.001$ ), b) low gestational age and birth weight, with a greater likelihood of hospitalization in the neonatal period (OR 6.26, $\mathrm{p}<0.001$ ), c) Prematurity and the no catch up in weight at to 4 months of age were associated with hospitalization for pneumonia, diarrhea and other reasons (OR 5, 15 and $0.65, p=0.036$ and 0.013 , respectively). The other variables were not associated with morbidity study. CONCLUSION: Prematurity, interruption of exclusive breastfeeding before four months and no catch up growth were associated with greater morbidity in children with low birthweight. In the population served by the PSF, maternal characteristics, environmental and economic were not associated with increased morbidity.

Descriptors: Infant, Low Birth Weight. Morbidity.Hospitalization. Breast feeding. Infant, Premature. 
1 INTRODUÇÃO 


\subsection{Caracterização do problema: a importância de estudar crianças com baixo peso ao nascer}

O baixo peso ao nascer (BPN) representa importante fator de risco para a morbidade e mortalidade neonatal e infantil. A proporção de nascidos vivos com baixo peso ao nascer é um indicador que serve como preditor da sobrevivência infantil: quanto menor o peso ao nascer, maior a probabilidade de morte precoce. Valores em torno de 5 a $6 \%$ de BPN são encontrados em países desenvolvidos e convenções internacionais estabelecem que esta proporção não deva ultrapassar 10\% (ONU, 1990).

A Organização Mundial da Saúde (OMS, 1995) classifica como peso de nascimento adequado entre 3000 a $3999 \mathrm{~g}$, peso inadequado ou insuficiente entre 2500 e 2999 g, baixo peso se inferior a 2500 g, muito baixo peso (MBP) se inferior a $1500 \mathrm{~g}$, e muitíssimo baixo peso menor que $1000 \mathrm{~g}$. Esta classificação permite quantificar o risco progressivo de morbidade e mortalidade a curto e a longo prazo.

A prevalência global de BPN é de $15,5 \%$, o que significa 20,6 milhões de novas crianças nascidas a cada ano, das quais $95,6 \%$ em países em desenvolvimento (OMS, 2004).

Estudos apontam que crianças com BPN contribuem direta ou indiretamente com cerca de 60 a $80 \%$ das mortes neonatais. Apesar da taxa 
de mortalidade infantil das crianças de baixo peso ser menor que das crianças de muito baixo peso, os recém-nascidos (RN) com peso entre 1500 g e $2500 \mathrm{~g}$ apresentam um risco relativo de morte elevado e são responsáveis por uma fração importante do coeficiente de morbimortalidade infantil em vista de sua maior prevalência (Manji et al.,1998; Kramer et al., 2000; Araújo et al., 2005; Young et al., 2007).

Como mostra o Quadro 1, durante o ano de 2007, no Brasil, cerca de 35 mil RN pesaram menos que $1500 \mathrm{~g}$ e mais de 201 mil com peso entre $1500 \mathrm{~g}$ e $2499 \mathrm{~g}$. 


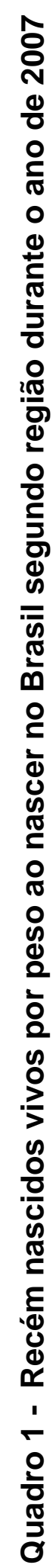

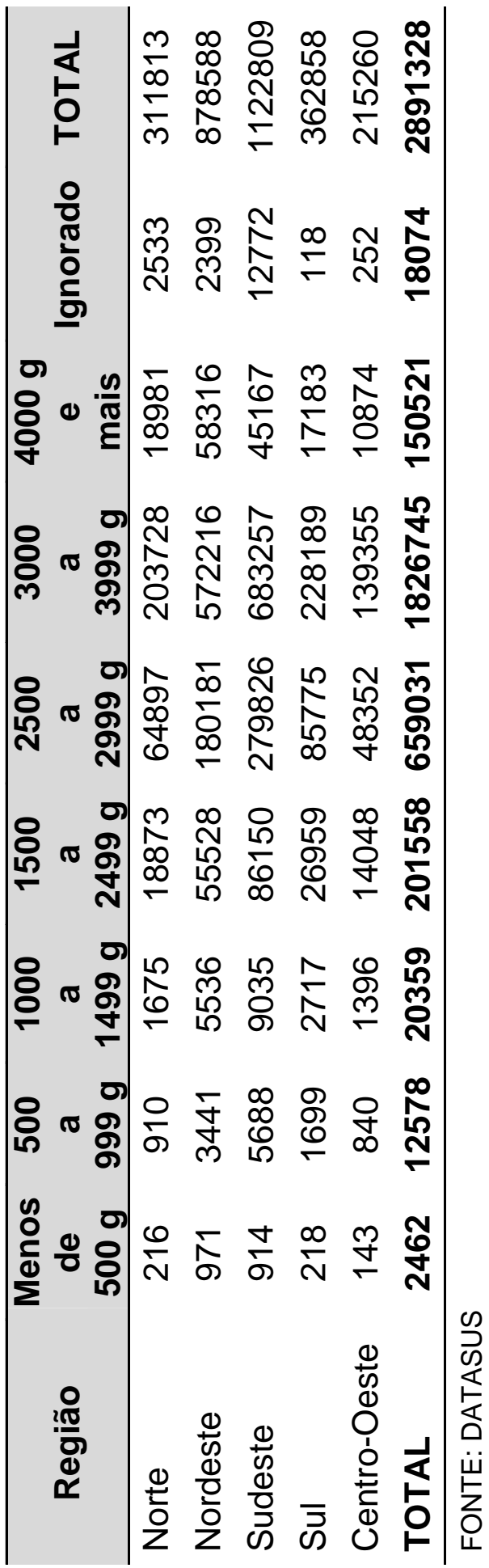


Em geral o BPN é acompanhado de prematuridade, retardo de crescimento intra-uterino ou ambos os fatores, os quais estão associadas a uma maior morbimortalidade no primeiro ano de vida, principalmente se não houver acompanhamento pediátrico regular (Mclntire et al.,1999; Chaudhari et al.,2000; Sharma et al., 2004; Mansour et al.,2005).

No Brasil, desde 1990, foi implantado no Ministério da Saúde (MS), um Sistema de Informação sobre Nascido Vivo (SINASC), utilizando-se documento individualizado e padronizado, em nível nacional, a Declaração de Nascido Vivo (DNV), que contempla a obtenção de dados fundamentais, inclusive peso ao nascer, permitindo estabelecer perfil epidemiológico dessa população, bem como o cálculo de taxas específicas de mortalidade infantil para o planejamento e decisão política na área de saúde materno-infantil (Costa e Gotlieb, 1998).

Segundo o Ministério da Saúde (2004), no Brasil, entre 1996 e 2000, o número de crianças com BPN apresentou uma redução de 1,8\% e, desde então, se mantém estável com incidência de $8,1 \%$ de todos os nascidos vivos. Com o aumento do desenvolvimento econômico, observa-se maior sobrevida destes $\mathrm{RN}$, embora ainda seja um fator de risco importante para óbito neonatal tanto nos países desenvolvidos como em desenvolvimento.

Em 1996, o Grupo Colaborativo de Estudos Perinatais estudou 1975 recém-nascidos patológicos pertencentes a nove unidades neonatais do município de São Paulo e observou que a morbidade e a letalidade foram cinco vezes maiores entre os $\mathrm{RN}$ com muito baixo peso.

Ribeiro et al., em 2009, verificaram que a ausência de companheiro, mais de seis filhos, parto em hospital sem unidade de terapia intensiva (UTI) 
neonatal, sexo masculino, asfixia neonatal, peso de nascimento e idade gestacional estavam associados a um maior risco de mortalidade para crianças de BPN. A mortalidade também tem sido relacionada às condições socioeconômicas como grau de escolaridade e renda da família (Andrade et al., 2004).

Dentre os vários Estados brasileiros, o coeficiente de mortalidade infantil (CMI) mostrou uma maior redução no Ceará $(20,9 \%)$ entre os anos de 2000 e 2004, enquanto no Brasil em geral, a queda foi de $15,9 \%$ no mesmo período. Isso se deve a redução das doenças infecciosas, especialmente as imunopreveníveis e da diarréia como causa de óbito. Houve melhorias das condições ambientais, sanitárias e nutricionais da população (Ministério da Saúde, 2009). Estudo realizado pelo Macinko et al. (2006), entre 1991 e 2002, mostrou que o Programa de Saúde da Família (PSF) teve impacto significativo na queda da mortalidade infantil no Brasil. Segundo os dados apresentados, para cada aumento de $10 \%$ da cobertura do PSF a mortalidade infantil caiu $4,5 \%$.

Há evidências de uma forte associação entre o baixo peso ao nascer e a morbidade neonatal e infantil, levando a OMS a identificá-lo como um dos fatores mais importante na sobrevivência infantil.

Stoll e Adams-Champman (2007) afirmaram que estas crianças têm maior tendência a apresentar síndrome da morte súbita do lactente, função imune inadequada, deficiência do desenvolvimento cognitivo, alto risco de desenvolver diarréia aguda e pneumonia e vínculo mãe-lactente inadequado particularmente entre os $\mathrm{RN}$ prematuros. Na fase adulta, uma criança com BPN 
apresenta um grande risco de adoecer e morrer prematuramente de doença cardiovascular, hipertensão e diabetes, quando comparada àquela nascida com peso adequado. Para aquelas crianças de MBP que sobrevivem, há um prejuízo elevado tanto para o desenvolvimento físico quanto intelectual, com dificuldades de aprendizagem durante todo período escolar.

Desta forma o BPN é um problema que pode se perpetuar entre as gerações, podendo as crianças se tornarem adolescentes desnutridos e com baixa estatura, mulheres em idade reprodutiva mal nutridas e, conseqüentemente, gestantes que irão gerar também crianças de BPN (Pojda e Kelley, 2000). O BPN, além do aumento na probabilidade de ocasionar danos biológicos, leva a um custo material e humano considerável, tanto para as famílias quanto para o sistema de saúde.

\subsection{Determinantes do baixo peso ao nascer}

A prematuridade e o retardo de crescimento intrauterino (RCIU) são as duas principais causas do baixo peso ao nascer. Nos países desenvolvidos, o BPN está relacionado à prematuridade na quase totalidade dos casos. Entretanto, nos países em desenvolvimento, tem como causa principal o RCIU.

No Brasil, país com diferenças regionais grandes, os estudos mostram que em cidades com mais de 50 mil habitantes encontram-se índices maiores de prematuridade e de BPN, quando comparados com municípios menores. As diferenças podem ser agravadas principalmente, pela menor sobrevida e registro inadequado desse $\mathrm{RN}$ nos municípios menores (Andrade et al., 2008). 
A prematuridade é definida como uma gestação com tempo inferior a 37 semanas, a contar do primeiro dia do último ciclo menstrual. Para verificar se uma criança alcançou um crescimento intra-uterino adequado, utiliza-se o peso esperado para a idade gestacional. Este é obtido através de curvas de crescimento intra-uterino, baseadas em percentis de uma distribuição do peso para a idade gestacional ao nascer, derivada de uma população aceita como referência. A classificação do peso para a idade gestacional ao nascer empregada com mais freqüência é: grande para a idade gestacional (GIG), isto é, recém-nascidos que estão acima do percentil 90, adequado para a idade gestacional (AIG), recém-nascidos cujo peso encontra-se entre os percentis 10 e 90, pequeno para a idade gestacional (PIG), os que se encontram abaixo do percentil 10 (OMS, 1995).

Kramer (1987) revendo cerca de 895 publicações com resultados significativos sobre os determinantes do BPN, observou que, nos países em desenvolvimento, os maiores determinantes da restrição de crescimento intrauterino foram: fatores étnicos, dieta pobre na gestação, ganho de peso gestacional insuficiente, fumo, consumo de álcool, episódios de malária e outras doenças como anemia materna. Nos países desenvolvidos destacaram-se o fumo e o pouco peso pré-gestacional. No que se refere à duração da gestação, apenas o peso pré-gestacional, história prévia de prematuridade, aborto espontâneo, mãe adolescente e fumo estiveram significativamente associados com o BPN.

Passini (1992) estudou as características das mães de 1.309 recémnascidos de BP sendo 550 recém nascido pré-termo (RNPT) e 659 recém 
nascido à termo (RNT) PIG, e as comparou com 3927 mães cujos recémnascidos pesaram $2500 \mathrm{~g}$ ou mais. O autor concluiu que ausência de companheiro, escolaridade baixa, ausência de pré-natal, alcoolismo, nuliparidade, sífilis e sexo feminino estiveram associados ao baixo peso no RNT. Enquanto que múltiplas variáveis como tabagismo, intervalo entre os partos menor que 12 meses, antecedentes de cesárea, natimorto, parto prematuro, patologias clínicas, número inferior a seis consultas de pré-natal, estatura materna menor que $155 \mathrm{~cm}$, peso habitual menor que $50 \mathrm{~kg}$, peso ao final da gravidez menor que $60 \mathrm{~kg}$, ganho de peso inferior a $6 \mathrm{~kg}$, rotura prematura de membranas, oligoâmnio, hipertensão em geral, DHEG, hipertensão crônica, hemorragia em geral, placenta prévia, peso placentário menor que $500 \mathrm{~g}$, e anomalias congênitas, mostraram-se significativamente associadas à prematuridade e ao BPN no RNT.

Horta et al. (1996) compararam também a ocorrência de BPN entre os RNPT e aqueles com RCIU, durante os anos de 1982 e 1993, em Pelotas, Rio Grande do Sul. Neste período, foram avaliados todos os nascimentos hospitalares, que representaram mais de $99 \%$ do total dos nascimentos. Entre as crianças com BPN houve um aumento de nascimentos prematuros de $5,6 \%$ para $7,5 \%$ e de $\mathrm{RCIU}$ de $15,0 \%$ para $17,5 \%$ naquele período, os dados foram estatisticamente significativos. A renda familiar esteve inversamente associada com o risco de baixo peso e retardo de crescimento intra-uterino onde as famílias de menor renda tinham o risco 1,7 vezes maior de terem crianças com RCIU e 2,4 vezes maior de terem recém nascido de baixo peso (RNBP) em 1993. 
Em 2008, Sgroi estudou os fatores de risco para BPN de 283 crianças menores de um ano de vida matriculadas no Centro de Saúde Escola em São Paulo e encontrou uma relação significativa entre o BPN e o número de consulta de pré-natal, tabagismo, ganho de peso na gestação e hipertensão arterial. A autora demonstrou que uma gestante com até cinco consultas de pré-natal, tabagista, com ganho de peso inferior a $8 \mathrm{~kg}$ e hipertensa, tinha a probabilidade de $87,8 \%$ de ocorrência de RNBP.

Desta forma, fatores como renda familiar, tabagismo, menor escolaridade materna, mãe adolescente ou com mais de 34 anos, multípara, número baixo de consultas de pré-natal, parto cesariano, gemelaridade, feto do sexo feminino, nível socioeconômico baixo da família, apresentaram risco elevado de BPN (Andrade et al., 2008; Carniel et al., 2008; Nascimento, 2005; Stoll e Adams-Champman, 2007; Costa e Gotlieb, 1998; Bertagnon, 1991)

\subsection{Baixo peso ao nascer como fator de risco}

Os mesmos fatores que tem sido descritos como determinantes do baixo peso ao nascer, permanecem após o nascimento e contribuem para uma maior morbidade e mortalidade desta população.

Segundo Mansano et al. (2004), o estudo da mortalidade infantil e os comitês têm a finalidade de investigar cada óbito, procurando determinar a evitabilidade e, nessa hipótese, especificar medidas de prevenção, podendo ter impacto direto nas mortes evitáveis. Os autores afirmaram também que a análise do óbito infantil e da assistência prestada serve como indicador do nível de qualidade e de acesso aos serviços de saúde, além de possibilitar 
conhecimento e intervenção nessa realidade. Essa estratégia baseia-se na busca da eqüidade, podendo identificar grupos populacionais de maior risco aos quais deve ser dirigida uma atenção diferenciada e interferindo positivamente no processo de produção da saúde, da doença e da morte. A análise evidencia, ainda, como e por que morrem os menores de um ano e identifica os grupos que apresentam maior risco de adoecer em determinadas regiões, contribuindo assim, para o alcance dos índices recomendados pela OMS.

Com a diminuição da mortalidade infantil, o estudo da morbidade capta aspectos do processo saúde-doença que escapam das estatísticas de mortalidade (Cesar et al, 1996). Assim, os estudos de morbidade são de grande importância no controle das doenças e no planejamento de ações em saúde. Permitem, ainda, avaliar a gravidade das doenças, além de serem extremamente úteis na apreciação e planejamento de serviços tanto hospitalares quanto ambulatoriais (Rouquayrol, 1994).

Em 1996, Cesar et al. compararam duas coortes de 6011 recémnascidos em 1982, com 5304 crianças de 1993, ambas procedentes de Pelotas, Rio Grande do Sul, e avaliaram o peso de nascimento, renda familiar e internações. Em ambas as coortes, o BPN e a renda familiar inferior a três salários mínimos ocasionaram o risco de internação duas a três vezes maior durante o primeiro ano de vida, quando comparadas com crianças com peso e renda maior.

Vasconcelos, em 2006, pesquisou fatores de risco para consulta e internação por diarréia e encontrou idade inferior a dois anos, tipo de 
habitação, numero de pessoas por habitação, falta de geladeira e baixo índice de altura para idade como fatores determinantes para maior numero de consultas e internações por diarréia aguda.

Caetano et al. (2002) consideraram que no Brasil, não obstante a diarréia ser ainda considerada problema de saúde pública importante e, em algumas regiões do País, permanecer como causa comum de internação e mortes infantis, reconheceram que os avanços alcançados em seu tratamento e a melhoria das condições sanitárias contribuíram na redução desta doença, cedendo lugar entretanto a outros tipos de infecção como as respiratórias que contribuem atualmente como causa principal de consultas, hospitalização e óbitos de crianças com idade inferior a cinco anos. Neste estudo, os autores apontaram como características importantes associadas à morbidade e à hospitalização, o BPN, as intercorrências neonatais, a presença de doença crônica, óbito de irmão menor de cinco anos, densidade domiciliar elevada e maior nível de escolaridade materna.

Nascimento et al. (2004), estudaram 103 crianças com diagnóstico de pneumonia comparadas com 156 crianças do grupo controle, e demonstraram que a chance de internação por pneumonia era o dobro em crianças com BPN. Os autores sugeriram que a resposta imune diminuída e função pulmonar comprometida pelo reduzido diâmetro das vias aéreas maiores favoreceriam a obstrução das vias aéreas periféricas nestas crianças.

Outros estudos demonstram que o nível socioeconômico baixo, condições ambientais inadequadas, incluindo aglomeração familiar, interrupção precoce do aleitamento materno e exposição passiva ao fumo, contribuem 
como fatores de risco principais envolvidos na ocorrência das doenças respiratórias agudas na infância (Goya e Ferrari, 2005; Macedo et al., 2007).

Perrin (1994) considerou as informações sobre taxas e causas de hospitalização indicadores importantes da qualidade da assistência oferecida e, também, indicadores indiretos da resolutividade ambulatorial, e o perfil da morbidade de crianças menores de cinco anos parâmetro básico para o estabelecimento das necessidades de saúde desse grupo da população.

Além do BPN estar associado à maior incidência de internações, pode também interferir no ganho de peso e na estatura final da criança.

Motta et al. (2005) acompanharam uma coorte de 528 crianças e identificaram que as crianças que nasceram com peso entre $1.500 \mathrm{~g}$ e 2.499 g apresentaram uma chance 29 vezes maior $\left(\mathrm{IC}_{95 \%}=9,77-87,49\right)$ de apresentar risco nutricional aos 12 meses de idade em relação àquelas com peso de nascimento maior que $3.500 \mathrm{~g}$.

Maranha (2004) estudou prospectivamente entre 2002 e 2003, 170 mães e crianças com peso ao nascer entre 1500 e 2500 g, no Município de Campinas. A autora identificou como fatores de risco para velocidade de crescimento abaixo do esperado: falta de planejamento da gravidez, domicílio com tipo de esgoto inadequado e sexo feminino.

De acordo com a literatura, as crianças com BPN têm maior morbidade com risco aumentado para doenças respiratórias, diarréia aguda e internações, o que indiretamente contribui com prejuízo para o crescimento e desenvolvimento infantil (Das et al.,1993; Fonseca et al.,1996; Rahmanifar et al.,1996; Pinto et al., 1998; Caetano,1999; Morris et al.,1999). 


\subsection{Justificativa do estudo}

Tendo em vista estes aspectos, decidiu-se realizar um estudo sobre a evolução clínica das crianças com baixo peso ao nascer na cidade de Sobral, interior do Nordeste, analisando os principais fatores que possam estar associados com morbidade neste grupo de crianças.

Acredita-se que o estudo possa esclarecer pontos importantes no processo de acompanhamento materno-infantil na atenção básica e hospitalar, no sentido de indicar ou ampliar as percepções sobre as fragilidades no sistema de saúde local e nortear um processo de reorganização e mudança dos serviços oferecidos a populações semelhantes.

Portanto o estudo da morbidade indica a magnitude, a importância e os danos à saúde da população, sendo extremamente útil na apreciação e no planejamento de serviços tanto hospitalares quanto ambulatoriais. 
2 Objetivos 


\subsection{Objetivo Geral}

Estudar as principais variáveis que possam estar relacionadas com o aumento da morbidade em crianças com baixo peso ao nascer durante o primeiro ano de vida no período de três anos (janeiro de 2005 a dezembro de 2007) na cidade de Sobral, Ceará.

\subsection{Objetivos Específicos}

a) Descrever na população estudada:

- as condições maternas;

- as características perinatais;

- as condições ambientais;

- a evolução ponderoestatural;

- e o tempo de aleitamento materno exclusivo.

b) Analisar a associação entre o número de consultas de pronto atendimento no Programa Saúde da Família, na emergência pediátrica e internações hospitalares na população estudada e as três primeiras variáveis de exposição.

c) Analisar a interação da amamentação e do incremento no escore-z de peso e crescimento até os quatro meses nas associações acima descritas. 
3 Métodos 


\subsection{Casuística}

\subsubsection{Modelo de estudo}

Trata-se de uma pesquisa de coorte retrospectiva e consiste na descrição e na análise dos dados da morbidade de crianças nascidas com baixo peso.

\subsubsection{Sobral: o local do estudo}

O estudo foi realizado no município de Sobral, localizado no Estado do Ceará, Brasil, (Figura 1), sendo a segunda cidade mais importante do Estado em termos econômicos e culturais, seguida por Juazeiro do Norte e Crato. O clima de Sobral é tipicamente tropical, quente e seco, com uma temperatura média de 30 graus centígrados e com uma altitude de 70 metros. Localiza-se a 238 quilômetros da capital do Estado, Fortaleza. (Prefeitura Municipal de Sobral, 2009). 


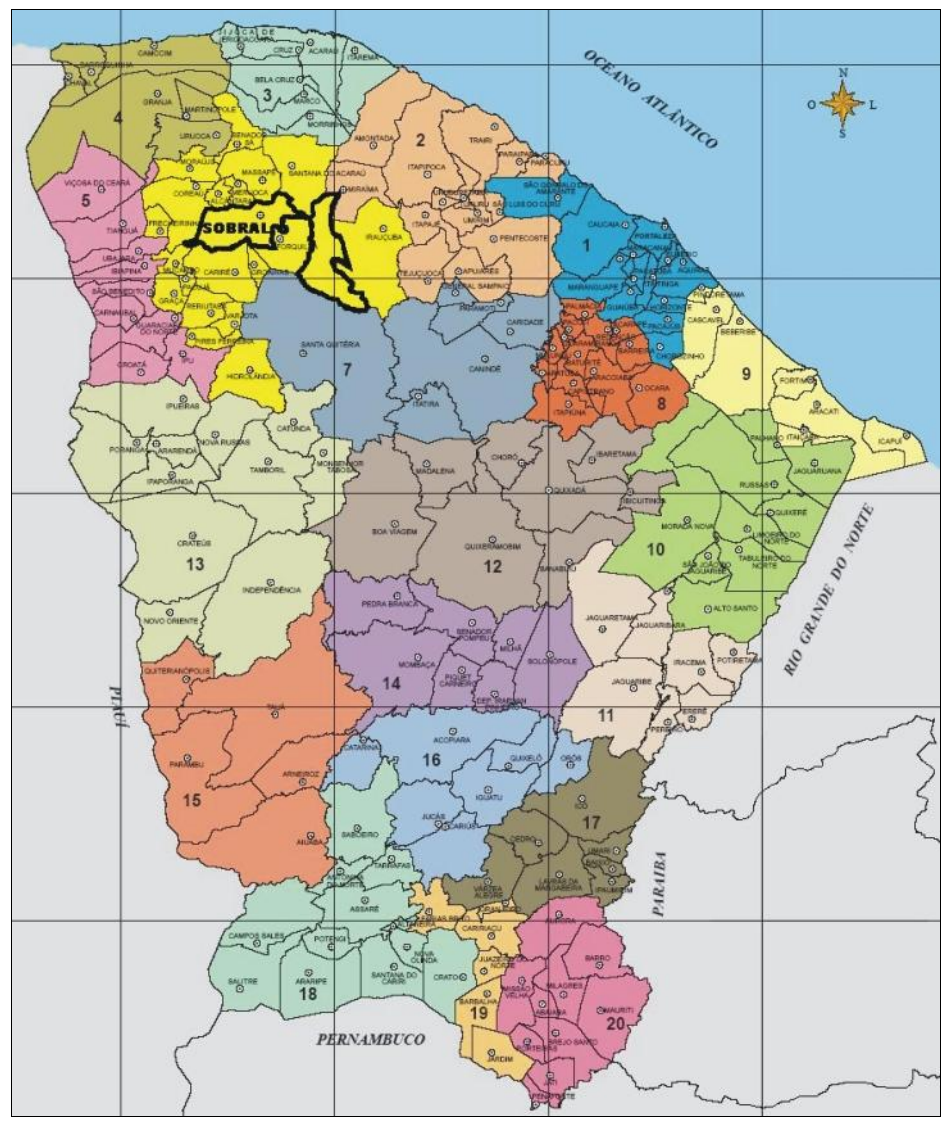

Figura 1 - A cidade de Sobral dentro do Estado do Ceara [FONTE: Pesquisa e Estratégia Econômica do Ceara (IPECE). Disponível em http://www.sobral.ce.gov.br/cidade/sobral.htm]

Com uma população de aproximadamente 182.000 habitantes, Sobral é a quinta cidade mais povoada do Estado sendo a segunda maior do interior, atrás apenas de Juazeiro do Norte (IBGE, 2009).

Cidade de médio porte, Sobral tem como principais atividades geradoras de emprego prestação de serviços (37\%), indústria de transformação (28\%) e o comércio (21\%). Segundo o DATASUS, a renda per capta do município em 2008 foi de $\mathrm{R} \$ 1611,54$. Em 2003 o índice de analfabetismo da população chega à $37,7 \%$ e o rendimento médio mensal de $79 \%$ dos chefes da família totaliza dois salários mínimos, 86,6 \% residem na zona urbana, e 41 \% da população são jovens de até 17 anos. 
Em divisão territorial datada de 2005 , do ponto de vista político e administrativo o município é constituído de 13 distritos: Sobral, a sede, e 12 vilas urbanas: Aprazível, Aracatiaçu, Bonfim, Caioca, Caracará, Jaibaras, Jordão, Patos, Rafael Arruda, Patriarca, São José do Torto e Taperuaba, sendo que a mais distante da sede fica a $70 \mathrm{~km}$ (Figura 2). Para os habitantes dos distritos, o Programa de Saúde da Família é a única opção de assistência, pois a rede hospitalar, com emergência, leitos para internação pediátrica e maternidade, concentra-se na sede.

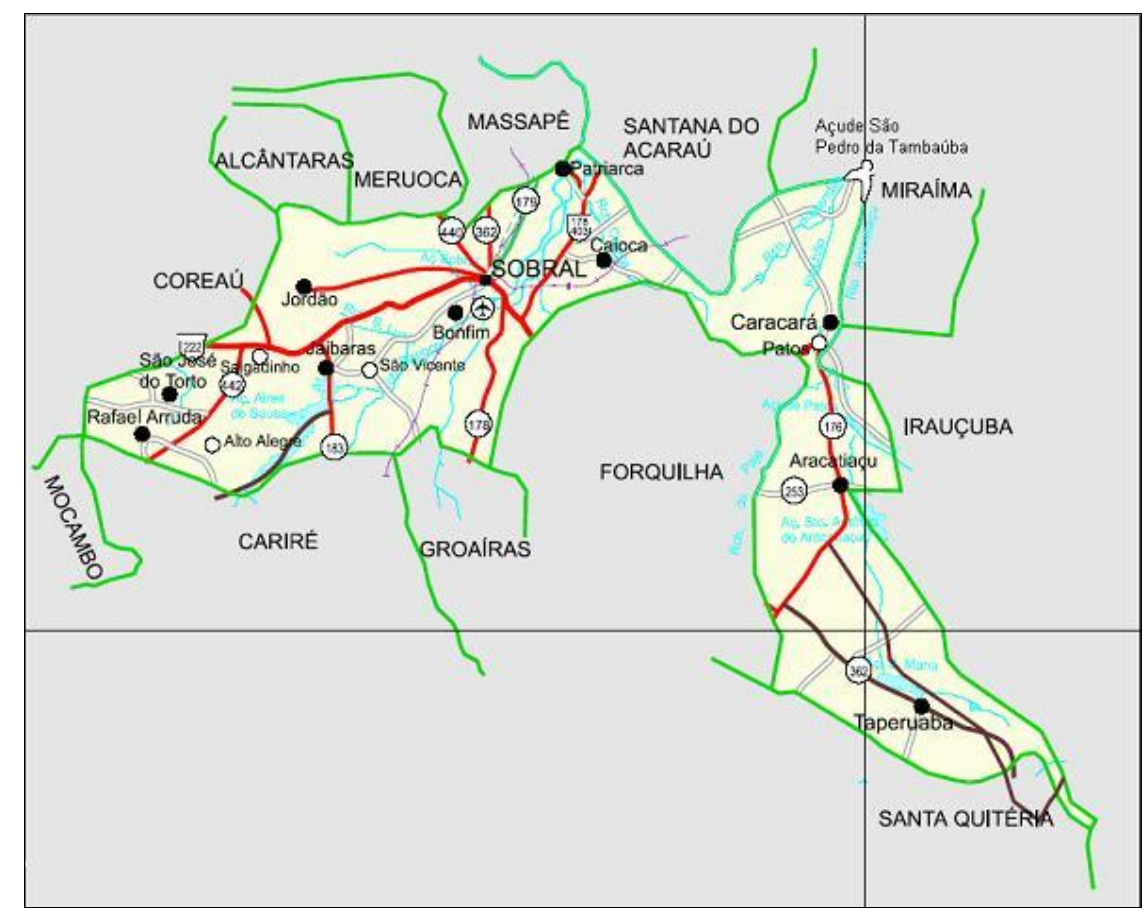

Figura 2-Município de Sobral - Sede e Distritos [FONTE: Disponível em http://www.sobral.ce.gov.br/cidade/sobral.htm]

Até 1997, o serviço de atenção primária à saúde do Município era oferecido ora em unidades de maior complexidade, o que subutilizava estas estruturas, ora em unidades sem praticamente nenhuma resolutividade, implantadas em sua maioria no interior de escolas com estruturas físicas 
totalmente inadequadas. A Secretaria da Saúde e Desenvolvimento Social de Sobral iniciou a implantação do Programa Saúde da Família (PSF), em 1997, como forma de promover a organização e melhoria destes serviços, estruturando a organização da atenção primária e descentralizando as ações de promoção à saúde (Andrade, 2002).

Desta forma, o PSF objetiva prestar assistência integral, contínua, com resolubilidade e boa qualidade às necessidades de saúde da população adscrita, intervir sobre os fatores de risco, aos quais, a população está exposta, humanizar as práticas de saúde, estabelecer parceria com ações intersetoriais, bem como estimular a organização da comunidade para o efetivo exercício do controle social (Costa e Carbone, 2004)

Desde 2005, o município tem $100 \%$ de cobertura de agente comunitário de saúde (ACS) e enfermagem. Conta, atualmente, com 28 Centros de Saúde da Família e 48 equipes multiprofissionais de Saúde da Família, localizadas de forma a garantir o acesso de toda a população do município (DATASUS, 2010a).

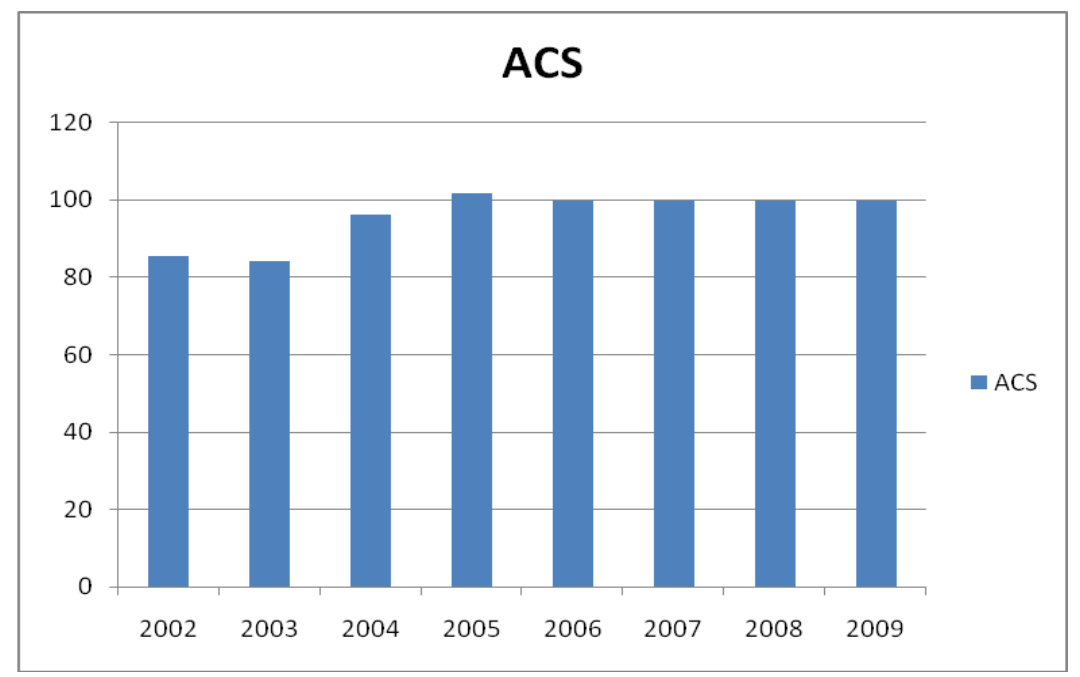

Figura 3 - Cobertura populacional pelo Agente Comunitário de Saúde do PSF na cidade de Sobral, CE - 2002 a 2009 [FONTE: DATASUS, 2010a] 
Atualmente a cidade de Sobral adota uma política diferenciada para as crianças de risco na tentativa de diminuir sua mortalidade e morbidade. A cidade possui Conselho de Saúde atuante, Comitê Municipal de Mortalidade Materno-Infantil e Projeto Trevo de Quatro Folhas, tendo os dois últimos a participação ativa desta pesquisadora.

Neste contexto, o Projeto Trevo de Quatro Folhas foi criado em 2001 com o objetivo de reduzir a morbimortalidade materna e infantil, através de ações e estratégias de reorganização e acompanhamento da assistência à saúde materno-infantil do Município de Sobral, focado na atenção ao prénatal, parto, puerpério e $\mathrm{RN}$ até os dois primeiros anos de vida.

As atividades da equipe focalizam a monitorização dos indicadores locais (natalidade, mortalidade, situações de risco, epidemias); visitas diárias às maternidades; entrevista às parturientes para avaliação do risco do recémnascido; avaliação do preenchimento da caderneta de pré-natal; notificação ao preceptor de pediatria e a equipe de PSF sobre o nascimento da criança de risco; suporte de mãe social, mulheres selecionadas em cada comunidade, capacitadas e remuneradas para assumir algumas tarefas domésticas da gestante ou da mãe de criança em situação de risco, quando o repouso é necessário e não conta com qualquer apoio em casa ou no hospital; e distribuição de cesta básica para família sem renda e sem apoio social (Silva, 2003).

Em 2002, foi criado o Comitê Municipal de Prevenção à Mortalidade Materna, Perinatal e Infantil, que avalia todos os óbitos de menores de um ano, natimortos e óbitos maternos baseado em análise de prontuários e autópsia verbal dos casos. 
Destaca-se aqui, como estratégia fundamental para acompanhamento das crianças sob responsabilidade das equipes de saúde da família, a construção e implantação do protocolo de puericultura, hoje utilizado por todas as equipes do município. Neste protocolo foi elaborado prontuário próprio que homogeneíza o atendimento e facilita a pesquisa. Com este instrumento as equipes têm possibilidade de manter um acompanhamento adequado às crianças de risco.

O município adotou como RN de risco aquele com peso de nascimento inferior a $2500 \mathrm{~g}$ ou superior a $4000 \mathrm{~g}$, que ficou internado no período neonatal, filho de mãe adolescente ou com filho anterior menor de cinco anos com óbito evitável. Ainda considera como risco adquirido, a criança com internação no primeiro ano de vida ou com três consultas em emergência no período de um mês. O Projeto Trevo de Quatro Folhas sempre notifica o PSF para cada RN, endereço, condições de nascimento e classificação de risco.

Todos os RN recebem visita domiciliar do ACS e da enfermeira durante a primeira semana de vida sendo a mãe orientada a realizar acompanhamento da criança pela equipe do PSF aos 15 dias de vida e após um, dois, quatro, seis, nove e 12 meses de idade, para avaliação do estado nutricional, vacinal, alimentação e desenvolvimento neuropsicomotor.

Nos casos das crianças de risco, além de consultas mensais, a família recebe visita da equipe do PSF logo após o nascimento e, na vigência de infecções gastrointestinais ou respiratórias e imediatamente após internação, é visitada diariamente pelo agente de saúde, para seguimento do tratamento 
ambulatorial. O RN com BPN é pesado duas a três vezes por semana até a criança atingir o peso mínimo de 2500 g, sendo prescrito suplementação com polivitamínico e ferro durante o primeiro ano de vida.

Segundo o Projeto Trevo de Quatro Folhas, durante o ano de 2006 nasceram 3.144 crianças no Município de Sobral, apresentando taxa de natalidade de 17,2 para cada 1.000 habitantes, com incidência de $8 \%$ de RNBP. Apesar de tais números se encontrar na média recomendada pela OMS, apresenta-se acima da média de 6,8\% do Estado do Ceará de acordo com o Ministério da Saúde.

De acordo com dados coletados pelo Projeto Trevo de Quatro Folhas, são realizadas aproximadamente 18 mil consultas de puericultura por ano pelas Equipes de Saúde da Família de Sobral, apesar desta cultura ainda não estar difundida em toda a população, onde alguns se reservam a trazer apenas as crianças doentes.

Portanto, o Projeto Trevo de Quatro Folhas configura-se como uma articulação entre todos os setores envolvidos na atenção materno-infantil, como hospitais, programas sociais e secretarias, buscando pactuar novas alternativas para melhorar o atendimento.

Apesar de ter um suporte de atenção básica considerado estruturado, o sistema hospitalar da cidade de Sobral não dispõe de unidade de terapia intensiva pediátrica e neonatal o que dificulta o tratamento da criança em situações de risco. Estes pacientes são transferidos para o serviço de referência em Fortaleza, capital do Estado do Ceará. 
O município possui duas maternidades principais: a Maternidade Santana da Santa Casa de Misericórdia de Sobral e a Maternidade do Hospital Dr. Estevam Pontes.

A Santa Casa de Misericórdia de Sobral (SCMS) é um Hospital filantrópico e de caráter regional, com $92 \%$ de sua área a serviço do Sistema Único de Saúde (SUS), atendendo a população da macrorregião de Sobral estimada em mais de 1.500 .000 habitantes, oriundos de 55 municípios (SCMS, 2010). A Maternidade Santana da SCMS realiza uma média de 300 partos por mês, referência na região para gestantes de alto risco, conta com uma estrutura de sala de pré-parto, parto e puerpério, prevalecendo o sistema de alojamento conjunto para a maioria dos casos. Conta ainda com suporte de uma Unidade de Cuidados Intermediários (UCI) com 15 leitos credenciados desde novembro de 2006 (CNES-DATASUS, 2010).

O Hospital Dr. Estevam Pontes é um estabelecimento particular, com atendimento quase que totalmente pelo SUS, referência na região para atendimento das gestantes de baixo risco, com cinco leitos de unidade neonatal (CNES-DATASUS, 2010).

Por serem hospitais que atendem à demanda da macroregião de Sobral, os pacientes do próprio município devem prioritariamente ser atendidos nos Centros de Saúde da Família e referenciados para a rede hospitalar, dependendo da gravidade do caso, procurando esgotar todas as possibilidades de resolução na atenção primária. Desta forma, o fluxo de atendimento é organizado evitando assim sobrecarregar o serviço terciário de saúde. 


\subsubsection{População e período do estudo}

Obteve-se uma relação através da base de dados nacional do Sistema de Informação de Nascidos Vivos (SINASC) com 714 crianças com peso de nascimento inferior a $2500 \mathrm{~g}$ na cidade de Sobral durante o período de janeiro de 2005 a dezembro de 2007. Após análise de prontuários, foram excluídas seis crianças cadastradas no SINASC com peso incorreto, quatro crianças com malformações congênitas complexas e 86 crianças que evoluíram a óbito.

Entre as crianças que foram a óbito, 62 ocorreram na primeira semana de vida, 21 no período neonatal tardio, entre sete dias e 28 dias de nascidos, e três óbitos infantil tardio com 35, 46 e 240 dias de nascido.

Das 618 crianças com BPN e vivas até completar um ano de vida foram encontrados 557 prontuários hospitalares e 261 prontuários do PSF. Portanto, durante o levantamento dos prontuários, 61 crianças não tinham prontuário hospitalar ou no PSF e 296 tinham apenas o prontuário hospitalar. Além disso, tais crianças sem prontuário do PSF não foram encontradas no endereço informado pelo SINASC ou pelos hospitais.

Deste modo, para estudar a morbidade durante o primeiro ano de vida, a casuística final do estudo foi constituída pela amostra de 261 crianças que sabidamente residiam em Sobral e utilizaram o sistema de saúde básico oferecido, conforme mostra o desenho do estudo. 


\subsubsection{Critérios de inclusão}

Foram incluídas as crianças com baixo peso ao nascer (menor que 2500 g) residentes na cidade de Sobral, Ceará, e acompanhadas pelo Programa de Saúde da Família (PSF).

\subsubsection{Critérios de exclusão}

Foram excluídos os recém-nascidos portadores de má formações congênitas complexas, doenças genéticas ou infecções congênitas e as crianças que mudaram o endereço de residência durante o primeiro ano de vida.

\subsection{Metodologia}

\subsubsection{Coleta de dados}

A coleta de dados foi feita inicialmente através da base de dados do SINASC, que a partir do peso de nascimento, informou o nome da mãe, o endereço de residência, idade, escolaridade e estado civil materno além do peso de nascimento, tipo de parto, idade gestacional, Apgar de 5 minutos e sexo do recém-nascido.

Com estes dados, foram identificados e avaliados os prontuários hospitalares e ambulatoriais das crianças de baixo peso ao nascer entre 0 período de 2005 e 2007 durante o primeiro ano de vida.

Nos dois hospitais com emergência pediátrica (SCMS e Hospital Dr. Estevam Pontes), o sistema informatizado permitiu que, a partir do nome da mãe e da data de nascimento, localizasse o número do prontuário, a data e 
o numero de consultas em emergência, data e duração das internações, e os diagnósticos da alta hospitalar.

Nas unidades do Programa de Saúde da Família, contou-se com ajuda da equipe, enfermeiro e agente comunitário de saúde, para localização do prontuário familiar. Na minoria das unidades, o sistema informatizado já implantado auxiliou na localização do prontuário. A presença dos Agentes Comunitário de Saúde (ACS) em 100\% do município neste período favoreceu a identificação das crianças e dos seus prontuários nas demais unidades.

O levantamento e a revisão dos prontuários foram realizados manualmente pela própria pesquisadora para o preenchimento do Banco de Dados.

Além disso, levantou-se todos os prontuários das crianças com BPN no período estudado que evoluíram para óbito através do Comitê de Mortalidade Materno e Infantil da cidade de Sobral.

\subsubsection{Variáveis de estudo}

\subsubsection{Variáveis de exposição}

Os fatores de risco estudados ou variáveis de exposição foram: condições maternas, perinatais, ambientais, e avaliação aos quatro, seis e 12 meses do peso, comprimento, perímetro cefálico e alimentação.

Variáveis maternas:

As variáveis maternas estudadas foram: idade, estado civil e escolaridade. 
As variáveis foram colhidas através do SINASC, conferidas com 0 prontuário do PSF e categorizadas da seguinte maneira:

- Idade: em até 19 anos, 20 a 34 anos, 35 anos ou mais.

- Estado civil: solteira, casada ou com união estável e desquitada ou viúva.

- Escolaridade: categorizada em nenhuma, de um a três anos, de quatro a sete anos, de oito a 11 anos, 12 ou mais e ignorada.

\section{Variáveis perinatais:}

As variáveis perinatais estudadas foram: tipo de parto, idade gestacional, peso, comprimento, Apgar de 5 minutos e sexo.

Tais variáveis foram fornecidas pelo SINASC, com exceção do comprimento ao nascer que foi obtido através do prontuário de puericultura. Da mesma forma, a idade gestacional fornecida pelo SINASC foi conferida com os dados da caderneta de pré-natal, data da última menstruação e ultrassonografias obstétricas, ou método do Capurro (Capurro et al., 1978) ou New Ballard (Ballard et al., 1991), quando o ultra-som não estivesse disponível.

$\mathrm{Na}$ rotina das maternidades, o peso ao nascer é aferido por meio de balança digital, modelo Filizola, com precisão de $5 \mathrm{~g}$, imediatamente após o nascimento.

Tais variáveis foram categorizadas da seguinte maneira:

- Tipo de parto: categorizado em vaginal ou cesárea. O parto fórceps foi incluído nos partos vaginais.

- Idade gestacional: inferior a 32 semanas, 32 a 36 semanas, acima de 37 semanas 
- Peso ao nascer: até 1499 g, de 1500 a 1999 g, e 2000 a 2499 g.

- Comprimento: foi tratada como variável contínua

- Apgar de 5 minutos de vida, tratado como categórica: 0 - 6 como hipoxemia prolongada e maior que 6 como normal

- Sexo: feminino e masculino

\section{Evolução ponderoestatural:}

As variáveis estudadas foram peso, comprimento e perímetro cefálico medidos durante a consulta de puericultura e registradas no prontuário aos quatro, seis e 12 meses de idade cronológica para o RNT e corrigida para os RNPT. Para o RNPT, ainda avaliou-se estes dados com 40 semanas de idade gestacional corrigida. Tais dados foram analisados como variáveis contínuas. Os dados antropométricos foram avaliados pelo programa WHO Anthro ${ }^{\circledR}$, baseado nos gráficos de crescimentos, peso, perímetro cefálico, peso/comprimento e IMC adotados pela OMS e que fornece os respectivos escores-z e sua distribuição gráfica.

\section{Alimentação:}

Analisou-se o tipo de alimentação oferecida pela mãe ou cuidador, referida durante as consultas de puericultura aos quatro e seis meses de idade cronológica de todas crianças e ainda com 40 semanas de idade

gestacional corrigida daquelas prematuras. Optou-se por não analisar a alimentação aos 12 meses por falta de dados sobre aleitamento materno nos prontuários nesta faixa etária. 
Tal variável foi categorizada baseada nas seguintes definições sugeridas pela OMS, em 1991:

- Aleitamento materno exclusivo: quando a criança recebe somente leite materno, diretamente da mama ou extraído, e nenhum outro líquido ou sólido, com exceção de gotas ou xaropes de vitaminas, minerais e medicamentos. Entretanto, pode ser considerada aquela criança que, no período de referência, fez uso esporádico, por algum motivo (doença, afastamento temporário da mãe etc.), de algum dos líquidos mencionados, sem que sua amamentação tenha sido interrompida.

- Aleitamento materno predominante quando o lactente recebe, além do leite materno, água ou bebidas à base de água, como sucos de frutas e chás.

- Aleitamento materno complementado quando o lactente recebe alem do leite materno, alimentos sólidos ou semisólidos

- Aleitamento artificial ou misto quando o lactente recebe leite de vaca ou fórmulas em mamadeiras com ou sem aleitamento materno

\section{Condições ambientais:}

As condições ambientais usualmente são verificadas durante a primeira visita domiciliar, logo após o nascimento, quando a equipe do PSF preenche o prontuário com as condições observadas.

Tais variáveis foram categorizadas como estão no prontuário, da seguinte maneira: 
- tipo de moradia: taipa (barro), concreto sem reboque ou tijolo rebocado

- tipo de fogão: fogão a gás exclusivamente e fogão a lenha/fogareiro com ou sem fogão a gás

- renda familiar: menos de um salário mínimo (SM), de um a três SM, mais de quatro SM

\subsubsection{Variáveis de desfecho}

\section{Número de consultas em Programa de Saúde da Família}

Foram quantificados os números de consultas e retornos com diagnóstico de diarréias, Pneumonia, outras infecções respiratórias (gripe, resfriados, otites, sinusites), e outras afecções. A criança doente é acolhida

e triada para consulta de pronto-atendimento no PSF, ou conforme a gravidade é encaminhada para o hospital.

O diagnóstico de pneumonia no PSF é clínico e baseado nas definições da Atenção às Doenças Prevalentes da Infância (Ministério da Saúde, 2005), onde a presença de taquipnéia ou dispnéia com tosse, sem melhora após inalação com broncodilatador nos casos de sibilância, justifica o diagnóstico e o tratamento para pneumonia como política para diminuição da mortalidade infantil.

Esta variável foi tratada de forma categórica: 0 a 4 e mais de 4 consultas. 


\section{Número de consultas em emergência}

O número de consultas em emergência pediátrica durante o primeiro ano de vida foi verificado através do sistema informatizado dos hospitais que possibilitou encontrar o prontuário através do nome da mãe e da data de nascimento. Esta variável foi tratada de forma categórica: ausência ou presença de consultas em emergência.

\section{$\underline{\text { Internações }}$}

Quanto às internações durante o primeiro ano de vida, pesquisou-se o número total de internações e a quantidade de diárias por diarréia aguda, pneumonia, afecções do período neonatal e outros. A variável foi categorizada em ausência ou presença de internações hospitalares.

\subsubsection{Análise estatística}

Os dados obtidos alimentaram um Banco de Dados construído com o auxílio do Programa Excel ${ }^{\circledR}$.

Para as variáveis categóricas foram calculadas as freqüências e expressas em porcentagem (\%). Para as variáveis contínuas foram calculadas as médias e respectivos desvio-padrão.

As proporções da população total e da amostra foram comparadas através do Teste Qui-quadrado ou do Teste Exato de Fisher. O Teste Exato de Fisher foi usado quando o valor esperado de pelo menos uma célula foi menor do que 5. Nas demais situações, foi usado o Teste do Qui-quadrado. 
A associação entre as variáveis de exposição e de desfecho foi estudada inicialmente mediante uma análise univariada, com o cálculo da Razão de Chances (RC) com intervalo de 95\% de confiança. As variáveis que apresentarem uma associação com $p<0,20$ foram analisadas através de regressão logística multivariada.

O nível de 0,05 ou $5 \%$ foi escolhido para rejeitar a hipótese de nulidade (ou a probabilidade de cometer erro alfa). O "p" entre 0,05 e 0,10 foi considerado como tendência a significância estatística.

\subsubsection{Desenho do estudo}

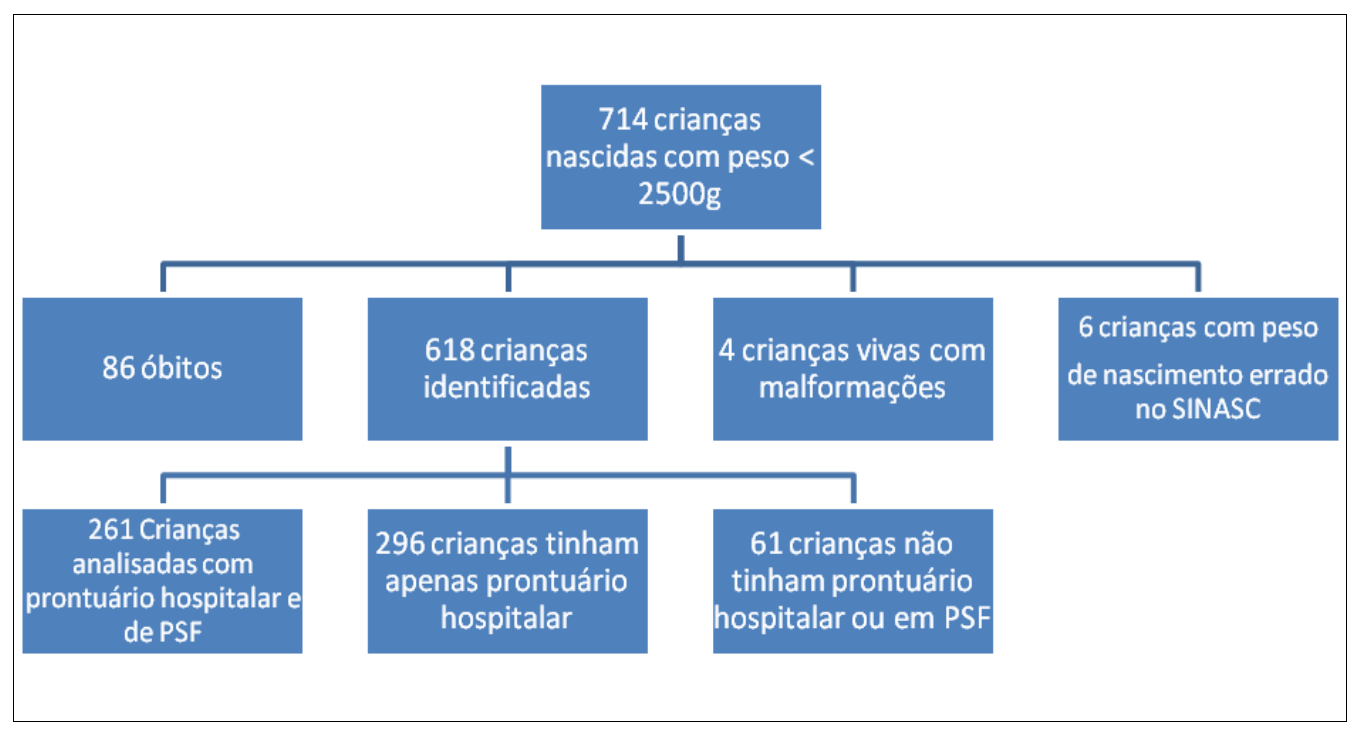

Figura 4 - Fluxograma da população de crianças nascidas vivas com BPN segundo o SINASC às vivas até um ano de idade com prontuário hospitalar e de PSF 


\subsubsection{Aprovação em Comissão de Ética}

O presente trabalho foi aprovado em Comissão de Ética para Análise de Projeto de Pesquisa - CAPPesq da Diretoria Clínica do Hospital das Clínicas da Faculdade de Medicina da Universidade de São Paulo e pelo Comitê de Ética da Universidade Estadual do Vale do Acaraú do Estado do Ceará (Anexo A). 
4 Resultados 
Os resultados serão demonstrados sob a forma de tabelas e gráficos, apresentados em quatro etapas. Na primeira etapa, serão comparadas as características maternas e perinatais da amostra de 261 crianças com prontuário de PSF e hospitalar e de todas as 618 crianças com BPN vivas durante o primeiro ano de vida (Tabela 1 e 2). Na segunda etapa, será apresentada a evolução ponderoestatural, as características ambientais e o tempo de aleitamento materno da amostra estudada (Tabela 3 a 5). Na terceira e quarta etapa, serão apresentadas a análise univariada e a análise de regressão logística multivariada (Tabela 6 a 20 e 21 a 24, respectivamente).

\subsection{Análise da amostra}

\subsubsection{Características maternas}

Com o objetivo de verificar se a amostra de estudo de 261 crianças com BPN era representativa da população de 618 crianças, comparou-se as diversas variáveis fornecidas pelo SINASC entre os dois grupos.

A Tabela 1 caracteriza as variáveis maternas de todas as crianças vivas nascidas com baixo peso ao nascer e daquelas avaliadas com prontuário hospitalar e do PSF. A média da idade materna no momento do 
parto era de 24 anos, com desvio padrão de 6,8 anos, idade mínima de 12 anos e máxima de 44 anos, sendo que 29,12\% das mães eram adolescentes. Além disso, 41,76\% das mães eram solteiras, $10,34 \%$ de mães tinham mais de 12 anos de estudo e $24,14 \%$ eram analfabetas.

Ao compararmos as características maternas das 618 crianças vivas até um ano de idade e nascidas com baixo peso com aquelas 261 crianças acompanhadas pelo PSF, não observamos diferença estatisticamente significativa.

Tabela 1 - Variáveis maternas da população de crianças com BPN e da amostra de estudo - Sobral, CE - 2005 a 2007

\begin{tabular}{|c|c|c|c|c|c|}
\hline \multirow[t]{2}{*}{ Variáveis } & \multicolumn{2}{|c|}{$\begin{array}{l}\text { População de mães } \\
\text { das crianças com BPN }\end{array}$} & \multicolumn{3}{|c|}{ Amostra de estudo } \\
\hline & $\mathbf{N}$ & $\%$ & $\mathbf{N}$ & $\%$ & $\mathbf{p}$ \\
\hline Idade materna & & & & & 0,721 \\
\hline 11 a 19 anos & 197 & 31,88 & 76 & 29,12 & \\
\hline 20 a 35 anos & 362 & 58,58 & 159 & 60,92 & \\
\hline Maior 35 anos & 59 & 9,54 & 26 & 9,96 & \\
\hline Estado civil & & & & & 0,391 \\
\hline Solteira & 284 & 45,96 & 109 & 41,76 & \\
\hline Casada/união estável & 168 & 27,18 & 82 & 31,42 & \\
\hline Desquitada/separada & 162 & 26,21 & 69 & 26,44 & \\
\hline Ignorada & 4 & 0,65 & 1 & 0,38 & \\
\hline Escolaridade & & & & & 0,327 \\
\hline Analfabeta & 157 & 25,41 & 63 & 24,14 & \\
\hline 1 a 3 anos & 90 & 14,56 & 50 & 19,16 & \\
\hline 4 a 7 anos & 152 & 24,60 & 61 & 23,37 & \\
\hline 8 a 11 anos & 166 & 26,86 & 60 & 22,99 & \\
\hline 12 ou mais & 51 & 8,25 & 27 & 10,34 & \\
\hline lgnorada & 2 & 0,32 & - & - & \\
\hline TOTAL & 618 & 100,00 & 261 & 100,00 & \\
\hline
\end{tabular}

BPN = Baixo Peso ao Nascer 


\subsubsection{Características perinatais}

Na Tabela 2 estão apresentadas as variáveis perinatais de todas as crianças vivas nascidas com baixo peso ao nascer e vivas até um ano de vida e daquelas avaliadas com prontuário hospitalar e do PSF.

Na população estudada, 52,11\% nasceram de parto vaginal, $47,51 \%$ das crianças nasceram a termo; $55,56 \%$ eram do sexo feminino e $98,08 \%$ das crianças obtiveram Apgar de 5 minutos maior que 6 . O peso médio entre as crianças da amostra foi $2140 \mathrm{~g}$ com desvio padrão de $327 \mathrm{~g}$, com peso mínimo de 640 g e máximo de 2495 g, sendo que 72,03\% das crianças nasceram com peso entre 2000 e $2500 \mathrm{~g}$.

Ao comparar as características perinatais de todas as crianças vivas até um ano de idade e nascidas com baixo peso com aquelas acompanhadas pelo PSF, não observamos novamente diferença estatisticamente significativa. 
Tabela 2 - Variáveis perinatais da população de crianças com BPN e da amostra de estudo - Sobral, CE - 2005 a 2007

\begin{tabular}{|c|c|c|c|c|c|}
\hline \multirow[t]{2}{*}{ Variáveis } & \multicolumn{2}{|c|}{$\begin{array}{c}\text { População de } \\
\text { crianças com BPN }\end{array}$} & \multicolumn{2}{|c|}{ Amostra de estudo } & \multirow{2}{*}{$\mathbf{p}$} \\
\hline & $\mathbf{N}$ & $\%$ & $\mathbf{N}$ & $\%$ & \\
\hline Tipo de parto & & & & & 0,661 \\
\hline Vaginal & 332 & 53,72 & 136 & 52,11 & \\
\hline Cesárea & 286 & 46,28 & 125 & 47,89 & \\
\hline Idade Gestacional & & & & & 0,751 \\
\hline$<32$ semanas & 39 & 6,31 & 16 & 6,13 & \\
\hline 32 a 36 semanas & 269 & 43,53 & 121 & 46,36 & \\
\hline 37 a 41 semanas & 309 & 50,00 & 124 & 47,51 & \\
\hline Ignorado & 1 & 0,16 & - & - & \\
\hline Sexo & & & & & 0,953 \\
\hline Feminino & 342 & 55,34 & 145 & 55,56 & \\
\hline Masculino & 276 & 44,66 & 116 & 44,44 & \\
\hline Apgar 5 minutos & & & & & 0,195 \\
\hline$\leq 6$ & 22 & 3,55 & 5 & 1,92 & \\
\hline$>6$ & 590 & 95,47 & 256 & 98,08 & \\
\hline Ignorado & 6 & 0,98 & - & & \\
\hline Peso ao nascer & & & & & 0,857 \\
\hline 500 a $1500 \mathrm{~g}$ & 33 & 5,34 & 16 & 6,13 & \\
\hline 1500 a $2000 \mathrm{~g}$ & 132 & 21,36 & 57 & 21,84 & \\
\hline 2000 a $2499 \mathrm{~g}$ & 453 & 73,30 & 188 & 72,03 & \\
\hline TOTAL & 618 & 100,00 & 261 & 100,00 & \\
\hline
\end{tabular}

BPN Baixo Peso ao Nascer

Desta forma, a população amostral das crianças acompanhadas pelo PSF é representativa e será analisada exclusivamente nas variáveis seguintes. 


\subsection{Evolução ponderoestatural}

Das 137 crianças prematuras nascidas com BP e acompanhadas pelo PSF, 117 compareceram a puericultura com 40 semanas de idade gestacional corrigida e foram pesadas e 107 tiveram o comprimento medido.

Das 261 crianças acompanhadas, 205 foram consultadas aos quatro meses e pesadas e 185 foram medidas o comprimento, aos seis meses 207 foram pesadas e 176 medidas e aos 12 meses de idade, 197 foram pesadas e 166 medidas no PSF.

O peso médio encontrado foi 2919 g, o que se aproximou do peso de nascimento dos RNT com peso adequado para idade gestacional. Nas demais consultas de puericultura, aos quatro, seis e 12 meses de idade observou-se que os RNPT alcançaram média de peso, comprimento e perímetro cefálico maior dos que os RNT (Tabela 3 e Gráficos 1 a 6).

Tabela 3 - Médias de peso, comprimento e perímetro cefálico e respectivos DP durante as consultas de puericultura no primeiro ano de vida. Sobral, CE - 2005 a 2007

\begin{tabular}{lccrrrrrr}
\hline & \multicolumn{2}{c}{$\begin{array}{c}\text { 40 semanas } \\
\text { IGC }\end{array}$} & \multicolumn{2}{c}{$\mathbf{4}$ meses } & \multicolumn{2}{c}{$\mathbf{6}$ meses } & \multicolumn{2}{c}{$\mathbf{1 2}$ meses } \\
\hline & Media & DP & Media & DP & Media & DP & Media & DP \\
\hline Peso & & & & & & & & \\
RNPT & 2919 & 664 & 6265 & 1024 & 7364 & 1187 & 9130 & 1342 \\
RNT & & & 5895 & 769 & 6886 & 875 & 8674 & 1105 \\
TOTAL & & & $\mathbf{6 1 0 2}$ & $\mathbf{9 3 7}$ & $\mathbf{7 1 4 5}$ & $\mathbf{1 0 7 9}$ & $\mathbf{8 9 1 5}$ & $\mathbf{1 2 5 4}$ \\
Comprimento & & & & & & & & \\
RNPT & 48,3 & 2,9 & 61,1 & 3,3 & 65,3 & 3,3 & 72,7 & 3,6 \\
RNT & & & 60,1 & 3,0 & 64,3 & 2,7 & 72,3 & 3,0 \\
TOTAL & & & $\mathbf{6 0 , 6}$ & $\mathbf{3 , 2}$ & $\mathbf{6 4 , 8}$ & $\mathbf{3 , 1}$ & $\mathbf{7 2 , 5}$ & $\mathbf{3 , 3}$ \\
PC & & & & & & & & \\
RNPT & 34,7 & 1,8 & 41,2 & 1,8 & 43,1 & 1,7 & 45,8 & 1,6 \\
RNT & & & 40,5 & 1,4 & 42,7 & 1,5 & 45,1 & 1,4 \\
TOTAL & & & $\mathbf{4 0 , 9}$ & $\mathbf{1 , 7}$ & $\mathbf{4 2 , 9}$ & $\mathbf{1 , 6}$ & $\mathbf{4 5 , 4}$ & $\mathbf{1 , 6}$ \\
\hline
\end{tabular}

DP = Desvio Padrão; IGC = Idade Gestacional Corrigida; PC = Perímetro Cefálico; RNPT = Recém-Nascido Pré-Termo; RNT = Recém-Nascido a Termo 
Gráfico 1 - Evolução da média de peso das crianças do sexo feminino e de BPN, pela idade gestacional, estudadas durante 0 primeiro ano de vida - Sobral, CE - 2005 a 2007

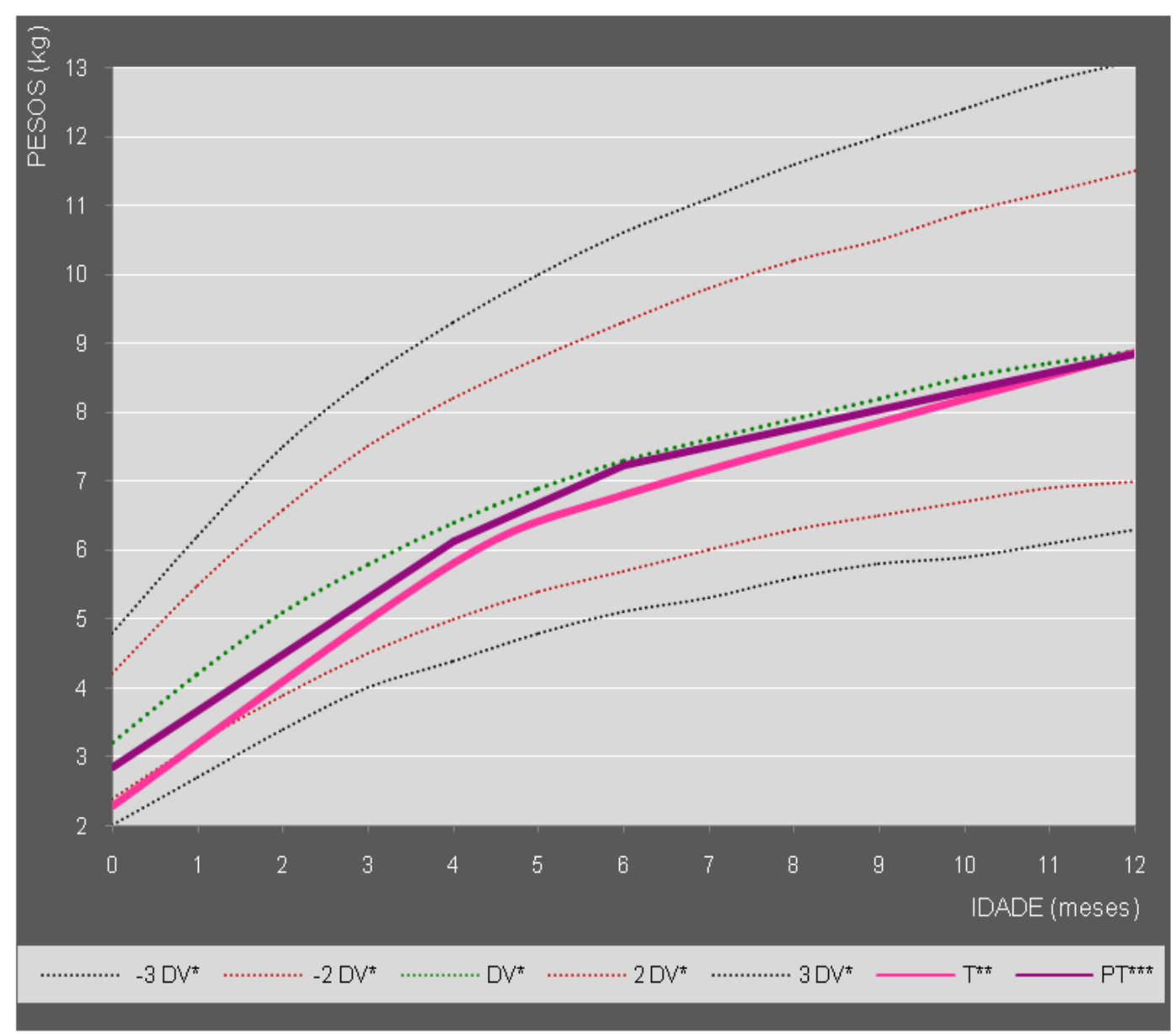

* DV Desvio Padrão segundo referências da Organização Mundial de Saúde

** T Crianças nascidas a termo

*** PT Crianças nascidas pré-termo 
Gráfico 2 - Evolução da média de peso das crianças do sexo masculino e de BPN, pela idade gestacional, estudadas durante o primeiro ano de vida - Sobral, CE - 2005 a 2007

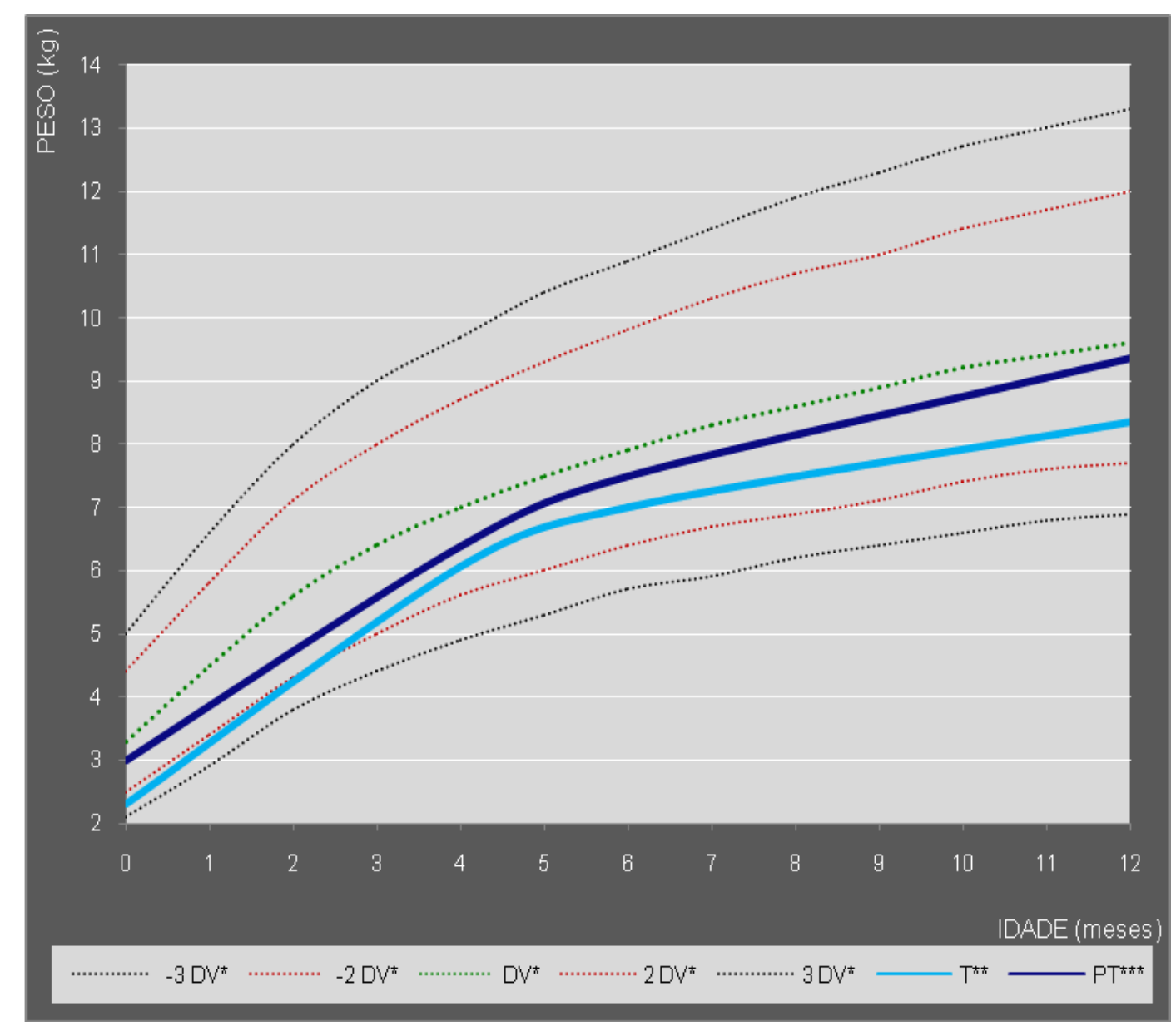

* DV Desvio Padrão segundo referências da Organização Mundial de Saúde

** $\mathrm{T}$ Crianças nascidas a termo

*** PT Crianças nascidas pré-termo 
Gráfico 3 - Evolução da média do comprimento das crianças do sexo feminino e de BPN, pela idade gestacional, estudadas durante o primeiro ano de vida - Sobral, CE - 2005 a 2007

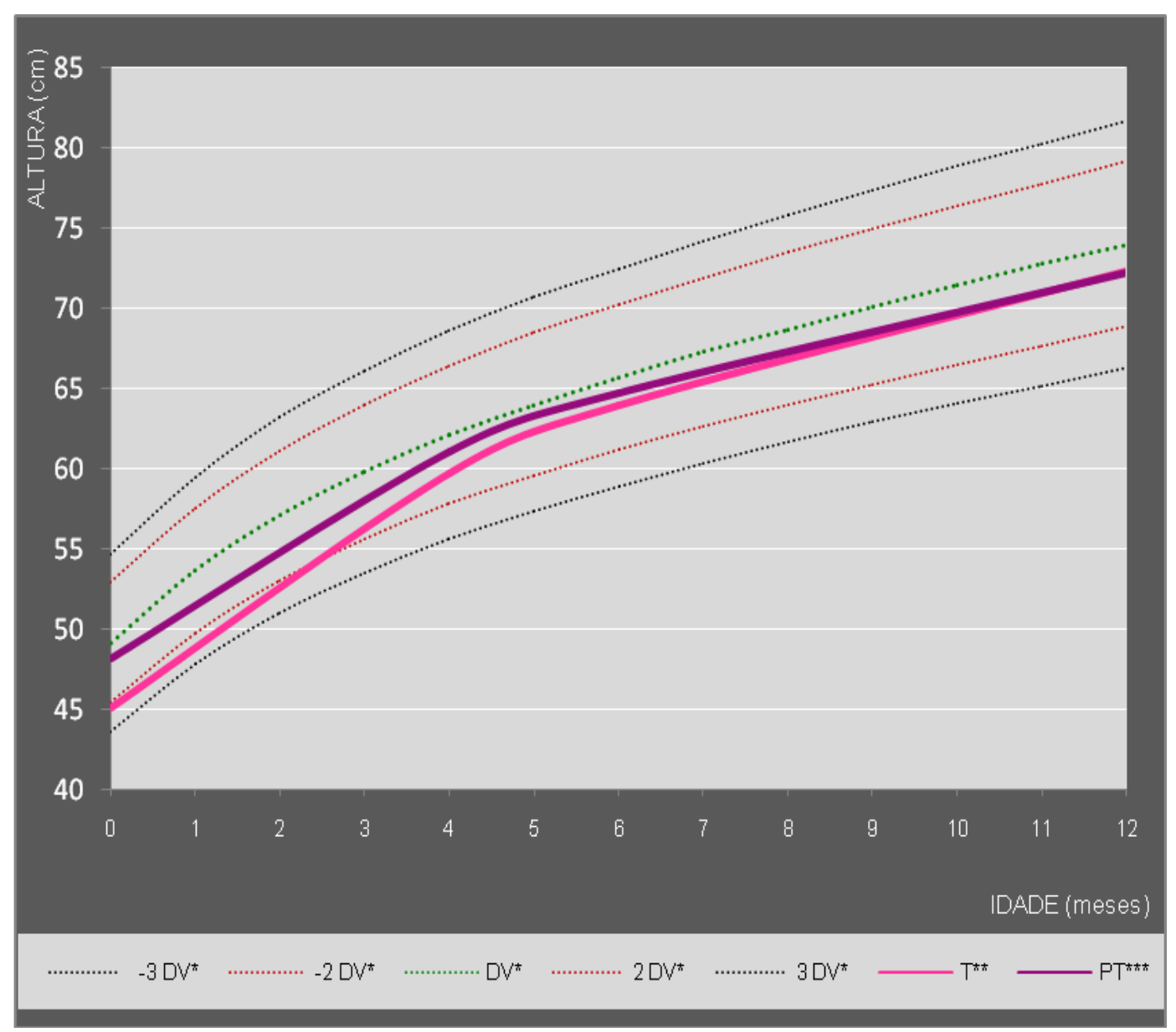

* DV Desvio Padrão segundo referências da Organização Mundial de Saúde

** T Crianças nascidas a termo

*** PT Crianças nascidas pré-termo 
Gráfico 4 - Evolução da média de peso do comprimento do sexo masculino e de BPN, pela idade gestacional, estudadas durante o primeiro ano de vida - Sobral, CE - 2005 a 2007

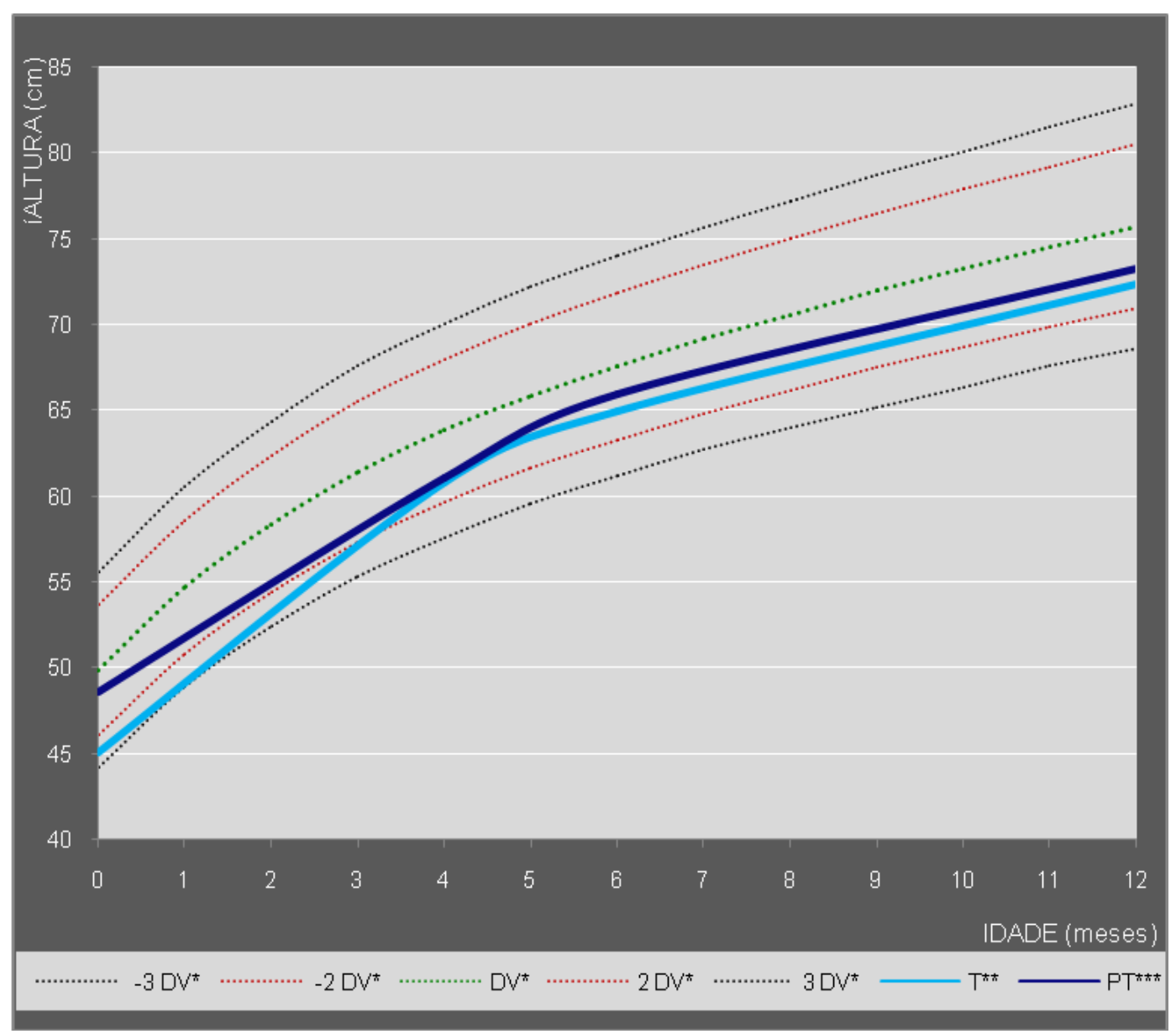

* DV Desvio Padrão segundo referências da Organização Mundial de Saúde

** T Crianças nascidas a termo

*** PT Crianças nascidas pré-termo 
Gráfico 5 - Evolução da média do perímetro cefálico das crianças do sexo feminino e de BPN, pela idade gestacional, estudadas durante o primeiro ano de vida - Sobral, CE - 2005 a 2007

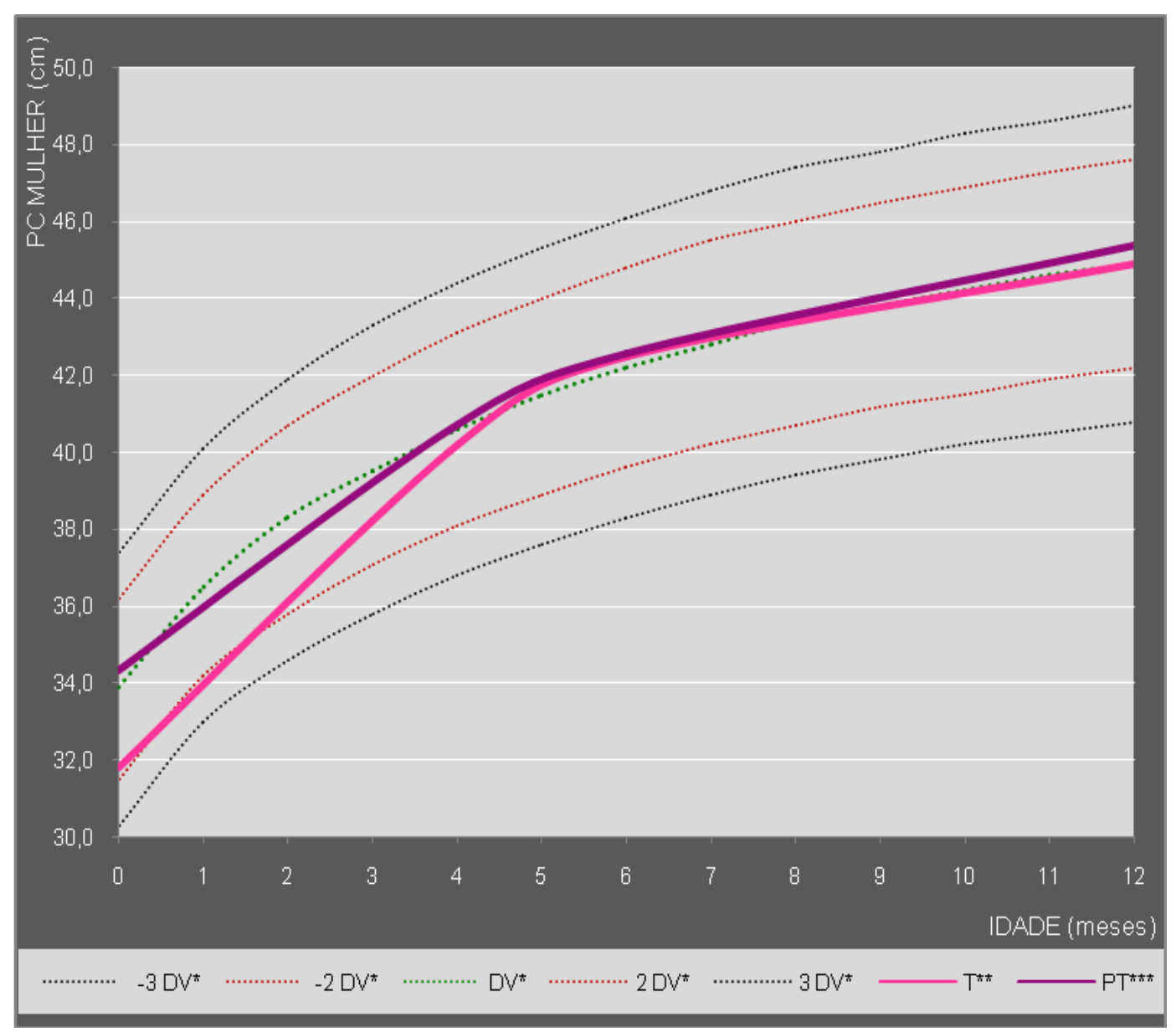

* DV Desvio Padrão segundo referências da Organização Mundial de Saúde

** T Crianças nascidas a termo

*** PT Crianças nascidas pré-termo 
Gráfico 6 - Evolução da média do perímetro cefálico das crianças do sexo masculino e de BPN, pela idade gestacional, estudadas durante o primeiro ano de vida - Sobral, CE 2005 a 2007

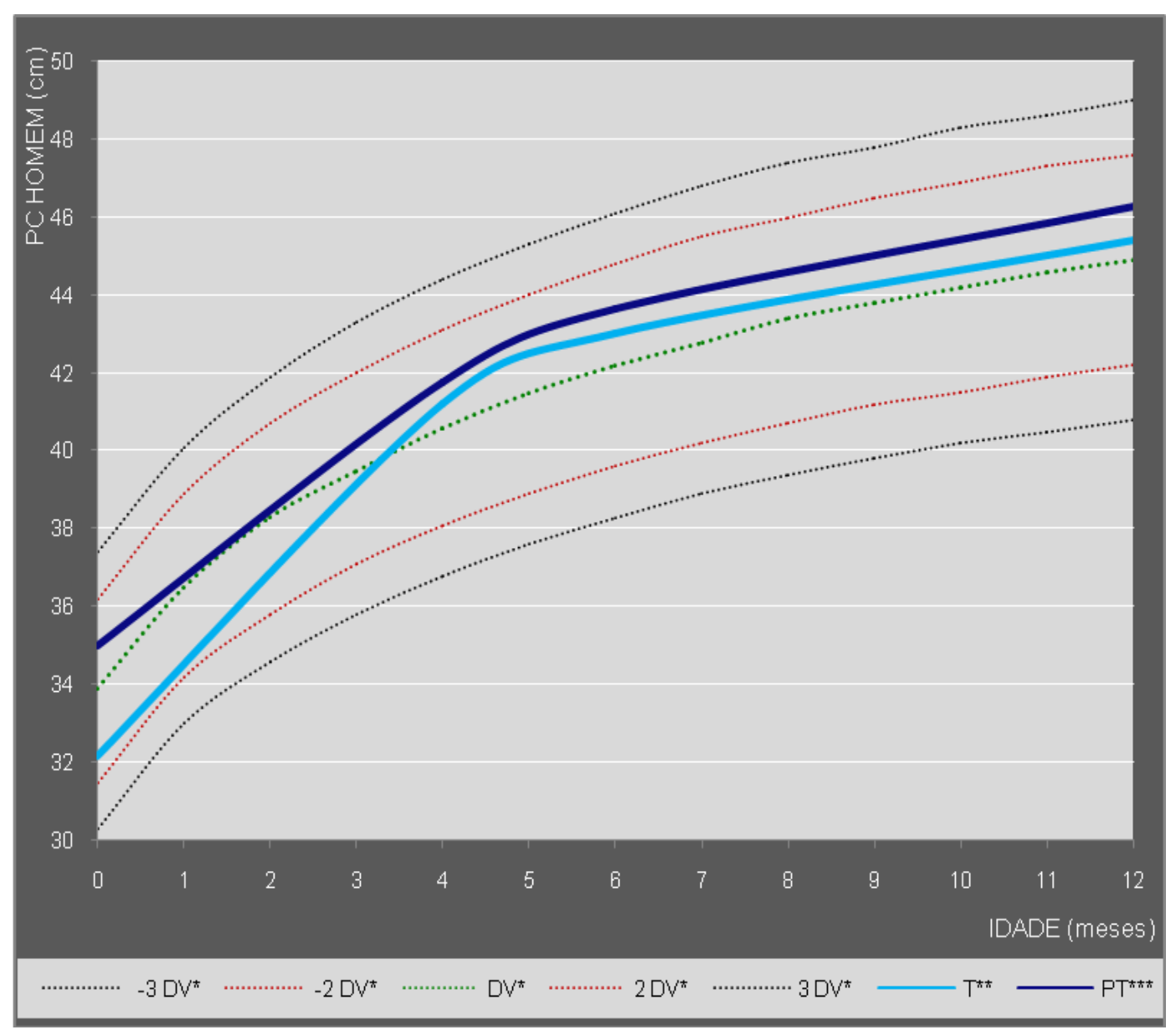

* DV Desvio Padrão segundo referências da Organização Mundial de Saúde

** $\mathrm{T}$ Crianças nascidas a termo

*** PT Crianças nascidas pré-termo 
Considerando um incremento de escore-z adequado aquele com aumento de 0,67 , o que corresponde à ascensão de um canal nas curvas de percentis (Rugolo, 2005), 30 (14,63\%) crianças não apresentaram incremento adequado do peso até os quatro meses, $31(14,97 \%)$ até os seis meses e $22(11,11 \%)$ até o final do primeiro ano de vida.

O incremento do escore-z do comprimento não foi adequado em 90 $(54,21 \%)$ crianças aos quatro meses, $94(61,03 \%)$ aos seis meses e 89 $(60,13 \%)$ aos 12 meses.

Para avaliação da morbidade, optou-se por considerar a presença ou ausência de incremento do escore-z do peso e do comprimento até os quatro meses, por se tratar de um período de tempo menor e, com a possibilidade de ser anterior a morbidade estudada. A velocidade de ganho de peso e altura até os 12 meses poderia ter sido influenciada pelas morbidades e suas internações durante o primeiro ano de vida.

Em relação escore-z do peso/comprimento, aos quatro meses de idade $12(6,4 \%)$ crianças estavam com a relação inferior a -2 DP e 12 (6,4\%) com relação superior a 2 DP; aos seis meses de idade, 4 (2,2\%) crianças com relação inferior a -2 DP e 7 (4,0\%) com relação superior a 2 DP; e até os 12 meses de idade, $9(5,4 \%)$ crianças apresentavam relação peso/comprimento inferior a -2 DP e $9(5,4 \%)$ com a relação superior a 2 DP, segundo os parâmetros adotados pela OMS. 


\subsubsection{Alimentação}

A Tabela 4 relaciona a alimentação oferecida às crianças estudadas de acordo com a faixa etária. Aos 12 meses não foi avaliado a prevalência do aleitamento materno (AM) por falta de dados do prontuário onde a equipe se limitava a anotar informações sobre outros alimentos.

Segundo as anotações das consultas, $57,66 \%$ das crianças prematuras com 40 semanas de IGC estavam em aleitamento materno exclusivo. Entre as 261 crianças de BPN, 26,05\% e 8,43\% sabidamente permaneceram em AM exclusivo até os quatro e seis meses de idade.

Tabela 4 - Alimentação referida durante as consultas de puericultura das crianças com BPN - Sobral, CE - 2005 a 2007

\begin{tabular}{lrrrrrr}
\hline & \multicolumn{2}{c}{$\begin{array}{c}\text { 40 semanas } \\
\text { IGC }\end{array}$} & \multicolumn{2}{c}{$\begin{array}{c}\text { meses } \\
\text { IGC }\end{array}$} & \multicolumn{2}{c}{$\mathbf{6}$ meses } \\
IGC
\end{tabular}

$\mathrm{AME}=$ Aleitamento Materno Exclusivo; IGC = Idade Gestacional Corrigida

\subsubsection{Condições ambientais}

A Tabela 5 descreve as condições ambientais das moradias das crianças estudadas durante a primeira consulta no PSF. Observou-se que $12,26 \%$ das crianças residiam em casa de taipa (barro), 31,04\% utilizavam fogão a lenha e $29,89 \%$ viviam com renda familiar inferior a um SM. 
Tabela 5 - Condições ambientais e econômicas das crianças com BPN por ocasião da primeira consulta de puericultura - Sobral, CE - 2005 a 2007

\begin{tabular}{lrr}
\hline & \multicolumn{2}{c}{ Crianças estudadas } \\
\cline { 2 - 3 } & $\mathbf{N}$ & \multicolumn{1}{c}{$\%$} \\
\hline Tipo de moradia & 32 & 12,26 \\
Taipa (barro) & 32 & 12,26 \\
Concreto & 165 & 63,22 \\
Tijolo rebocado & 32 & 12,26 \\
Sem informação & & \\
Tipo de fogão & 141 & 54,02 \\
Fogão a gás & 51 & 19,54 \\
Fogão a lenha/fogareiro & 30 & 11,50 \\
Ambos & 39 & 14,94 \\
Sem informação & & \\
Renda familir & & \\
< 1 SM & 78 & 29,89 \\
1 a 3 SM & 116 & 44,44 \\
4 SM ou mais & 22 & 8,43 \\
Sem informação & 45 & 17,24 \\
TOTAL & $\mathbf{2 6 1}$ & $\mathbf{1 0 0 , 0 0}$ \\
\hline
\end{tabular}

SM = Salário Mínimo

\subsubsection{Condições mórbidas}

\subsubsection{Consultas com patologias durante o acompanhamento do PSF no primeiro ano de vida}

Entre as 261 crianças nascidas com baixo peso, além das consultas de puericultura, foram realizadas 1103 consultas no PSF para atendimento destas crianças doentes durante o primeiro ano de vida, o que corresponde em média a 4,2 consultas por criança. Neste grupo, 121 crianças realizaram entre zero e quatro consultas, 94 mais de cinco consultas com patologias.

O Gráfico 7 apresenta a distribuição das consultas segundo a patologia onde se destacou em $65,91 \%$ as infecções respiratórias agudas, sendo que $14,69 \%$ de todas as consultas tinham diagnostico de pneumonia, 
$12,15 \%$ as diarréias agudas e $21,94 \%$ por outros motivos, principalmente afecções dermatológicas (escabiose, pediculose e outras).

\section{Gráfico 7 - Distribuição das consultas em PSF segundo a patologia das crianças com BPN durante o primeiro ano de vida. Sobral,} CE - 2005 a 2007

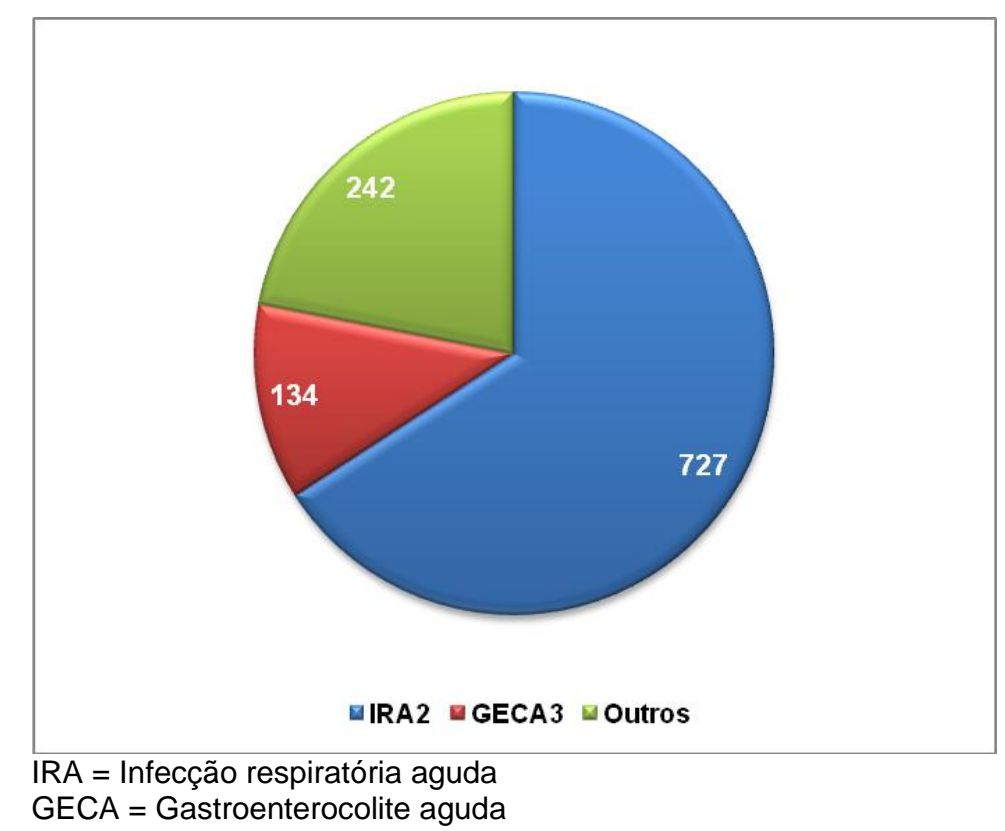

\subsubsection{Consultas e internações hospitalares}

Entre as 261 crianças acompanhadas no PSF, observou-se 469 consultas de emergência pediátrica com média de 1,79 consultas por criança estudada.

Constatou-se que havia 156 internações e 1469 diárias hospitalares entre os dois hospitais da cidade de Sobral, além de 14 transferências para a cidade de Fortaleza, capital do Estado do Ceará, por necessidade de cuidados em Unidade de Terapia Intensiva Neonatal (UTI neonatal).

O Gráfico 8 mostra a distribuição dos diagnósticos na alta hospitalar destas internações. 
Gráfico 8 - Distribuição do número de dias de internação de acordo com o diagnóstico por ocasião da alta hospitalar das crianças de BPN durante o primeiro ano de vida - Sobral, CE - 2005 a 2007

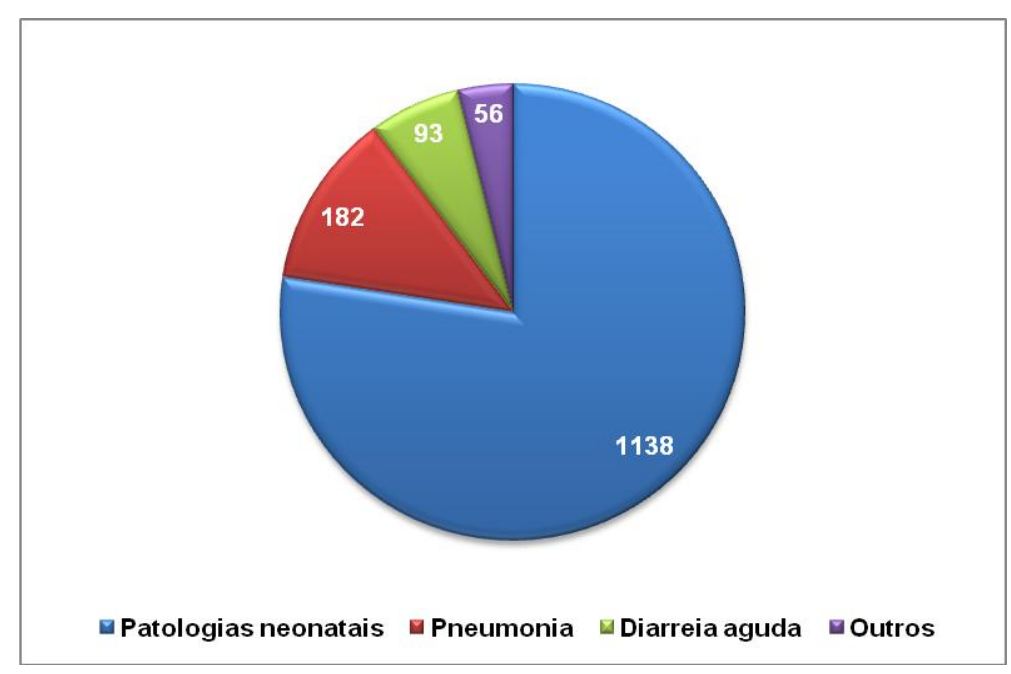

\subsection{Análise univariada}

\subsubsection{Relação entre consultas por doença no PSF e variáveis de exposição}

As Tabelas 6 a 9 apresentam o resultado da análise univariada entre as características maternas, perinatais, condições ambientais, econômicas, evolução ponderoestatural, alimentação oferecida aos quatro meses e o numero de consultas por patologia no PSF durante o primeiro ano de vida das crianças de BPN estudadas.

As crianças com mães casadas ou com união estável tiveram menor chance de consulta por doença no PSF durante o primeiro ano de vida quando comparadas com as filhas de mães solteiras $(p<0,05)$.

Pela análise univariada, as variáveis escolaridade, estado civil materno, tipo de parto, incremento no escore-z de peso e altura até os quatro meses serão analisadas na regressão logística multivariada $(p<0,20)$. 
Tabela 6 - Distribuição percentual das consultas por doença em PSF e variáveis maternas das crianças com BPN estudadas durante o primeiro ano de vida - Sobral, CE - 2005 a 2007

\begin{tabular}{|c|c|c|c|c|c|c|c|}
\hline \multirow{2}{*}{ Variáveis } & \multicolumn{2}{|c|}{$\begin{array}{c}\text { Até } 4 \\
\text { consultas }\end{array}$} & \multicolumn{2}{|c|}{$\begin{array}{c}>4 \\
\text { consultas }\end{array}$} & \multirow[t]{2}{*}{ OR } & \multirow{2}{*}{$\mathrm{IC}_{95 \%}$} & \multirow{2}{*}{$\mathbf{p}$} \\
\hline & $\mathbf{N}$ & $\%$ & $\mathbf{N}$ & $\%$ & & & \\
\hline \multicolumn{8}{|l|}{ Idade materna } \\
\hline 11 a 19 anos & 45 & 26,95 & 31 & 32,98 & 1,37 & $0,78-2,42$ & 0,265 \\
\hline 20 a 34 anos & 106 & 63,47 & 53 & 56,38 & 1,00 & & \\
\hline 35 anos ou mais & 16 & 9,58 & 10 & 10,64 & 1,25 & $0,53-2,94$ & 0,609 \\
\hline TOTAL & 167 & 100,00 & 94 & 100,00 & & & \\
\hline \multicolumn{8}{|l|}{ Estado civil } \\
\hline Solteira & 63 & 37,95 & 46 & 48,94 & 1,00 & & \\
\hline Casada/união estável & 59 & 35,54 & 23 & 24,47 & 0,53 & $0,28-0,98$ & $0,045^{\star}$ \\
\hline Desquitada/separada & 44 & 26,51 & 25 & 26,59 & 0,77 & $0,41-1,44$ & 0,428 \\
\hline TOTAL & 166 & 100,00 & 94 & 100,00 & & & \\
\hline \multicolumn{8}{|l|}{ Escolaridade } \\
\hline Analfabeta & 35 & 20,96 & 28 & 29,78 & 1,00 & & \\
\hline 1 a 3 anos & 35 & 20,96 & 15 & 15,96 & 0,53 & $0,24-1,17$ & 0,118 \\
\hline 4 a 7 anos & 38 & 22,75 & 23 & 24,47 & 0,75 & $0,36-1,55$ & 0,446 \\
\hline 8 a 11 anos & 42 & 25,15 & 18 & 19,15 & 0,53 & $0,25-1,12$ & 0,100 \\
\hline 12 ou mais anos & 17 & 10,18 & 10 & 10,64 & 0,73 & $0,29-1,85$ & 0,515 \\
\hline TOTAL & 167 & 100,00 & 94 & 100,00 & & & \\
\hline
\end{tabular}

${ }^{*} \mathrm{p}<0,05$ 
Tabela 7 - Distribuição percentual das consultas por doença em PSF e variáveis perinatais das crianças com BPN estudadas durante o primeiro ano de vida - Sobral, CE - 2005 a 2007

\begin{tabular}{|c|c|c|c|c|c|c|c|}
\hline \multirow[t]{2}{*}{ Variáveis } & \multicolumn{2}{|c|}{$\begin{array}{c}\text { Ate } 4 \\
\text { consultas }\end{array}$} & \multicolumn{2}{|c|}{$\begin{array}{c}>4 \\
\text { consultas }\end{array}$} & \multirow[t]{2}{*}{ OR } & \multirow[t]{2}{*}{$I_{95 \%}$} & \multirow[t]{2}{*}{$\mathbf{p}$} \\
\hline & $\mathbf{N}$ & $\%$ & $\mathbf{N}$ & $\%$ & & & \\
\hline \multicolumn{8}{|l|}{ Tipo de parto } \\
\hline Vaginal & 92 & 55,09 & 44 & 46,80 & 1,00 & & \\
\hline Cesárea & 75 & 44,91 & 50 & 53,20 & 1,39 & $0,83-2,31$ & 0,199 \\
\hline \multicolumn{8}{|l|}{ Idade Gestacional } \\
\hline$<32$ sem & 11 & 6,58 & 5 & 5,32 & 0,77 & $0,25-2,36$ & 0,648 \\
\hline 32 a 36 sem & 78 & 46,7146 & 43 & 45,74 & 0,93 & $0,54-1,63$ & 0,800 \\
\hline 37 a 41 sem & 78 & ,71 & 46 & 48,94 & 1,00 & & \\
\hline \multicolumn{8}{|l|}{ Sexo } \\
\hline Feminino & 96 & 57,49 & 49 & 52,13 & 1,00 & & \\
\hline Masculino & 71 & 42,51 & 45 & 47,87 & 1,24 & $0,74-2,06$ & 0,403 \\
\hline \multicolumn{8}{|l|}{ Apgar 5 minutos } \\
\hline$\leq 6$ & 4 & 2,40 & 1 & 1,06 & 0,43 & $0,04-3,97$ & 0,463 \\
\hline$>6$ & 163 & 97,60 & 93 & 98,94 & 1,00 & & \\
\hline \multicolumn{8}{|l|}{ Peso ao nascer } \\
\hline 500 a $1500 \mathrm{~g}$ & 11 & 6,59 & 5 & 5,32 & 0,80 & $0,26-2,40$ & 0,694 \\
\hline 1500 a $2000 \mathrm{~g}$ & 36 & 21,56 & 21 & 22,34 & 1,02 & $0,55-1,90$ & 0,926 \\
\hline 2000 a $2499 \mathrm{~g}$ & 120 & 71,85 & 68 & 72,34 & 1,00 & & \\
\hline TOTAL & 167 & 100,00 & 94 & 100,00 & & & \\
\hline
\end{tabular}


Tabela 8 - Distribuição percentual das consultas por doença em PSF e variáveis ambientais e econômicas das crianças com BPN estudadas durante o primeiro ano de vida - Sobral, CE 2005 a 2007

\begin{tabular}{|c|c|c|c|c|c|c|c|}
\hline \multirow[t]{2}{*}{ Variáveis } & \multicolumn{2}{|c|}{$\begin{array}{c}\text { Ate } 4 \\
\text { consultas }\end{array}$} & \multicolumn{2}{|c|}{$\begin{array}{c}>4 \\
\text { consultas }\end{array}$} & \multirow[t]{2}{*}{ OR } & \multirow[t]{2}{*}{$I C_{95 \%}$} & \multirow[t]{2}{*}{$\mathbf{p}$} \\
\hline & $\mathbf{N}$ & $\%$ & $\mathbf{N}$ & $\%$ & & & \\
\hline $\begin{array}{l}\text { Tipo de moradia } \\
\text { Taipa (barro) } \\
\text { Concreto } \\
\text { Tijolo rebocado }\end{array}$ & $\begin{array}{l}21 \\
25 \\
97\end{array}$ & $\begin{array}{l}14,69 \\
17,48 \\
67,83\end{array}$ & $\begin{array}{r}11 \\
7 \\
68\end{array}$ & $\begin{array}{r}12,79 \\
8,14 \\
79,07\end{array}$ & $\begin{array}{l}1,00 \\
0,53 \\
1,33\end{array}$ & $\begin{array}{l}0,17-1,62 \\
0,60-2,95\end{array}$ & $\begin{array}{l}0,269 \\
0,471\end{array}$ \\
\hline TOTAL & 143 & 100,00 & 86 & 100,00 & & & \\
\hline \multicolumn{8}{|l|}{ Tipo de fogão } \\
\hline $\begin{array}{l}\text { Apenas fogão a gás } \\
\text { Fogão a } \\
\text { lenha/fogareiro }\end{array}$ & $\begin{array}{l}92 \\
46\end{array}$ & $\begin{array}{l}66,67 \\
33,33\end{array}$ & $\begin{array}{l}49 \\
35\end{array}$ & $\begin{array}{l}58,33 \\
41,67\end{array}$ & $\begin{array}{l}1,00 \\
1,42\end{array}$ & $0,81-2,50$ & 0,212 \\
\hline TOTAL & 138 & 100,00 & 84 & 100,00 & & & \\
\hline $\begin{array}{l}\text { Renda familiar } \\
\text { Inferior a } 1 \text { SM } \\
1 \text { a } 3 \text { SM } \\
4 \text { SM ou mais }\end{array}$ & $\begin{array}{l}47 \\
71 \\
14\end{array}$ & $\begin{array}{l}35,61 \\
53,79 \\
10,60\end{array}$ & $\begin{array}{r}31 \\
45 \\
8\end{array}$ & $\begin{array}{r}36,91 \\
53,57 \\
9,52\end{array}$ & 0,94 & $0,60-1,45$ & 0,786 \\
\hline TOTAL & 132 & 100,00 & 84 & 100,00 & & & \\
\hline
\end{tabular}

SM = Salário Mínimo 
Tabela 9 - Distribuição percentual das consultas por doença em PSF e a evolução ponderoestatural e alimentação até os 4 meses das crianças com BPN estudadas durante o primeiro ano de vida - Sobral, CE - 2005 a 2007

\begin{tabular}{|c|c|c|c|c|c|c|c|}
\hline \multirow{2}{*}{ Variáveis } & \multicolumn{2}{|c|}{$\begin{array}{c}\text { Ate } 4 \\
\text { consultas }\end{array}$} & \multicolumn{2}{|c|}{$\begin{array}{c}>4 \\
\text { consultas }\end{array}$} & \multirow[t]{2}{*}{ OR } & \multirow{2}{*}{$\mathrm{IC}_{95 \%}$} & \multirow{2}{*}{$\mathbf{p}$} \\
\hline & $\mathbf{N}$ & $\%$ & $\mathbf{N}$ & $\%$ & & & \\
\hline \multicolumn{8}{|l|}{ AME aos 4 meses } \\
\hline Sim & 42 & 36,21 & 26 & 32,10 & 1,00 & & \\
\hline Não & 74 & 63,79 & 55 & 67,90 & 1,20 & $\begin{array}{l}0,65- \\
2,18\end{array}$ & 0,551 \\
\hline TOTAL & 116 & 100,00 & 81 & 100,00 & & & \\
\hline \multicolumn{8}{|l|}{$\begin{array}{l}\text { Incremento no } \\
\text { escore-z de peso }\end{array}$} \\
\hline ate os 4 meses & 105 & 87,76 & 70 & 80,46 & 0,51 & $0,22-$ & 0,089 \\
\hline $\begin{array}{l}\text { Sim } \\
\text { Não }\end{array}$ & 13 & 12,24 & 17 & 19,54 & 1,00 & 1,19 & \\
\hline TOTAL & 118 & 100,00 & 87 & 100,00 & & & \\
\hline \multicolumn{8}{|l|}{$\begin{array}{l}\text { Incremento no } \\
\text { escore-z de }\end{array}$} \\
\hline comprimento até os & 39 & 41,05 & 37 & 52,11 & 1,56 & $0,84-$ & 0,158 \\
\hline $\begin{array}{l}4 \text { meses } \\
\text { Sim } \\
\text { Não }\end{array}$ & 56 & 58,95 & 34 & 47,89 & 1,00 & 2,90 & \\
\hline TOTAL & 95 & 100,00 & 71 & 100,00 & & & \\
\hline
\end{tabular}

AME Aleitamento Materno Exclusivo

\subsubsection{Relação entre consultas em emergência hospitalar e variáveis de exposição}

As Tabelas 10 a 13 apresentam a análise univariada entre as características maternas, perinatais, condições ambientais, econômicas, evolução ponderoestatural e alimentação oferecida aos quatro meses do grupo de crianças que necessitaram de consulta de emergência durante o primeiro ano e o grupo das que não foram consultadas em emergência pediátrica dos dois Hospitais da cidade de Sobral. 
A interrupção do $\mathrm{AME}$ antes dos quatro meses esteve associado a presença de consultas de emergência durante o primeiro ano de vida das crianças estudadas $(p<0,001)$. As crianças cujas famílias utilizavam fogão a lenha ou fogareiro também tiveram menos consultas em emergência $(p<0,05)$.

As variáveis parto, peso ao nascer, tipo de moradia, tipo de fogão, renda familiar e AME até os quatro meses serão analisadas na regressão logística multivariada $(p<0,20)$.

Tabela 10 - Distribuição percentual das consultas em emergência hospitalar e características maternas das crianças com BPN estudadas durante o primeiro ano de vida - Sobral, CE 2005 a 2007

\begin{tabular}{|c|c|c|c|c|c|c|c|}
\hline \multirow[t]{2}{*}{ Variáveis } & \multicolumn{2}{|c|}{$\begin{array}{l}\text { Nenhuma } \\
\text { consulta }\end{array}$} & \multicolumn{2}{|c|}{$\begin{array}{l}1 \text { ou mais } \\
\text { consultas }\end{array}$} & \multirow[t]{2}{*}{ OR } & \multirow[t]{2}{*}{$I C_{95 \%}$} & \multirow{2}{*}{$\mathbf{p}$} \\
\hline & $\mathbf{N}$ & $\%$ & $\mathbf{N}$ & $\%$ & & & \\
\hline \multicolumn{8}{|l|}{ Idade materna } \\
\hline 11 a 19 anos & 37 & 33,04 & 39 & 26,17 & 0,74 & $0,43-1,29$ & 0,300 \\
\hline 20 a 34 anos & 66 & 58,93 & 93 & 62,42 & & & \\
\hline 35 anos ou mais & 9 & 8,03 & 17 & 11,41 & 1,34 & $0,56-3,19$ & 0,508 \\
\hline TOTAL & 112 & 100,00 & 149 & 100,00 & & & \\
\hline \multicolumn{8}{|l|}{ Estado civil } \\
\hline Solteira & 44 & 39,64 & 65 & 43,61 & & & \\
\hline Casada/união estável & 35 & 31,53 & 47 & 31,54 & 0,90 & $0,50-1,62$ & 0,748 \\
\hline Desquitada/separada & 32 & 28,83 & 37 & 24,83 & 0,78 & $0,42-1,43$ & 0,430 \\
\hline TOTAL & 111 & 100,00 & 149 & 100,00 & & & \\
\hline \multicolumn{8}{|l|}{ Escolaridade } \\
\hline Analfabeta & 29 & 25,89 & 34 & 22,82 & & & \\
\hline 1 a 3 anos & 23 & 20,54 & 27 & 18,12 & 1,00 & $0,47-2,10$ & 0,997 \\
\hline 4 a 7 anos & 22 & 19,64 & 39 & 26,17 & 1,51 & $0,73-3,10$ & 0,260 \\
\hline 8 a 11 anos & 29 & 25,89 & 31 & 20,81 & 0,91 & $0,44-1,85$ & 0,798 \\
\hline 12 ou mais & 9 & 8,04 & 18 & 12,08 & 1,70 & $0,66-4,37$ & 0,266 \\
\hline TOTAL & 112 & 100,00 & 149 & 100,00 & & & \\
\hline
\end{tabular}


Tabela 11 - Distribuição percentual das consultas em emergência hospitalar e características perinatais das crianças com BPN estudadas durante o primeiro ano de vida - Sobral, CE - 2005 a 2007

\begin{tabular}{|c|c|c|c|c|c|c|c|}
\hline \multirow[t]{2}{*}{ Variáveis } & \multicolumn{2}{|c|}{$\begin{array}{l}\text { Nenhuma } \\
\text { consulta }\end{array}$} & \multicolumn{2}{|c|}{$\begin{array}{l}1 \text { ou mais } \\
\text { consultas }\end{array}$} & \multirow[t]{2}{*}{ OR } & \multirow[t]{2}{*}{$I C_{95 \%}$} & \multirow[t]{2}{*}{$\mathbf{p}$} \\
\hline & $\mathbf{N}$ & $\%$ & $\mathbf{N}$ & $\%$ & & & \\
\hline \multicolumn{8}{|l|}{ Tipo de parto } \\
\hline Vaginal & 65 & 58,04 & 71 & 47,65 & & & \\
\hline Cesárea & 47 & 41,96 & 78 & 52,35 & 1,51 & $0,92-2,49$ & 0,097 \\
\hline \multicolumn{8}{|l|}{ IG } \\
\hline$<32$ sem & 6 & 5,36 & 10 & 6,71 & 1,16 & $0,40-3,41$ & 0,781 \\
\hline 32 a 36 sem & 55 & 49,11 & 66 & 44,30 & 1,19 & $0,71-1,97$ & 0,495 \\
\hline 37 a 41 sem & 51 & 45,53 & 73 & 48,99 & & & \\
\hline \multicolumn{8}{|l|}{ Sexo } \\
\hline Feminino & 65 & 58,04 & 80 & 53,69 & & & \\
\hline Masculino & 47 & 41,96 & 69 & 46,31 & 1,19 & $0,72-1,95$ & 0,485 \\
\hline \multicolumn{8}{|l|}{ Apgar 5 minutos } \\
\hline$\leq 6$ & 1 & 0,89 & 4 & 2,68 & 3,06 & $0,33-27,77$ & 0,320 \\
\hline$>6$ & 111 & 99,11 & 145 & 97,32 & & & \\
\hline \multicolumn{8}{|l|}{ Peso ao nascer } \\
\hline 500 a $1500 \mathrm{~g}$ & 8 & 7,14 & 8 & 5,37 & 0,82 & $0,29-2,29$ & 0,712 \\
\hline 1500 a $2000 \mathrm{~g}$ & 19 & 16,97 & 38 & 25,50 & 1,65 & $0,88-3,07$ & 0,114 \\
\hline 2000 a $2499 \mathrm{~g}$ & 85 & 75,89 & 103 & 69,13 & & & \\
\hline TOTAL & 112 & 100,00 & 149 & 100,00 & & & \\
\hline
\end{tabular}

IG Idade Gestacional 
Tabela 12 - Distribuição percentual das consultas em emergência hospitalar e características ambientais e econômicas das crianças com BPN estudadas durante o primeiro ano de vida - Sobral, CE - 2005 a 2007

\begin{tabular}{|c|c|c|c|c|c|c|c|}
\hline \multirow[t]{2}{*}{ Variáveis } & \multicolumn{2}{|c|}{$\begin{array}{l}\text { Nenhuma } \\
\text { consulta }\end{array}$} & \multicolumn{2}{|c|}{$\begin{array}{l}1 \text { ou mais } \\
\text { consultas }\end{array}$} & \multirow[t]{2}{*}{ OR } & \multirow{2}{*}{$\mathrm{IC}_{95 \%}$} & \multirow[t]{2}{*}{$\mathbf{p}$} \\
\hline & $\mathbf{N}$ & $\%$ & $\mathbf{N}$ & $\%$ & & & \\
\hline \multicolumn{8}{|l|}{ Tipo de moradia } \\
\hline Taipa (barro) & 18 & 18,00 & 14 & 10,85 & & & \\
\hline Concreto & 16 & 16,00 & 16 & 12,40 & 1,28 & $0,48-3,43$ & 0,617 \\
\hline Tijolo rebocado & 66 & 66,00 & 99 & 76,75 & 1,92 & $0,89-4,14$ & 0,092 \\
\hline TOTAL & 100 & 100,00 & 129 & 100,00 & & & \\
\hline \multicolumn{8}{|l|}{ Tipo de fogão } \\
\hline Apenas fogão a gás & 55 & 56,12 & 86 & 69,35 & & & \\
\hline Fogão a lenha/fogareiro & 43 & 43,88 & 38 & 30,65 & 0,56 & $0,32-0,98$ & $0,043^{*}$ \\
\hline TOTAL & 98 & 100,00 & 124 & 100,00 & & & \\
\hline Renda familiar & & & & & 1,49 & $0,96-2,31$ & 0,070 \\
\hline$<1 \mathrm{SM}$ & 42 & 44,21 & 36 & 29,76 & & & \\
\hline 1 a 3 SM, & 44 & 46,32 & 72 & 59,50 & & & \\
\hline $4 \mathrm{SM}$ ou mais & 9 & 9,47 & 13 & 10,74 & & & \\
\hline TOTAL & 95 & 100,00 & 121 & 100,00 & & & \\
\hline
\end{tabular}

SM Salário Mínimo

${ }^{*} p<0,05$ 
Tabela 13 - Distribuição percentual das consultas em emergência hospitalar e a evolução ponderoestatural e alimentação aos quatro meses das crianças com BPN estudadas durante o primeiro ano de vida - Sobral, CE - 2005 a 2007

\begin{tabular}{|c|c|c|c|c|c|c|c|}
\hline \multirow[t]{2}{*}{ Variáveis } & \multicolumn{2}{|c|}{$\begin{array}{l}\text { Nenhuma } \\
\text { consulta }\end{array}$} & \multicolumn{2}{|c|}{$\begin{array}{l}1 \text { ou mais } \\
\text { consultas }\end{array}$} & \multirow[t]{2}{*}{ OR } & \multirow{2}{*}{$\mathrm{IC}_{95 \%}$} & \multirow[t]{2}{*}{$\mathbf{p}$} \\
\hline & $\mathbf{N}$ & $\%$ & $\mathbf{N}$ & $\%$ & & & \\
\hline \multicolumn{8}{|l|}{ AME aos 4 meses } \\
\hline Sim & 44 & 48,89 & 24 & 22,43 & & & \\
\hline Não & 46 & 51,11 & 83 & 77,57 & 3,30 & $1,78-6,11$ & $0,000^{*}$ \\
\hline Total & 90 & 100,00 & 107 & 100,00 & & & \\
\hline \multicolumn{8}{|c|}{ Incremento no escore-z de } \\
\hline $\operatorname{Sim}$ & & & & & 0,69 & $0,29-1,63$ & 0,357 \\
\hline Não & $\begin{array}{l}80 \\
11\end{array}$ & $\begin{array}{l}87,91 \\
12,09\end{array}$ & $\begin{array}{l}95 \\
19\end{array}$ & $\begin{array}{r}83,3 \\
16,66\end{array}$ & & & \\
\hline Total & 91 & 100,00 & 114 & 100,00 & & & \\
\hline $\begin{array}{l}\text { Incremento no escc } \\
\text { comprimento até os }\end{array}$ & & & & & & & \\
\hline meses & & & & & 1,38 & $0,71-2,67$ & 0,311 \\
\hline Sim & 32 & 42,85 & 44 & 45,45 & & & \\
\hline Não & 45 & 57,14 & 45 & 54,55 & & & \\
\hline Total & 77 & 100,00 & 99 & 100,00 & & & \\
\hline
\end{tabular}

AME Aleitamento Materno Exclusivo ${ }^{*} \mathrm{p}<0,05$

\subsubsection{Relação entre internações hospitalares e variáveis de exposição}

As Tabelas 14 a 16 apresentam a análise univariada da relação entre internação neonatal com as características maternas, perinatais e as condições ambientais, econômicas das crianças estudadas. Optou-se por não relacionar com variáveis posteriores a internação neonatal como aleitamento materno e evolução ponderoestatural, visto que não foram variáveis de exposição anteriores a internação neonatal.

As crianças de mães com mais de 35 anos e com mais de 12 anos de estudos, do sexo masculino, de menor peso e de menor idade gestacional ao nascer, que moravam em habitação de tijolo rebocado e 
com maior renda familiar tiveram maior chance de internação no período neonatal.

Além dessas, as variáveis estado civil e tipo de fogão também serão analisadas na análise multivariada $(p<0,20)$.

Tabela 14 - Distribuição percentual das características maternas e presença de internação neonatal das crianças com BPN estudadas durante o primeiro ano de vida - Sobral, CE 2005 a 2007

\begin{tabular}{|c|c|c|c|c|c|c|c|}
\hline \multirow[t]{2}{*}{ Variáveis } & \multicolumn{2}{|c|}{$\begin{array}{l}\text { Nenhuma } \\
\text { internação }\end{array}$} & \multicolumn{2}{|c|}{$\begin{array}{c}\text { Internação } \\
\text { neonatal }\end{array}$} & \multirow[t]{2}{*}{ OR } & \multirow[t]{2}{*}{$\mathrm{IC}_{95 \%}$} & \multirow{2}{*}{$\mathbf{p}$} \\
\hline & $\mathbf{N}$ & $\%$ & $\mathbf{N}$ & $\%$ & & & \\
\hline \multicolumn{8}{|l|}{ Idade materna } \\
\hline 11 a 19 anos & 53 & 32,12 & 23 & 23,96 & 0,72 & $0,39-1,30$ & 0,283 \\
\hline 20 a 34 anos & 101 & 61,21 & 58 & 60,42 & & & \\
\hline 35 anos ou mais & 11 & 6,67 & 15 & 15,62 & 2,37 & $1,02-5,51$ & $0,044^{*}$ \\
\hline TOTAL & 165 & 100,00 & 96 & 100,00 & & & \\
\hline \multicolumn{8}{|l|}{ Estado civil } \\
\hline Solteira & 74 & 44,85 & 35 & 36,84 & & & \\
\hline Casada/união & 51 & 30,91 & 31 & 32,63 & 1,24 & $0,67-2,27$ & 0,479 \\
\hline estável & 40 & 24,24 & 29 & 30,53 & 1,53 & $0,82-2,86$ & 0,180 \\
\hline $\begin{array}{l}\text { Desquitada/separa } \\
\mathrm{da}\end{array}$ & & & & & & & \\
\hline TOTAL & 165 & 100,00 & 95 & 100,00 & & & \\
\hline \multicolumn{8}{|l|}{ Escolaridade } \\
\hline Analfabeta & 42 & 25,45 & 21 & 21,87 & & & \\
\hline de 1 a 3 anos & 38 & 23,03 & 12 & 12,50 & 0,66 & $0,28-1,53$ & 0,338 \\
\hline de 4 a 7 anos & 35 & 21,21 & 26 & 27,09 & 1,56 & $0,74-3,25$ & 0,236 \\
\hline de 8 a 11 anos & 39 & 23,64 & 21 & 21,87 & 1,13 & $0,53-2,39$ & 0,749 \\
\hline 12 ou mais & 11 & 6,67 & 16 & 16,67 & 3,05 & $1,20-7,77$ & $0,019^{*}$ \\
\hline TOTAL & 165 & 100,00 & 96 & 100,00 & & & \\
\hline
\end{tabular}


Tabela 15 - Distribuição percentual das características perinatais e a presença de internação neonatal das crianças com BPN estudadas durante o primeiro ano de vida - Sobral, CE 2005 a 2007

\begin{tabular}{|c|c|c|c|c|c|c|c|}
\hline \multirow[t]{2}{*}{ Variáveis } & \multicolumn{2}{|c|}{$\begin{array}{c}\text { Sem internação } \\
\text { neonatal }\end{array}$} & \multicolumn{2}{|c|}{$\begin{array}{c}\text { Internação } \\
\text { neonatal }\end{array}$} & \multirow[t]{2}{*}{ OR } & \multirow{2}{*}{$\mathrm{IC}_{95 \%}$} & \multirow{2}{*}{$\mathbf{p}$} \\
\hline & $\mathbf{N}$ & $\%$ & $\mathbf{N}$ & $\%$ & & & \\
\hline \multicolumn{8}{|l|}{ Tipo de parto } \\
\hline Vaginal & 89 & 53,94 & 47 & 48,96 & & & \\
\hline Cesárea & 76 & 46,06 & 49 & 51,04 & 1,24 & $0,75-2,06$ & 0,391 \\
\hline \multicolumn{8}{|l|}{ Idade Gestacional } \\
\hline$<32$ semanas & - & - & 16 & 16,67 & & & \\
\hline 32 a 36 semanas & 64 & 38,79 & 57 & 59,37 & & & \\
\hline 37 a 41 semanas & 101 & 61,21 & 23 & 23,96 & 0,25 & $0,14-0,45$ & $0,000^{*}$ \\
\hline \multicolumn{8}{|l|}{ Sexo } \\
\hline Feminino & 103 & 62,42 & 42 & 43,75 & & & \\
\hline Masculino & 62 & 37,58 & 54 & 56,25 & 2,09 & $1,25-3,50$ & $0,005^{\star}$ \\
\hline \multicolumn{8}{|l|}{ Apgar 5 minutos } \\
\hline$\leq 6$ & 2 & 1,21 & 3 & 3,12 & 1,75 & $0,24-12,64$ & 0,578 \\
\hline$>6$ & 163 & 98,79 & 93 & 96,88 & & & \\
\hline \multicolumn{8}{|l|}{ Peso ao nascer } \\
\hline 500 a $1500 \mathrm{~g}$ & - & - & 16 & 16,66 & & & \\
\hline 1500 a $2000 \mathrm{~g}$ & 17 & 10,30 & 40 & 41,67 & 8,70 & $4,47-16,97$ & $0,000^{*}$ \\
\hline 2000 a 2499 a & 148 & 89.70 & 40 & 41.67 & & & \\
\hline TOTAL & 165 & 100,00 & 96 & 100,00 & & & \\
\hline
\end{tabular}

${ }^{*} p<0,05$ 


\begin{tabular}{|c|c|c|c|c|c|c|c|}
\hline \multirow[t]{2}{*}{ Variáveis } & \multicolumn{2}{|c|}{$\begin{array}{c}\text { Sem } \\
\text { internação } \\
\text { neonatal }\end{array}$} & \multicolumn{2}{|c|}{$\begin{array}{c}\text { Internação } \\
\text { neonatal }\end{array}$} & \multirow[t]{2}{*}{ OR } & \multirow[t]{2}{*}{$\mathrm{IC}_{95 \%}$} & \multirow[t]{2}{*}{$\mathbf{p}$} \\
\hline & $\mathbf{N}$ & $\%$ & $\mathbf{N}$ & $\%$ & & & \\
\hline \multicolumn{8}{|l|}{ Tipo de moradia } \\
\hline Taipa (barro) & 24 & 16,78 & 8 & 9,30 & 2,23 & $0,94-5,26$ & 0,066 \\
\hline Concreto & 25 & 17,48 & 7 & 8,14 & 2,71 & $1,10-6,59$ & $0,025^{*}$ \\
\hline Tijolo rebocado & 94 & 65,74 & 71 & 82,56 & & & \\
\hline TOTAL & 143 & 100,00 & 86 & 100,00 & & & \\
\hline \multicolumn{8}{|l|}{ Tipo de fogão } \\
\hline Apenas fogão a gás & 83 & 59,71 & 58 & 69,88 & & & \\
\hline Com fogão a lenha/fogareiro & 56 & 40,29 & 25 & 30,12 & 0,61 & $0,34-1,09$ & 0,101 \\
\hline TOTAL & 139 & 100,00 & 83 & 100,00 & & & \\
\hline Renda familiar & & & & & 2,11 & $1,33-3,36$ & $0,001^{*}$ \\
\hline$<1 \mathrm{SM}$ & 60 & 44,44 & 18 & 22,22 & & & \\
\hline 1 a 3 SM & 64 & 47,41 & 52 & 64,20 & & & \\
\hline $4 \mathrm{SM}$ ou mais & 11 & 8,15 & 11 & 13,58 & & & \\
\hline TOTAL & 135 & 100,00 & 81 & 100,00 & & & \\
\hline
\end{tabular}

$\mathrm{SM}$ = Salário mínimo

${ }^{*} \mathrm{p}<0,05$

As Tabelas 17 a 20 apresentam a análise univariada da relação entre as características maternas, perinatais, ambientais, econômicas, evolução ponderoestatural, alimentação aos quatro meses de idade, e internação após o período neonatal por pneumonia, diarréia aguda ou outros motivos durante o primeiro ano de vida das crianças estudadas.

A ausência de incremento no escore-z de peso até os quatro meses de idade foi a principal variável relacionada à internação após o período neonatal durante o primeiro ano de vida das crianças estudadas na análise univariada. 
As variáveis estado civil materno, idade gestacional ao nascer e aleitamento materno exclusivo até os quatro meses também serão analisadas na análise multivariada $(p<0,20)$.

Tabela 17 - Distribuição percentual das características maternas e a presença de internação após o período neonatal das crianças com BPN estudadas durante o primeiro ano de vida - Sobral, CE - 2005 a 2007

\begin{tabular}{|c|c|c|c|c|c|c|c|}
\hline \multirow[t]{2}{*}{ Variáveis } & \multicolumn{2}{|c|}{$\begin{array}{c}\text { Sem } \\
\text { internação }\end{array}$} & \multicolumn{2}{|c|}{$\begin{array}{c}\text { Com } \\
\text { internação }\end{array}$} & \multirow[t]{2}{*}{ OR } & \multirow{2}{*}{$\mathrm{IC}_{95 \%}$} & \multirow[t]{2}{*}{ p } \\
\hline & $\mathbf{N}$ & $\%$ & $\mathbf{N}$ & $\%$ & & & \\
\hline \multicolumn{8}{|l|}{ Idade materna } \\
\hline 11 a 19 anos & 62 & 28,97 & 14 & 29,79 & 1,01 & $0,49-2,05$ & 0,973 \\
\hline 20 a 34 anos & 130 & 60,75 & 29 & 61,70 & & & \\
\hline 35 anos ou mais & 22 & 10,28 & 4 & 8,51 & 0,81 & $0,26-2,54$ & 0,725 \\
\hline TOTAL & 214 & 100,00 & 47 & 100,00 & & & \\
\hline \multicolumn{8}{|l|}{ Estado civil } \\
\hline Solteira & 88 & 41,32 & 21 & 44,68 & & & \\
\hline Casada/união estável & 72 & 33,80 & 101 & 21,28 & 0,58 & $0,25-1,31$ & 0,193 \\
\hline Desquitada/separada & 53 & 24,88 & 6 & 34,04 & 1,26 & $0,60-2,63$ & 0,530 \\
\hline TOTAL & 213 & 100,00 & 47 & 100,00 & & & \\
\hline \multicolumn{8}{|l|}{ Escolaridade } \\
\hline Analfabeta & 51 & 23,83 & 12 & 25,53 & & & \\
\hline 1 a 3 anos & 42 & 19,63 & 8 & 17,02 & 0,80 & $0,30-2,16$ & 0,674 \\
\hline 4 a 7 anos & 50 & 23,36 & 11 & 23,41 & 0,93 & $0,37-2,31$ & 0,884 \\
\hline 8 a 11 anos & 49 & 22,90 & 11 & 23,41 & 0,95 & $0,38-2,36$ & 0,919 \\
\hline 12 ou mais & 22 & 10,28 & 5 & 10,63 & 0,96 & $0,30-3,07$ & 0,953 \\
\hline TOTAL & 214 & 100,00 & 47 & 100,00 & & & \\
\hline
\end{tabular}


Tabela 18 - Distribuição percentual das características perinatais e a presença de internação após o período neonatal das crianças com BPN estudadas durante o primeiro ano de vida - Sobral, CE - 2005 a 2007

\begin{tabular}{|c|c|c|c|c|c|c|c|}
\hline \multirow[t]{2}{*}{ Variáveis } & \multicolumn{2}{|c|}{$\begin{array}{c}\text { Sem } \\
\text { internação }\end{array}$} & \multicolumn{2}{|c|}{$\begin{array}{c}\text { Com } \\
\text { internação }\end{array}$} & \multirow[t]{2}{*}{ OR } & \multirow{2}{*}{$I C_{95 \%}$} & \multirow[t]{2}{*}{$\mathbf{p}$} \\
\hline & $\mathbf{N}$ & $\%$ & $\mathbf{N}$ & $\%$ & & & \\
\hline \multicolumn{8}{|l|}{ Tipo de parto } \\
\hline Vaginal & 113 & 52,80 & 23 & 48,94 & & & \\
\hline Cesárea & 101 & 47,20 & 24 & 51,06 & 1,16 & $0,62-2,19$ & 0,631 \\
\hline \multicolumn{8}{|l|}{ Idade Gestacional } \\
\hline$<32$ sem & 11 & 5,14 & 5 & 10,64 & 2,23 & $0,70-7,09$ & 0,167 \\
\hline 32 a 36 sem & 100 & 46,73 & 21 & 44,68 & 0,97 & $0,49-1,88$ & 0,931 \\
\hline 37 a 41 sem & 103 & 48,13 & 21 & 44,68 & & & \\
\hline \multicolumn{8}{|l|}{ Sexo } \\
\hline Feminino & 119 & 55,60 & 26 & 55,32 & & & \\
\hline Masculino & 95 & 44,40 & 21 & 44,68 & 1,01 & $0,53-1,90$ & 0,971 \\
\hline \multicolumn{8}{|l|}{ Apgar 5 minutos } \\
\hline$\leq 6$ & 4 & 1,90 & 1 & 2,13 & 1,14 & $0,12-10,44$ & 0,907 \\
\hline$>6$ & 210 & 98,10 & 46 & 97,87 & & & \\
\hline \multicolumn{8}{|l|}{ Peso ao nascer } \\
\hline 500 a $1500 \mathrm{~g}$ & 11 & 5,14 & 5 & 10,64 & 2,05 & $0,67-6,31$ & 0,478 \\
\hline 1500 a $2000 \mathrm{~g}$ & 49 & 22,90 & 8 & 17,02 & 0,73 & $0,32-1,70$ & 0,207 \\
\hline 2000 a $2499 \mathrm{~g}$ & 154 & 71,96 & 34 & 72,34 & & & \\
\hline TOTAL & 214 & 100,00 & 47 & 100,00 & & & \\
\hline
\end{tabular}


Tabela 19 - Distribuição percentual das características ambientais e econômicas e a presença de internação após o período neonatal das crianças com BPN estudadas durante 0 primeiro ano de vida - Sobral, CE - 2005 a 2007

\begin{tabular}{|c|c|c|c|c|c|c|c|}
\hline \multirow[t]{2}{*}{ Variáveis } & \multicolumn{2}{|c|}{$\begin{array}{c}\text { Sem } \\
\text { internação }\end{array}$} & \multicolumn{2}{|c|}{$\begin{array}{c}\text { Com } \\
\text { internação }\end{array}$} & \multirow[t]{2}{*}{ OR } & \multirow{2}{*}{$I C_{95 \%}$} & \multirow[t]{2}{*}{$\mathbf{p}$} \\
\hline & $\mathbf{N}$ & $\%$ & $\mathbf{N}$ & $\%$ & & & \\
\hline \multicolumn{8}{|l|}{ Tipo de moradia } \\
\hline Taipa (barro) & 29 & 15,03 & 3 & 8,33 & 0,49 & $0,14-1,70$ & 0,251 \\
\hline Concreto & 28 & 14,51 & 4 & 11,11 & 0,67 & $0,22-2,06$ & 0,482 \\
\hline Tijolo rebocado & 136 & 70,47 & 29 & 80,56 & & & \\
\hline TOTAL & 193 & 100,00 & 36 & 100,00 & & & \\
\hline \multicolumn{8}{|l|}{ Tipo de fogão } \\
\hline Apenas fogão a gás & 116 & 62,03 & 25 & 71,43 & & & \\
\hline fogão a lenha/ fogareiro & 71 & 37,97 & 10 & 28,57 & 0,65 & $0,29-1,44$ & 0,292 \\
\hline TOTAL & 187 & 100,00 & 35 & 100,00 & & & \\
\hline Renda familiar & & & & & 1,02 & $0,56-1,86$ & 0,928 \\
\hline < 1 SM & 68 & 36,96 & 10 & 31,25 & & & \\
\hline 1 a 3 SM, & 96 & 52,17 & 20 & 62,50 & & & \\
\hline $4 \mathrm{SM}$ ou mais & 20 & 10,87 & 2 & 6,25 & & & \\
\hline TOTAL & 184 & 100,00 & 32 & 100,00 & & & \\
\hline
\end{tabular}

SM Salário Mínimo 
Tabela 20 - Distribuição percentual da evolução ponderoestatural e alimentação aos 4 meses de idade e internação após o período neonatal das crianças com BPN estudadas durante o primeiro ano de vida - Sobral, CE - 2005 a 2007

\begin{tabular}{|c|c|c|c|c|c|c|c|}
\hline \multirow[t]{2}{*}{ Variáveis } & \multicolumn{2}{|c|}{$\begin{array}{c}\text { Nenhuma } \\
\text { internação }\end{array}$} & \multicolumn{2}{|c|}{$\begin{array}{c}\text { Com } \\
\text { internação }\end{array}$} & \multirow[t]{2}{*}{ OR } & \multirow{2}{*}{$\mathrm{IC}_{95 \%}$} & \multirow[t]{2}{*}{$\mathbf{p}$} \\
\hline & $\mathbf{N}$ & $\%$ & $\mathbf{N}$ & $\%$ & & & \\
\hline \multicolumn{8}{|l|}{ AME até os 4 meses } \\
\hline Sim & 61 & 37,20 & 7 & 21,21 & & & \\
\hline Não & 103 & 62,80 & 26 & 78,78 & 2,19 & $0,90-5,37$ & 0,083 \\
\hline TOTAL & 164 & 100,00 & 33 & 100,00 & & & \\
\hline $\begin{array}{l}\text { Incremento no escore-z } \\
\text { de peso ate os } 4 \text { meses }\end{array}$ & & & & & 010 & 011091 & 0031 \\
\hline Sim & 146 & 87,95 & 29 & 74,36 & 0,40 & $0,14-0,04$ & * \\
\hline Não & 20 & 12,05 & 10 & 25,64 & & & \\
\hline TOTAL & 166 & 100,00 & 39 & 100,00 & & & \\
\hline \multicolumn{8}{|l|}{ Incremento no escore-z } \\
\hline $\begin{array}{l}\text { de comprimento até os } 4 \\
\text { meses }\end{array}$ & & & & & 1,48 & $0,67-2,94$ & 0,374 \\
\hline Sim & 63 & 44,37 & 13 & 54,17 & & & \\
\hline Não & 79 & 55,63 & 11 & 45,83 & & & \\
\hline TOTAL & 142 & 100,00 & 24 & 100,00 & & & \\
\hline
\end{tabular}

\subsection{Análise multivariada}

A análise de regressão logística múltipla incluiu as variáveis que, na análise univariada, mostraram-se associadas com nível de significância (valor de p) até 0,20.

Analisou-se a presença de mais de quatro consultas em PSF por doença e as variáveis reagrupadas: estado civil materno, escolaridade materna, tipo de parto e a presença incremento do escore-z do peso e do comprimento até os quatro meses de idade corrigida (Tabela 21). As variáveis estudadas não se mostraram relacionadas a um maior número de consultas em PSF. 
Tabela 21 - Análise multivariada entre consultas por doença em PSF e as variáveis características maternas, perinatais, evolução ponderoestatural durante 0 primeiro ano de vida das crianças com BPN estudadas - Sobral, CE - 2005 a 2007

\begin{tabular}{lllll}
\hline \multicolumn{1}{c}{ Variável } & \multicolumn{1}{c}{ Categoria } & OR & IC $_{95 \%}$ & P \\
\hline Estado civil materno & Casada/união estável & 0,73 & $0,36-1,48$ & 0,387 \\
Escolaridade materna* & & 0,96 & $0,75-1,23$ & 0,779 \\
Tipo de parto & Cesárea & 1,34 & $0,70-2,56$ & 0,368 \\
$\begin{array}{l}\text { Incremento no escore-z de } \\
\text { peso }\end{array}$ & Presença & 0,91 & $0,71-1,17$ & 0,499 \\
$\begin{array}{l}\text { Incremento no escore-z de } \\
\text { comprimento }\end{array}$ & Presença & 1,10 & $0,91-1,33$ & 0,290 \\
\hline *Variável tratada como contínua, OR corresponde a mudança de uma categoria & &
\end{tabular}

Realizou-se análise multivariada entre a presença ou ausência de consulta em emergência pediátrica e as variáveis reagrupadas: tipo de parto, peso ao nascer, tipo de moradia, tipo de fogão, renda familiar e alimentação oferecida aos quatro meses de idade (Tabela 22). As crianças que interromperam o AME antes dos quatro meses de idade tiveram risco três vezes maior de ser consultada em emergência pediátrica.

Tabela 22 - Análise multivariada entre consulta em emergência pediátrica e as variáveis características perinatais, condições ambientais e alimentação durante o primeiro ano de vida das crianças com BPN estudadas - Sobral, CE - 2005 a 2007

\begin{tabular}{llrrr}
\hline \multicolumn{1}{c}{ Variável } & \multicolumn{1}{c}{ Categoria } & OR & \multicolumn{1}{c}{ IC $_{95 \%}$} & P \\
\hline Tipo de parto & Cesárea & 1,04 & $0,54-2,01$ & 0,902 \\
Peso ao nascer* & & 0,87 & $0,51-1,50$ & 0,634 \\
Moradia* $^{*}$ & & 0,97 & $0,61-1,56$ & 0,925 \\
Fogão & Fogão a gás & 1,18 & $0,66-2,10$ & 0,562 \\
Renda familiar* & & 0,78 & $0,36-1,68$ & 0,538 \\
Alimentação aos 4 meses & Sem AME & 3,07 & $1,53-6,15$ & $0,001^{* *}$ \\
\hline $\begin{array}{l}\text { AME Aleitamento Materno exclusivo } \\
* \text { Variável tratada como contínua, OR corresponde a mudança de uma categoria. } \\
{ }^{* *} \mathrm{p}<0,01\end{array}$ & & & \\
& & & &
\end{tabular}


A Tabela 23 apresenta a análise multivariada entre a presença de internação neonatal e as variáveis reagrupadas: idade materna, estado civil materno, escolaridade materna, idade gestacional, sexo, peso ao nascer, tipo de moradia, fogão utilizado, e renda familiar. A principal variável relacionada com internação neonatal foi o peso ao nascer (OR 6,1; $p=0,00)$. A idade gestacional também mostrou relação inversa com o risco de internação neonatal (OR 2,21; $\mathrm{p}=0,028)$. Após a análise multivariada, as demais variáveis não mostraram relação com a internação neonatal.

Tabela 23 - Análise multivariada entre internação neonatal e as variáveis características maternas, perinatais, condições ambientais e econômicas durante o primeiro ano de vida das crianças com BPN estudadas - Sobral, CE - 2005 a 2007

\begin{tabular}{|c|c|c|c|c|}
\hline Variável & Categoria & OR & $I_{95 \%}$ & $p$ \\
\hline Idade materna* & & 1,35 & $0,81-2,24$ & 0,240 \\
\hline Estado civil materno & Casada/união estável & 0,94 & $0,43-2,04$ & 0,883 \\
\hline Escolaridade materna* & & 1,21 & $0,92-1,59$ & 0,168 \\
\hline Idade Gestacional* & & 2,21 & $1,08-4,50$ & $0,028^{* *}$ \\
\hline Peso ao nascer* & & 6,10 & $2,78-13,38$ & $0,000^{* \star \star}$ \\
\hline Sexo & Masculino & 1,45 & $0,71-2,96$ & 0,299 \\
\hline Moradia* & & 1,49 & $0,85-2,60$ & 0,156 \\
\hline Fogão & Fogão a gás & 1,11 & $0,48-2,52$ & 0,803 \\
\hline Renda familiar* & & 1,56 & $0,82-2,97$ & 0,170 \\
\hline
\end{tabular}

$\mathrm{Na}$ Tabela 24 apresenta a análise multivariada entre a presença de internação após o período neonatal por pneumonia, diarréia e outras afecções e as variáveis reagrupadas: estado civil materno, idade gestacional, alimentação oferecida aos quatro meses e incremento no 
escore-z de peso até os quatro meses de idade corrigida. Os filhos de mães casadas ou com união estável e as crianças que apresentaram incremento no escore-z de peso até os quatro meses de IGC tiveram menor chance de internação por diarréia, pneumonia e outras causas após o período neonatal. As demais variáveis não mostraram relação com a internação após o período neonatal segundo a análise multivariada.

Tabela 24 - Análise multivariada entre internação após o período neonatal e as variáveis características maternas, perinatais, alimentação e evolução ponderoestatural durante 0 primeiro ano de vida das crianças com BPN estudadas Sobral, CE - 2005 a 2007

\begin{tabular}{|c|c|c|c|c|}
\hline Variável & Categoria & OR & $\mathrm{IC}_{95 \%}$ & $\mathbf{p}$ \\
\hline Estado civil materno & Casada/união estável & 0,26 & $0,08-0,77$ & $0,015^{*}$ \\
\hline Idade Gestacional** & & 1,98 & $0,98-4,01$ & 0,055 \\
\hline Alimentação aos 4 meses & Sem AME & 2,45 & $0,95-6,34$ & 0,063 \\
\hline $\begin{array}{l}\text { Incremento no escore-z de } \\
\text { peso }\end{array}$ & Sim & 0,65 & $0,47-0,91$ & $0,013^{*}$ \\
\hline
\end{tabular}

AME Aleitamento Materno Exclusivo

${ }^{*} p<0,05$

** Variável tratada como contínua, OR corresponde a mudança de uma categoria 
5 Discussão 
O primeiro ano de vida é um período caracterizado por crescimento ponderoestatural rápido, aquisições de diversas habilidades neuropsicomotoras e alta morbidade, que necessita de um acompanhamento para promoção da saúde, prevenção de doenças, educação da criança e de seus familiares por meio de orientações contínuas visando evitar riscos de agravos à saúde, e oferecer medidas preventivas mais eficazes.

As crianças com BPN apresentam maior morbidade durante 0 primeiro ano de vida do que aquelas nascidas a termo e adequadas para a idade gestacional. Após a alta hospitalar, os serviços de atendimento à saúde devem estar estruturados para proporcionar melhorias a esta população visando maximizar o bem-estar físico, emocional e social, e reduzir as diferenças de oportunidades e riscos. O Programa de Saúde da Família na cidade de Sobral, no Ceará fornece cobertura a 100\% da população e realiza puericultura com abordagem diferenciada para criança de risco, inclusive aquelas com BPN, desde 2005.

Em Sobral, as três primeiras unidades de PSF foram implantadas em 1997 nas áreas de maior risco de morbidade, com o objetivo de desenvolver a capacitação contínua dos profissionais, utilizar caderneta da Saúde da Mãe e da Criança, adotar protocolos específicos, inclusive para RNBP, e oferecer suporte social para o acompanhamento destas crianças no 
domicílio diminuindo as consultas em serviços hospitalares e paralelamente aumentando as consultas nas unidades básicas de saúde (Andrade e Martins Júnior, 2000).

\subsection{Características maternas das crianças com BPN acompanhadas pelo PSF da cidade de Sobral, CE}

Conforme mostra a Tabela 1, constatamos que a média da idade materna no momento do parto foi de 24 anos, com a idade mínima de 12 anos e a máxima de 44 anos. O índice de mães com idade entre 11 e 19 anos foi de $29,12 \%, 60,92 \%$ eram mães com idade entre 20 e 34 anos, e 9,96\% eram mães com 35 anos ou mais. O índice de mães adolescentes das crianças de BPN foi maior do que o encontrado para todos os RN na cidade de Sobral $(25,08 \%)$ e no restante do Brasil $(20,55 \%)$ no mesmo período (DATASUS, 2010b).

Dentre os fatores maternos de risco para RNBP destaca-se a gravidez na adolescência, que estaria sujeita à maior incidência de complicações na gestação, parto e puerpério, particularmente quando a gestante pertence a classe socioeconômica menos favorecida. Costa e Gotlieb (1998) verificaram que os riscos de baixo peso ao nascer entre os filhos de mulheres com menos de 15 anos e daquelas de 35 ou mais anos foram 3,45 e 1,38 vezes maior, respectivamente.

Em nosso estudo, no momento do parto, $31,42 \%$ eram casadas ou com união estável e tinham o apoio do companheiro; $41,76 \%$ das mães eram solteiras, e $26,44 \%$ desquitadas, separadas ou viúvas (Tabela 1). Tais 
dados diferem do DATSUS onde mãe com união estável tem sido caracterizada como solteira. A ausência do companheiro já havia sido relacionada ao baixo peso ao nascer no RNT, possivelmente por este dar apoio financeiro e emocional e garantir menor risco na gestação (Passini, 1992).

De acordo com a Tabela 1, entre as mães das crianças com BPN, $10,34 \%$ tinham 12 anos ou mais de estudo; 22,99\%, 8 a 11 anos de estudo; $23,37 \%$, quatro a sete anos de estudo; $19,16 \%$ de um a três anos de estudo e $24,14 \%$ das mães declararam não ter estudado. Apesar do alto índice de analfabetismo, ele ainda está abaixo da taxa de $37,7 \%$ referente à população de Sobral conforme o IBGE, senso de 2000.

Segundo Nascimento (2005), mães com baixa escolaridade, inferior a oito anos de estudo, têm o dobro de chance de ter RNBP, comparadas com aquelas de maior escolaridade. Neste estudo, o autor associa renda inferior a três salários mínimos e idade inferior a 19 anos ao BPN. As características acima podem ser entendidas como uma aproximação do estrato socioeconômico materno, assumindo significados diferentes nos diversos contextos sociais e continuam sendo consideradas como fatores relevantes associados ao peso ao nascer e à morbimortalidade neonatal. 


\subsection{Características perinatais das crianças com BPN acompanhadas pelo PSF da cidade de Sobral, CE}

Como mostra a Tabela 2, o parto cesariano foi realizado em $47,89 \%$ da população estudada, bem acima dos $15 \%$ preconizado pela OMS e próximo dos $39,1 \%$ encontrados na população atendida pelo Centro de Saúde Escola Butantã em São Paulo por Sgroi, em 2008. A autora não encontrou relação entre baixo peso ao nascer e parto cesariano, porém relatou sobre os partos cesarianos eletivos, principalmente na rede privada, onde a prematuridade iatrogênica poderia ser responsável pelo aumento do BPN.

Conforme os dados da Tabela 2, entre as crianças com BPN, 47,51\% nasceram a termo, portanto, com restrição de crescimento intrauterino; $46,36 \%$ das crianças foram prematuras com IG entre 32 e 36 semanas e 6,13\% com IG inferior a 32 semanas de gestação. Estes resultados são semelhantes àqueles do estudo realizado por Maranha (2004), na cidade de Campinas em São Paulo, no qual a autora constatou uma maior prevalência de prematuridade $(57,65 \%)$.

O sexo feminino representou $55,56 \%$ da população (Tabela 2). Apesar de não ter relação com prematuridade, sabe-se que o feto masculino tem peso maior que o feminino (Kramer, 1987). Costa e Gotlieb (1998) encontraram coeficiente de 1,16 de prevalência de BPN entre as meninas com relação aos meninos.

Apesar das crianças desse estudo serem de BPN, o Apgar de 5 minutos foi maior que seis na sua grande maioria $(98,08 \%)$. Maranha, em 2004, encontrou proporção semelhante, e constatou ainda que as crianças 
nascidas com Apgar de 5 minutos baixo apresentaram velocidade de crescimento abaixo da média, porém sem significado estatístico após análise multivariada.

O peso médio entre as crianças nascidas com BP e vivas foi $2140 \mathrm{~g}$ com desvio padrão de 327 g, com peso mínimo de 640 g e máximo de 2495 g. Sendo que, 21,36\% das crianças nasceram com peso entre 1500 e 1999 g e 5,34\% com peso inferior a $1500 \mathrm{~g}$. A prevalência de crianças com peso entre 2000 e 2499 g tem sido grande, o que justifica a preocupação com esta população apesar da alta morbidade e mortalidade observada nas crianças com MBP.

\subsection{A evolução ponderoestatural das crianças com BPN acompanhadas pelo PSF da cidade de Sobral, CE}

Durante as consultas de puericultura, aos quatro, seis e 12 meses de idade cronológica para os RN a termo e corrigida para os RNPT, houve recuperação do peso e comprimento, mas estando abaixo ainda da média da referência da OMS (Gráficos 1 a 6). Observou-se que os RNPT alcançaram média de peso e do comprimento maior dos que os RNT-PIG (Tabela 3), fato semelhante aos achados por Hack et al. (1996).

Segundo Maranha (2004), o risco para velocidade de crescimento abaixo da média foi 3,36 vezes maior para as crianças do sexo feminino, quatro vezes para aquelas que viviam em domicílios sob condições inadequadas de saneamento e 2,35 maior para aquelas de gravidez não planejada. 
O baixo peso ao nascer tem papel determinante na desnutrição infantil. No entanto, foi demonstrado por Post et al. (1996) em um estudo com duas coortes na cidade de Pelotas, Rio Grande do Sul que a desnutrição secundária ao BPN parece estar diminuindo. Isto provavelmente se deve ao fato de, em relação a 1982, as crianças de baixo peso nascidas em 1993 ganharam $820 \mathrm{~g}$ a mais durante o primeiro ano de vida, associados ainda ao aumento na duração do aleitamento materno, melhora no saneamento básico, reduções nas hospitalizações e na mortalidade por diarréia. De acordo com a autora, crianças nascidas com peso igual ou superior a $3.000 \mathrm{~g}$ apresentam risco quase três vezes superior de serem obesas aos 12 meses de vida do que aquelas com BPN. Chama a atenção para o fato de em 1982 não haver nenhum caso de obesidade aos 12 meses entre os nascidos de baixo peso, enquanto que em 1993 esta prevalência atingiu $3 \%$.

Em nosso estudo, o incremento do escore-z do peso foi adequado em $86 \%$ das crianças com BP entre quatro e seis meses de idade alcançando 89\% nas crianças com 12 meses de idade. Em relação ao incremento do escore-z do comprimento, $54 \%$ das crianças estudadas não tiveram um incremento adequado até os quatro meses, índice que se manteve em $60 \%$ até o final do primeiro ano de vida. É provável que o crescimento abaixo do esperado desta população se deva por ser a metade das crianças nascidas a termo e com RCIU. Estes dados são semelhantes aos descritos por Strauss e Dietz (1997) em um estudo com crianças prematuras no qual observaram aumento da velocidade de crescimento até os oito meses de 
IGC; porém, as crianças nascidas com RCIU alcançaram velocidade de ganho de peso e altura significativamente inferiores àquelas nascidas com peso AIG.

Atualmente, o incremento do escore-z de peso tem sido visto com cuidado, pois tem sido relacionado com doenças metabólicas na fase adulta. (Nobili et al., 2008).

Entre as 137 crianças prematuras com BPN do nosso estudo, apenas $2(1,46 \%)$ não estavam em amamentação com 40 semanas de IGC (Tabela 4). Este alto índice de amamentação está associado à política dos hospitais que são reconhecidos como Hospitais Amigos da Criança e referência em amamentação para o município de Sobral. A SCMS conta ainda com uma enfermaria para o Método Canguru, o que facilita as orientações e o maior sucesso da amamentação mesmo nos RNMBP.

De acordo com a Tabela 4, 162 e 117 das crianças estudadas com BPN estavam em aleitamento materno aos quatro e seis meses respectivamente, o que corresponde a $82,40 \%$ e $59,69 \%$ entre as crianças que foram consultadas. Estes valores são mais elevados do que aqueles observados no estudo realizado por Xavier et al. (1991). Os autores estudaram a duração do aleitamento materno no primeiro ano de vida de 222 crianças nascidas com peso menor ou igual a 2500 gramas no Hospital das Clínicas da Faculdade de Medicina de Ribeirão Preto (São Paulo), no período de outubro de 1985 a setembro de 1986. A prevalência de amamentação foi de $62,5 \%$ aos três meses e $38,5 \%$ aos seis meses com mediana da duração do aleitamento materno de quatro meses. A incidência 
do aleitamento materno e sua duração foram maiores nas crianças de maior peso e com maior escolaridade materna.

Embora Dewey et al (1999) não terem observado vantagens na introdução de alimentos antes dos seis meses, neste estudo encontrou-se dificuldade na manutenção do aleitamento materno exclusivo nas crianças de BPN. Entre as crianças prematuras, $57,66 \%$ estavam em aleitamento materno exclusivo com 40 semanas de idade gestacional corrigidas. Entre as 261 crianças de BPN, apenas 26,05\% permaneceram em AM exclusivo por quatro meses e $8,43 \%$ até os seis meses de idade (Tabela 4). Estes dados estão bem inferiores ao índice geral de $70 \%$ de aleitamento materno exclusivo até os quatro meses encontrado na cidade de Sobral, o que mostra a dificuldade do grupo de crianças com BPN em manter o aleitamento materno exclusivo (DATASUS, 2010c). Índices baixos de aleitamento materno exclusivo até os seis meses são encontrados mesmos nas crianças nascidas a termo e AIG, cuja prevalência não ultrapassa a 10\% em todas as regiões do país (Sena et al., 2007).

Além do BPN, Venâncio et al. (2002) em outro estudo, mostraram que as mães com baixa escolaridade, adolescentes e primíparas constituem categorias de risco para introdução de outros alimentos na dieta da criança. Já o trabalho materno não apresentou significância quando analisado em conjunto com outras variáveis. Mas, a análise permitiu concluir que o fato de a criança nascer em um Hospital Amigo da Criança, reconhecido por cumprir os "Dez passos para o sucesso do aleitamento materno" propostos pela OMS/Unicef (1990), possibilitou um impacto significativo na prática do AME e do AM. 


\subsection{Condições ambientais e econômicas das crianças com BPN acompanhadas pelo PSF da cidade de Sobral, CE}

De acordo com a Tabela 5, a maioria das crianças residia em casa rebocada, enquanto $12,26 \%$ das crianças residiam em casa de taipa (barro) e outras $12,26 \%$ em casa de concreto sem reboque.

A casa de taipa sem piso e sem revestimento é característica da camada populacional economicamente mais desfavorecida e deixa as famílias expostas à poluição ambiental, as mudanças climáticas e aos animais transmissores de doenças. Barreto, em 2006, também realizou estudos na cidade de Sobral em que $5,7 \%$ das residências de crianças de cinco a nove anos eram de taipa sem revestimento e $11 \%$ eram de taipas revestidas, concluindo que a qualidade de vida oferecida por estes (taipa revestida) não difere muito da oferecida por casa de tijolos das mesmas dimensões.

Em nossa pesquisa verificamos que o fogão a lenha era utilizado em $31,04 \%$ das moradias, exclusivamente ou associado com fogão a gás; enquanto $54,02 \%$ das famílias utilizavam apenas fogão a gás (Tabela 5). 0 fogão a lenha ou o fogareiro, ao liberar fumaça no interior das residências, podem aumentar a morbidade respiratória das crianças e suas famílias, particularmente as de BPN, como descreveram Prietsch et al. em 2006. Em seu estudo, as crianças menores de cinco anos cujas mães utilizavam fogão a lenha para cozinhar apresentaram um risco de 2,7 vezes maior de apresentar sibilância recorrente.

Com relação à renda familiar, em $29,89 \%$ das famílias foi inferior a 1 SM, 44,44\% entre um a três salários e 8,43\% com quatro ou mais salários mínimos mensais caracterizando uma população de baixo poder aquisitivo (Tabela 5). 


\subsection{Morbidades das crianças com BPN acompanhadas pelo PSF da cidade de Sobral, CE}

As afecções respiratórias na criança em geral constituem um grupo heterogêneo de doenças associadas, onde nos primeiros anos de vida destacam-se as infecções virais. As infecções de vias aéreas superiores constituem causa freqüente de atendimento em pronto-socorro pediátrico, sendo que em geral uma criança tem em média oito a 10 quadros de IVAS por ano (Simon Jr. et al., 2009).

A incidência de pneumonia nos dois primeiros anos de vida é de 1,79/1000 nascidos vivos. Diferente de outras faixas etárias pediátricas, as bactérias representam a causa principal de pneumonia entre os lactentes (Rodrigues e Silva Filho, 2009). Por isso, na cidade de Sobral, as equipes do PSF utilizam-se do manual do AIDPI como política para diminuição da mortalidade infantil, aumentando a possibilidade de diagnóstico e tratamento destas infecções.

Como mostra o Gráfico 7 , as patologias mais freqüentes nas consultas no PSF das crianças com BPN foram afecções respiratórias (65,91\%), sendo que $14,69 \%$ tinham o diagnóstico de pneumonia e $51,22 \%$ eram outras afecções respiratórias como infecções de vias aéreas superiores (IVAS). As diarréias agudas foram responsáveis por 12,15\% das consultas realizadas durante o primeiro ano de vida e os outros diagnósticos, $21,94 \%$, onde se destacaram as patologias de pele como escabiose, impetigo e outras dermatites.

$\mathrm{Na}$ população estudada, houve 469 consultas de emergência pediátrica com média de 1,79 consultas por criança de BPN, e 156 
internações nos dois hospitais da cidade de Sobral, além de 14 transferências para a cidade de Fortaleza, por necessidade de cuidados em Unidade de Terapia Intensiva Neonatal (UTI neonatal).

Com relação às internações, estas ocorreram principalmente no período neonatal, no qual se verificou a ocorrência de 96 internações nesta faixa etária, correspondendo a 1138 dias de internação hospitalar, 74,47\% das diárias totais durante o primeiro ano de vida, e média de internação de 11 dias.

Gomes et al. (2005) avaliaram as internações neonatais em quatro Unidades de Terapia Intensiva Neonatal (UTIN) da rede pública do Rio de Janeiro e observaram que $70 \%$ de todos os RN internados eram de BPN, sendo $31 \%$ de $\mathrm{MBP}$, de todos os $\mathrm{RN}$ internados $81 \%$ eram pré-termos, e constataram tempo médio de internação de 38 dias.

Na cidade de Sobral, a falta de UTI neonatal dificulta o tratamento do paciente de maior risco como aquele cujo peso de nascimento é menor que $1000 \mathrm{~g}$, necessitando serem transferido para um serviço de referência. Além disso, os RNBP recebem alta precoce muitas vezes antes de alcançarem um peso de $1800 \mathrm{~g}$, peso mínimo recomendado pela alta conforme a literatura (Stoll e Adams-Champman, 2007).

Conforme o Gráfico 8, a pneumonia foi a segunda causa de internação $(12,39 \%)$ seguida pela doença diarréica com $6,33 \%$ dos casos. As doenças respiratórias geram despesas para o Sistema Único de Saúde. No ano 2000, no Estado de São Paulo, a despesa com internações por doenças respiratórias aproximou-se de $R \$ 45$ milhões (aproximadamente 
US\$ 18 milhões). Ferrer (2009) constatou que as doenças respiratórias, em particular a pneumonia, foram as principais causas de internação nas três faixas etárias de seu estudo (menores de um ano, entre um e quatro anos e entre cinco e nove anos), além disso, observou um aumento nos coeficientes de internação no município de São Paulo, em todas as idades avaliadas entre 2002 e 2006.

Goya e Ferrari (2005) relataram que as crianças com BPN apresentam um risco 6,4 vezes maior de evoluir para óbito por pneumonia nos primeiros seis meses de vida e, de 2,9 vezes entre seis e 12 meses. $O$ baixo peso tem sido relacionado ainda a maior risco de adquirir pneumonia e necessidade de hospitalização por esta doença.

Mello et al (2004) realizaram um estudo com o objetivo de verificar a incidência de morbidade respiratória no primeiro ano de vida de prematuros de muito baixo peso e observaram que mais de 50 por cento das crianças acompanhadas apresentaram intercorrências respiratórias no curso do primeiro ano de vida, sendo elevada a incidência de pneumonia e de internação. Os autores observaram ainda que as crianças que usaram oxigênio por tempo prolongado (além de 28 dias de vida) apresentaram morbidade respiratória significativamente maior do que aquelas que não usaram oxigênio por tempo prolongado.

Apesar da diarréia ser ainda um problema de saúde pública importante, terceira causa de internação em nosso estudo, tem se verificado uma redução na morbimortalidade associada a essa doença. No estudo de Campos et al (1995), através de inquérito domiciliar sobre crianças menores 
de 5 anos, observaram que o número de episódios de diarréia por criança ao ano foi reduzido de 6,3, em 1986, para 2,1, em 1989 e que a taxa de mortalidade caiu de 12,8 por mil para 4,9 por mil no mesmo período.

Benício e Monteiro (2000) comparando os resultados dos inquéritos realizados em 1984/85 e 1995/96, na cidade de São Paulo, constataram reduções expressivas tanto na prevalência (declínio de 50\%) como na incidência anual de hospitalizações por diarréia (redução de dois terços), principalmente na faixa mais pobre da população.

Um estudo realizado no Rio Grande do Sul avaliou três coortes de crianças em 1982, 1993 e 2004, constatando uma redução drástica nas hospitalizações referentes à diarréia, principalmente pelo uso da Terapia de reidratação oral (Matijasewich et al., 2008).

A vacinação contra rotavírus, incluída no Calendário Básico de vacinas da criança no Brasil desde março de 2006, é responsável pela redução das internações por esta patologia, principalmente nos menores de um ano de vida. Palma et al. (2010) constataram redução de $51 \%$ nas admissões hospitalares por diarréia aguda após três anos de introdução da vacina contra rotavírus monovalente no calendário de El Salvador. 


\subsection{Relações das variáveis de exposição estudadas e o número de consultas por patologia das crianças com BPN no PSF da cidade de Sobral, CE}

A relevância do baixo peso ao nascer para a saúde pública é determinada não apenas pelos riscos subseqüentes de mortalidade e morbidade, mas também pela freqüência com que o mesmo ocorre. As maiores prevalências de baixo peso ao nascer são observadas nos países em desenvolvimento, como uma conseqüência das piores condições de vida existentes nestes locais (Horta et al, 1996).

O sucesso na sobrevida das crianças de baixo peso é multifatorial, atribuído não só a melhor tecnologia médica que proporciona o suporte vital imediato principalmente no período perinatal, como ao suporte social e ao acesso ao serviço de saúde disponível para essas famílias.

De acordo com Starfield (2002), a atenção primária à saúde se caracteriza como o nível de um sistema de saúde que oferece a entrada nos demais serviços de saúde, podendo ser compreendida como uma tendência de se inverter a priorização das ações de saúde, de uma abordagem curativa, desintegrada e centrada no papel hegemônico do médico, para uma abordagem preventiva promocional, integrada com outros níveis de atenção e construída de forma coletiva com outros profissionais de saúde

O PSF foi criado pelo Ministério da Saúde em 1994 com o objetivo principal de contribuir para a reorientação do modelo assistencial a partir da atenção básica, em conformidade com os princípios do Sistema Único de Saúde (SUS), imprimindo uma nova dinâmica de atuação nos Centros de Saúde e dividindo a responsabilidade entre seus serviços e a população. 
Desta maneira, de um modelo assistencial voltado para o indivíduo doente, centralizado nos hospitais e nos centros urbanos, onde a saúde é considerada como ausência de doença, procurou-se adotar um sistema voltado para a comunidade e para o indivíduo saudável, com equipes multiprofissionais e serviços de saúde distribuídos por todo o território, garantindo o acesso a toda a população e com base no conceito de saúde entendida como qualidade de vida. Além disso, o PSF trabalha com uma base de dados epidemiológicos para o seu planejamento e programação, priorizando as famílias ou grupos com maior risco de adoecer e morrer (Andrade e Martins Júnior, 2000).

O PSF foge à concepção usual dos demais programas concebidos pelo Ministério da Saúde, já que não é uma intervenção vertical e paralela às atividades dos serviços de saúde. Pelo contrário, caracteriza-se por possibilitar a integração e promover a organização das atividades em um território definido, com o propósito de propiciar o combate e a resolução dos problemas identificados.

Escorel et al (2007) complementa quando afirma que o PSF encerra, em sua concepção, mudanças na dimensão organizacional do modelo assistencial ao constituir uma equipe multiprofissional responsável pela atenção à saúde de uma população circunscrita, definir o generalista como o profissional médico de atenção básica e instituir novos profissionais, como os ACS voltados para a ação comunitária, ampliando a atuação da equipe sobre os determinantes mais gerais do processo saúde-enfermidade. 
Segundo Ferrer (2009) ainda há poucos relatos na literatura a respeito do impacto do PSF na saúde e na morbidade infantil. Um estudo realizado em 2006 por Roncalli et al. no qual foi avaliado o impacto do PSF nos indicadores de saúde da criança em quatro municípios do Nordeste, não encontraram diferenças significativas entre os indicadores de áreas cobertas pelo PSF. O único efeito positivo encontrado foi a redução das internações por diarréia.

Na cidade de Sobral, a implantação do PSF em 1997 está associada à melhora dos índices e foi estudada por Silva (2003). Segundo a autora, houve redução da taxa de mortalidade infantil de 71,66 em 1995 para 21,45 por mil nascidos vivos em 2002 ( $p=0,001$ ), com redução da mortalidade neonatal e pós-neonatal. Comparando os anos de 1997 e 2002 a autora encontrou redução do percentual de óbitos infantis no domicílio, aumento percentual de gestantes com pré-natal em dia de $76,01 \%$ para $95,14 \%$, aumento percentual de crianças em aleitamento materno exclusivo até o $4^{\circ}$ mês de idade de $50 \%$ para $69,48 \%$, aumento da cobertura vacinal das crianças de $68 \%$ para $96,50 \%$ e redução percentual de crianças internadas por desnutrição de $8,6 \%$ para $1,40 \%$.

O PSF, responsável pelo acolhimento e triagem, encaminha para o serviço secundário e terciário apenas o que não possa ser resolvido na unidade básica de saúde. Neste estudo, realizou em média 4,72 consultas por doença nas crianças com BPN durante o primeiro ano de vida enquanto este mesmo grupo foi consultado uma média de 1,79 atendimentos em emergência pediátrica. Esta diferença poderia ser ainda maior se houvesse 
médicos em todas as unidades básicas, pois no período estudado a cobertura de PSF com equipes completas estava em torno de 60\% (2005), aumentando para $90 \%$ até os dias atuais (DATASUS, 2010a).

Conforme mostram as Tabelas 6 a 9, no grupo com mais de quatro consultas por motivo de doença em PSF houve uma porcentagem maior de mães adolescentes, solteiras e sem escolaridade; de crianças nascidas de parto cesariano, do sexo masculino, sem incremento adequado no escore-z de peso e com incremento do escore-z de comprimento; e de residências que utilizavam fogão a lenha pra cozinhar quando comparado com o grupo de menor número de consultas. Estas variáveis estudadas não tiveram diferença significativa após a análise de regressão logística univariada e multivariada.

As crianças que apresentaram menor recuperação do comprimento, que normalmente está relacionado aos RNPIG, foram maioria no grupo de menor número de consultas em PSF. Isto se deve, provavelmente, por que o RNT-PIG tem menor morbidade quando comparado com RNPT adequado para idade gestacional. Este paradoxo do BPN foi descrito por Wilcox, em 2001, quando o autor descreveu que RNBP filhos de mães fumantes têm mortalidade menor do que os RNBP filhos de mães não fumantes.

Neste estudo nenhumas das variáveis de exposição estudadas conferiram risco para um maior número de consultas por doença no PSF (Tabela 21). Provavelmente, seja resultado da priorização na prevenção e promoção à saúde para estes grupos de risco adotadas na política do PSF, com intuito de diminuir o risco de agravos. 


\subsection{Relações das variáveis de exposição estudadas e a presença de consultas em emergência pediátrica das crianças com BPN da cidade de Sobral, CE}

De acordo com as Tabelas 10 a 13, crianças nascidas de parto cesariano, com menor peso ao nascer, que interromperam o aleitamento materno exclusivo antes dos quatro meses, que moravam em residência com reboque, com famílias que utilizavam apenas o fogão a gás para cozinhar e ainda aquelas com maior renda familiar, representavam porcentagem maior no grupo com consultas em emergência pediátrica comparadas com o grupo sem consulta das crianças com BPN da cidade de Sobral.

Isso provavelmente se deve ao fato que as residências de taipas, que utilizam fogão a lenha e com menor renda familiar normalmente se encontram mais distantes do centro da sede onde se localiza os serviços hospitalares. Em geral são regiões com menor densidade populacional, com menor número de veículos automotores e de indústrias com ambientes menos poluídos. Quanto mais distante da sede e mais próximos dos distritos, maior o contato com hábitos e costumes da zona rural. Além de costumes mais saudáveis, a própria dificuldade de acesso e o menor poder aquisitivo dificultam o acesso à rede hospitalar.

Após a análise multivariada (Tabela 22), a interrupção do aleitamento materno exclusivo antes dos quatro meses foi o único fator de risco com significado estatístico para consulta em emergência pediátrica, onde tais crianças apresentaram risco 3,1 vezes maior de serem consultadas quando comparadas com as crianças em AME até os quatro meses $(p<0,001)$. 
O aleitamento materno é considerado um dos pilares fundamentais para a promoção e proteção da saúde das crianças em todo o mundo. A superioridade do leite humano como fonte de alimento, de proteção contra doenças e da amamentação para um maior vínculo com a criança fazem com que especialistas do mundo inteiro recomendem a amamentação exclusiva por pelo menos quatro a seis meses de vida do lactente e complementado até dois anos de vida ou mais. A ausência de amamentação, sua interrupção e a introdução de outros alimentos à dieta da criança que acontece frequentemente pode ter consequências importantes para a saúde do bebê, como exposição a agentes infecciosos, contato com proteínas estranhas, prejuízo da digestão e assimilação de elementos nutritivos, entre outras (Kummer et al., 2000; Venâncio et al., 2002).

Victora et al (1987) constataram que crianças que não recebiam leite materno tinham maiores riscos de morrer por diarréia (risco 14,2 vezes maior), por doenças respiratórias (3,6 vezes) e por outros tipos de infecções $(2,5$ vezes) quando comparadas às que recebiam aleitamento materno exclusivo.

Xavier et al. (1991) afirmam ainda que a prática da amamentação muda com as transformações históricas e apresenta especificidades de uma cultura para outra. $\mathrm{O}$ amamentar reflete, em cada indivíduo, a sua vivência com os conceitos de sua cultura, traduzidos inconscientemente em suas atitudes e opiniões com relação à amamentação. A prática da amamentação é ao mesmo tempo afetiva e cultural, devendo-se levar em conta a identidade dos indivíduos envolvidos, a especificidade da cultura da qual provém e o seu momento histórico. 
Diversas pesquisas têm mostrado que medidas simples podem causar impacto importante na prevalência e na duração do aleitamento materno. Em um estudo realizado no Guarujá (São Paulo), foi mostrado que $55 \%$ das mulheres que freqüentaram um grupo que abordava problemas relativos ao aleitamento materno estavam amamentando exclusivamente ao final do primeiro mês de vida de seus bebês, enquanto entre as mães que não frequentaram o grupo, o índice de aleitamento materno exclusivo era de $31 \%$. Aos quatro meses, $43 \%$ das mulheres freqüentadoras do grupo amamentavam exclusivamente, ao passo que entre as não-freqüentadoras esse índice foi de 18\% (Barros, et al., 1995).

Outro estudo mostrou que a orientação sobre aleitamento materno ainda na maternidade, após o nascimento da criança, aumentou os conhecimentos maternos sobre o tema e, conseqüentemente, a prevalência da amamentação nos primeiros seis meses de vida (Susin et al, 1998).

Segundo nosso estudo, o aleitamento materno deve continuar sendo foco da atenção das políticas públicas, sendo o único fator que poderá diminuir a procura pela emergência pediátrica. 


\subsection{Relações das variáveis de exposição estudadas e a presença de internação no período neonatal nas crianças com BPN da cidade de Sobral, CE}

Observou-se nas Tabelas 14 a 16 que, no grupo dos $\mathrm{RN}$ com internação neonatal, houve maior proporção de mães com mais idade e escolaridade, $\mathrm{RN}$ do sexo masculino, com menores idade gestacional e peso ao nascer, e melhores condições ambientais e econômicas quando comparados com aqueles RN sem internação neonatal. Provavelmente, por que condições socioeconômicas inferiores tem sido relacionadas ao RNBP com RCIU. Como citado na introdução deste estudo, segundo Horta et al. (1996), o risco de crianças com retardo de crescimento intra-uterino foi de 1,7 vezes maior entre as famílias mais pobres comparadas com as de melhor situação sócio-econômica em 1993, enquanto os nascimentos prétermos não estiveram associados com a renda familiar.

Conforme a tabela 16 , a maioria das crianças que ficaram internadas no período neonatal eram prematuras $(76,04 \%)$, e no grupo das crianças que não ficaram internadas predominou aquelas nascidas a termo-PIG $(61,21 \%)$.

Da mesma maneira, $89,70 \%$ das crianças que não necessitaram de internação no período neonatal tinham peso de nascimento entre 2000 e $2499 \mathrm{~g}$, enquanto que no grupo internado a maioria era composta por crianças com peso de nascimento inferior a $2000 \mathrm{~g}(58,33 \%)$.

A análise multivariada da Tabela 23 indica que a idade gestacional e 0 peso ao nascer foram fatores determinantes na internação neonatal (OR 2,21 e 6,10; $p<0,05$ e $p<0,001$, respectivamente). 
A prematuridade tem sido associada com morbidade neonatal elevada, incluindo os pré-termos tardios. Khashu et al. (2009) estudaram a mortalidade e morbidade de lactentes pré-termo tardio (entre 33 a 36 semanas) em relação aos nascidos de termo (37 a 40 semanas), e concluíram que a taxa de mortalidade neonatal era 5,5 vezes maior no grupo pré-termo tardio, principalmente na primeira semana de vida, com um risco de 4,4 vezes maior de morbidade respiratória, 5,2 vezes de infecção, e uma duração significativamente maior de internação quando comparado com os RNT.

\subsection{Relações das variáveis de exposição estudadas e a presença de internação após o período neonatal nas crianças com BPN da cidade de Sobral, CE}

De acordo com as Tabelas 17 a 20, a internação além do período neonatal durante o primeiro ano de vida das crianças com BPN de Sobral esteve relacionada com o estado civil materno, a idade gestacional ao nascer, a interrupção do aleitamento materno exclusivo e a ausência do incremento no escore-z do peso até os quatro meses.

Através da tabela 25 , observou-se que as crianças filhas de mães casadas ou com união estável tiveram risco muito menor de serem internadas após o período neonatal (OR 0,26, $p=0,015$ ) quando comparadas com as filhas de mães sem apoio do companheiro (solteiras, desquitadas, viúvas e separadas). Algumas variáveis são difíceis de serem explicadas. Porém, podemos admitir que mães sem apoio do companheiro rotineiramente também não têm o apoio da família; tiveram gestações não 
planejadas, podendo negligenciar cuidados, atrasar o diagnóstico e tratamento, e aumentando a incidência de internação.

As crianças nascidas com IG inferior a 32 semanas também tiveram percentualmente mais internação do que as crianças nascidas a termo com BPN na cidade de Sobral, embora sem significado estatístico, diferente da literatura (Tabela 18).

Davidson et al. (2010) estudaram uma coorte retrospectiva de 248 612 registros de nascimentos entre 1970 e 1989 e os registros de internação subseqüente para 4017 crianças com asma, até 1999. Os autores concluíram que a prematuridade e o BPN apresentam risco de 1,6 e 1,4 vezes maior respectivamente de se internar por asma no primeiro ano de vida, além de outros fatores como sexo masculino, antecedentes de asma materna, tabagismo materno, e paridade.

Quanto à alimentação oferecida aos quatro meses de idade, uma porcentagem menor das crianças internadas estava em aleitamento materno exclusivo do que aquelas que não se internaram $(21,21 \%$ e $37,20 \%$ respectivamente) embora sem significado estatístico (Tabela 20).

Apesar da interrupção do aleitamento materno não ter oferecido risco para internação neste estudo, a Tabela 24 mostra que o incremento do escore-z de peso diminuiu o risco de internação após o período neonatal (OR $0,65, p=0,013$ ). Dados semelhantes são descritos na literatura onde a desnutrição está relacionada à mortalidade e morbidade infantil.

Chisti et al. (2009) realizaram uma revisão sistemática para quantificar em quanto a desnutrição aumenta o risco de mortalidade por pneumonia. 
Verificaram que, na desnutrição moderada, os riscos relativos variaram de 1,2 até 36,5 sendo os riscos maiores na desnutrição grave. Além disso, observaram agentes etiológicos diferentes quando comparados com as crianças nutridas.

Creek et al. (2010) acompanharam 153 crianças hospitalizadas com diarréia durante um surto em 2006 em Botswana e verificaram que 97\% eram menores de dois anos de idade, $88 \%$ não estavam sendo amamentadas, $25 \%$ estavam desnutridas e 33 crianças, ou seja, $22 \%$ desta população evoluiu para óbito. Concluíram então que a desnutrição e a ausência do aleitamento materno estiveram fortemente relacionadas com quadros clínicos graves e com óbitos destas crianças.

Conforme mostra a análise multivariada na Tabela 24, além do estado civil materno e do incremento do escore-z do peso, as demais variáveis estudadas não tiveram relação com internação por pneumonia, diarréia ou outros motivos durante o primeiro ano de vida, resultado este diferente de outros estudos onde as condições socioeconômicas são fatores de risco para aumento da morbidade infantil (Lins et al., 2003).

Segundo Barros et al. (2010), as crianças de famílias pobres, em comparação com aquelas de famílias mais ricas, são mais suscetíveis à exposição a agentes patogênicos, tendo deste modo risco aumentado de adoecer, devido à sua menor resistência e deficiência de medidas preventivas. Uma vez doentes, o acesso é mais difícil e a qualidade dos serviços inferiores, com menor acesso a tratamentos médicos que garantam sua sobrevivência. Como conseqüência, crianças de famílias mais pobres 
apresentam maiores taxas de mortalidade e maior risco de serem subnutridas.

Contudo, nenhumas das variáveis relacionadas às condições socioeconômicas constituíram fatores de risco para maior morbidade durante o primeiro ano de vida nas crianças de BPN de Sobral. Provavelmente, resultado da priorização na promoção e na prevenção da saúde para estes grupos de risco, já adotada na política do PSF do município.

O seguimento regular em serviço ambulatorial tanto serve para prevenir agravos como para evitar agravamento de enfermidades existentes, com diagnóstico e tratamento precoce, reduzindo o risco de internação. 
6 CONCLUSÕES 
Os resultados do estudo permitem concluir que:

a) As principais variáveis relacionadas com o aumento da morbidade durante o primeiro ano de vida em crianças com baixo peso ao nascer da cidade de Sobral estatisticamente significativas foram ausência do companheiro, menor idade gestacional e peso ao nascer, a interrupção do aleitamento materno exclusivo antes dos quatro meses e ausência de incremento do peso até os quatro meses.

b) Entre as características maternas das crianças estudadas se destacaram: incidência elevada de mães adolescentes e sem o apoio do companheiro (solteira, separada, viúva, desquitada).

c) Entre as características perinatais, metade das crianças de BPN era nascidas a termo e, portanto, pequenas para idade gestacional;

d) Entre as condições ambientais, $36,49 \%$ das moradias utilizavam fogão a lenha ou fogareiro, 27,94 \% dos domicílios não eram rebocados, e $36,11 \%$ das famílias tinham renda inferior a um salário mínimo.

e) Cerca de $11 \%$ das crianças não apresentaram incremento satisfatório do escore-z de peso e $60 \%$ do escore-z de comprimento até o final do primeiro ano de vida.

f) $73,15 \%$ das crianças prematuras estavam em aleitamento materno exclusivo com 40 semanas de idade gestacional corrigidas; $34,52 \%$ de todas 
as crianças de BPN permaneceram em aleitamento materno exclusivo por quatro meses e $11,22 \%$ até os seis meses de idade.

g) Nenhumas das variáveis de exposição estudadas conferiram risco para um maior número de consultas por doença no PSF.

h) A interrupção do aleitamento materno exclusivo antes dos quatro meses aumenta em 3,1 vezes a chance de ser consultada em emergência pediátrica quando comparada com aleitamento materno exclusivo até os quatro meses $(p<0,001)$.

i) Quanto menor a idade gestacional e o peso ao nascer maior a chance de ficar internado no período neonatal (OR 2,21 e 6,10; $p<0,05$ e $p$ $<0,001$, respectivamente) .

j) O apoio do companheiro (mães casadas ou com união estável) e o incremento do escore-z de peso até os 4 meses diminuíram a chance de internação após o período neonatal (OR 0,26 e 0,65 respectivamente, $p<$ 0,05 em ambos).

k) As variáveis: idade e escolaridade materna, tipo de parto, Apgar de 5 minutos, sexo, tipo de moradia, tipo de fogão, renda familiar e incremento no escore-z de comprimento não apresentaram relação estatisticamente significativa com a morbidade durante o primeiro ano de vida das crianças de BPN. 
7 ANEXo 


\section{Anexo A - Aprovação da Comissão de Ética}

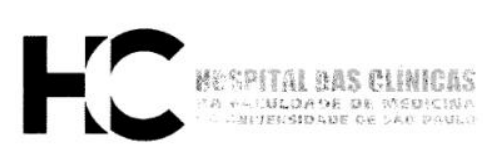

\section{APROVAÇÃO}

A Comissão de Ética para Análise de Projetos de Pesquisa CAPPesa da Diretoria Clínica do Hospital das Clínicas e da Faculdade de Medicina da Universidade de São Paulo, em sessão de 18/02/2009, APROVOU o Protocolo de Pesquisa $n^{\circ}$ 0043/09, intitulado: "MORBIMORTALIDADE DE CRIANÇA COM BAIXO PESO AO NASCER DURANTE O PRIMEIRO ANO DE VIDA NA CIDADE DE SOBRAL, CEARÁ." apresentado pelo Departamento de PEDIATRIA.

Cabe ao pesquisador elaborar e apresentar à CAPPesq, os relatórios parciais e final sobre a pesquisa (Resolução do Conselho Nacional de Saúde $n^{\circ} 196$, de 10/10/1996, inciso IX.2, letra "c").

Pesquisador (a) Responsável: Profa. Dra. Edna Maria Albuquerque Diniz Pesquisador (a) Executante: Juliana Rodrigues Pinto

CAPPesq, 19 de Fevereiro de 2009

$$
\ddot{c} \Delta
$$

Prof. Dr. Eduardo Massad Presidente da Comissão de Ética para Análise de Projetos de Pesquisa

Comissão de Ética para Análise de Projetos de Pesquisa do HCFMUSP e da FMUSP Diretoria Clínica do Hospital das Clinicas da Faculdade de Medicina da Universidade de São Paulo Rua Ovídio Pires de Campos, 225, 5a andar - CEP 05403010 - São Paulo - SP Fone: 01130696442 Fax: 01130696492 e-mail: cappesq@hcnet.usp.br / secretariacappesq2@hcnet.usp.br 


\section{REFERÊNCIAS}


Andrade CLT, Szwarcwald CL, Castiliho EA. Baixo peso ao nascer no Brasil de acordo com as informações sobre nascidos vivos do Ministério da Saúde, 2005. Cad Saúde Pública (Rio de J). 2008; 24(11):2564-72.

Andrade CLT, Szwarcwald CL, Gama SGN, Leal MC. Desigualdades sócioeconômicas do baixo peso ao nascer e da mortalidade perinatal no Município do Rio de Janeiro, 2001. Cad Saúde Pública (Rio de J). 2004; 20(suppl.1):s44-51.

Andrade LOM, Martins Júnior T. Sistema local de saúde de Sobral: um processo em construção. Sanare. 2000; 1:54-73. Disponível em <http://www.sobral.ce.gov.br/saudedafamilia/>. Acesso em 20 jul 2009.

Andrade LOM. O desafio da formação - A Escola de Formação em Saúde da Família Visconde de Sabóia, em Sobral, aponta caminhos. In: Revista Brasileira de Saúde da Família. Ano II, n. 4. Brasília: Ministério da Saúde, 2002.

Araújo BF, Tanaka ACd'A, Madi JM, Zatti H. Estudo da mortalidade de recém-nascidos internados na UTI neonatal do Hospital Geral de Caxias do Sul, Rio Grande do Sul. Rev Bras Saúde Matern Infant (Recife). 2005; $5(4): 463-9$. 
Ballard JL, Khoury JC, Wedig K, Wang L, Eilers-Walsman BL, Lipp R. New Ballard score, expanded to include extremely premature infants. J Pediatr. $1991 ; 119: 417-23$

Barreto ICHC. Mortalidade referida e seus condicionantes em crianças de 5 a 9 anos da zona urbana de Sobral - CE [tese]. São Paulo: Universidade de São Paulo, 2006.

Barros FC, Semer TC, Tonioli Filho S, Tomasi E, Victora CG. The impact of lactation centres on breastfeeding patterns, morbidity and growth: a birth cohort study. Acta Paediatr. 1995; 84:1221-6.

Barros FC, Victora CG, Scherpbier R, Gwatkin D. Iniquidades sociais na saúde e nutrição de crianças em países de renda baixa e média. Rev Saúde Pública (S Paulo). 2010; 44(1):1-16.

Benício MHDA, Monteiro CA. Tendência secular da doença diarréica na infância na cidade de São Paulo (1984-1996). Rev Saúde Pública. 2000; 34(6 Supl):83-90.

Bertagnon, RD. Recém-nascido pequeno para a idade gestacional: algumas características epidemiológicas [dissertação]. São Paulo: Faculdade de Sáude Pública da Universidade de São Paulo, 1991.

Caetano JRM, Bordin IAS, Puccini RF, Peres CA. Fatores associados à internação hospitalar de crianças menores de cinco anos, São Paulo, SP. Rev. Saúde Pública (São Paulo). 2002; 36(3):285-91. 
Caetano JRM. Fatores de risco associados a internação hospitalar e infecção respiratória aguda grave em crianças menores de cinco anos no município de Embu - SP [dissertação]. São Paulo: Escola Paulista de Medicina da UNIFESP, 1999.

Campos GJV, Reis Filho AS, Silva AAM, Novochadio MAS, Silva RA, Galvão CES. Morbimortalidade infantil por diarréia aguda em área metropolitana da região nordeste do Brasil, 1986-1989. Rev Saúde Pública. 1995; 29(2):132-9.

Capurro H, Konichezky S, Fonseca D, Caldeyro-Barcia R. A simplified method for diagnosis of gestational age in the newborn infant. $J$ Pediatr. 1978; 93:120-2.

Carniel EF, Zanolli ML, Antônio MARG, Morcillo AM. Determinantes do baixo peso ao nascer a partir das Declarações de Nascidos Vivos. Rev Bras Epidemiol (São Paulo). 2008; 11(1):169-79.

Cesar JA, Victoria CG, Barros FC, Ramos FA, Albernaz EP, Oliveira LM, Halpern R, Breitenbach A, Stone MH, Fracalossi V. Hospitalizações em menores de um ano pertecentes a duas coortes de base populacional no Sul do Brasil: tendências e diferenciais. Cad Saúde Publ (Rio J). 1996; 12(Supl.1):67-71

Chaudhari S, Kulkami S, Pandit A, Deshmukh S. Mortality and morbidity in high risk infants during a six year follow-up. Indian Pediatr. 2000; $37(12): 1314-20$. 
Chisti MJ, Tebruegge M, La Vincente S, Graham SM, Duke T. Pneumonia in severely malnourished children in developing countries - Mortality risk, aetiology and validity of WHO clinical signs: a systematic review. Trop Med Int Health. 2009; 14(10):1173-89.

CNES-DATASUS. Estabelecimento por endereço. Disponível em $<$ http://cnes.datasus.gov.br/Lista_Es_Nome_Por_Estado_Municipio.asp?VEs tado=23\&VMun=231290>. Acesso 20 fev 2010 .

Costa CE, Gotlieb LD. Estudo epidemiológico do peso ao nascer a partir da declaração de nascido vivo. Rev Saúde Pública (São Paulo). 1998; 32(4):328-34 .

Creek TL, Kim A, Lu L, Bowen A, Masunge J, Arvelo W, Smit M, Mach O, Legwaila K, Motswere C, Zaks L, Finkbeiner T, Povinelli L, Maruping M, Ngwaru G, Tebele G, Bopp C, Puhr N, Johnston SP, Dasilva AJ, Bern C, Beard RS, Davis MK. Hospitalization and mortality among primarily nonbreastfed children during a large outbreak of diarrhea and malnutrition in Botswana, 2006. J Acquir Immune Defic Syndr. 2010; 53(1):14-9.

Das BK, Mishra RN, Mishra OP, Bhargava V, Prakash A. Compartive outcome of low birth weight babies. Indian Pediatr. 1993; 30(1):15-21.

DATASUS. Informações em Saúde. Assistência à Saúde. Atenção Básica - Saúde da Família - Desde 1998. Situação de saúde. Ministério da Saúde. Disponível em $<$ http://www2.datasus.gov.br/DATASUS/index.php?area=0202>. Acesso 18 fev 2010b. 
DATASUS. Informações em Saúde. Estatísticas Vitais. Ministério da Saúde. Disponível em <http://www2.datasus.gov.br/DATASUS/index.php>. Acesso 18 fev 2010c.

DATASUS. Sala de Situação em Saúde. Ministério da Saúde. Disponível em <http://www2.datasus.gov.br/DATASUS/index.php?area=0201>. Acesso em 18 fev 2010a.

Davidson R, Roberts SE, Wotton CJ, Goldacre MJ. Influence of maternal and perinatal factors on subsequent hospitalization for asthma in children: evidence from the Oxford record linkage study. BMC Pulm Med. 2010, 10:14. Disponível em <http://www.biomedcentral.com/1471-2466/10/14>. Acesso em 29 jan 2010

Dewey KG, Cohen RJ, Brown KH, Rivera LL. Age of introduction of complementary foods and growth of term, low-birth-weight, breast-fed infants: a randomized intervention study in Honduras. Am J Clin Nutr. 1999; 69(4):679-86.

Escorel LS, Giovanella MH, Mendonça M, Senna MCM. O Programa de Saúde da Família e a construção de um novo modelo para a atenção básica no Brasil. Pan Am J Public Health. 2007; 21(2):164-76.

Ferrer APS. Estudo das causas de internação hospitalar das crianças de 0 a 9 anos de idade no município de São Paulo [dissertação] São Paulo: Faculdade de Medicina da Universidade de São Paulo, 2009. 
Fonseca W, Kirkwood BR, Victoria CG, Fuchs SR, Flores JA, Misago C. Risk factors for childhood pneumonia among the urban poor in Fortaleza, Brazil: a case-control study. Bull. World Health Organ. 1996; 74(2):199-208.

Gomes MASM, Lopes JMA, Moreira MEL, Gianini NOM. Assistência e mortalidade neonatal no setor público do Município do Rio de Janeiro, Brasil: uma análise do período 1994/2000. Cad Saúde Pública (Rio J). 2005; 21(4):1269-77.

Goya A, Ferrari GF. Fatores de risco para morbimortalidade por pneumonia em crianças. Rev Paul Pediatr. 2005; 23(2);99-105.

Grupo Colaborativo de Estudos Perinatais, São Paulo. Fatores perinatais relacionados com a morbidade e a mortalidade de recém-nascidos pertencentes a nove unidades neonatais do município de São Paulo. $J$ Pediatr (Rio J). 1996; 72(6):379-87.

Hack M, Weissman B, Borawski-Clark E. Catch-up growth during childhood among very low-birth-weight children. Arch Pediatr Adolesc Med. 1996; $150(11): 1122-9$

Horta BL, Barros FC, Halpern R, Victora CG. Baixo peso ao nascer em duas coortes de base populacional no Sul do Brasil. Rio de Janeiro: Cad Saúde Públ (Rio J). 1996; 12(Supl.1):27-31.

IBGE - Instituto Brasileiro de Geografia e Estatística. Estimativas da população para $1^{\circ}$ de julho de 2009. Disponível em 
<http://www.ibge.gov.br/home/estatistica/populacao/estimativa2009/estimativ a.shtm>. Acesso em 16 ago 2009.

Khashu M, Narayanan M, Bhargava S, Osiovich H. Perinatal outcomes associated with preterm birth at 33 to 36 weeks' gestation: a population Based cohort study. Pediatrics. 2009; 123(1):109-13.

Kramer MS, Demissie K, Yang H, Platt RW, Sauvé R, Liston R. The contribution of mild e moderate preterm birth to infant mortality. JAMA. 2000; 284(7):843-9 .

Kramer, MS. Determinants of low birth weight: methodological assessment and meta-analysis. Bull World Health Organ. 1987; 65(5):663-737.

Kummer S, Giugliani ERJ, Susin LO, Folletto JL, Lermen NR, Wu VYJ; Santos L, Caetano, MB. Evolução do padrão de aleitamento materno. Rev. de Saúde Pública (S Paulo). 2000; 34(2):143-8.

Lins MGM, Motta MEFA, Silva GAP. Fatores de risco para diarréia persistente em lactentes. Arq Gastroenterol. 2003; 40(4):239-46.

Macedo SEC, Menezes AMB, Albernaz E, Post P, Knorst M. Fatores de risco para internação por doença respiratória aguda em crianças até um ano de idade. Rev. Saúde Pública (São Paulo). 2007; 41(3): 351-8.

Macinko J, Guanais FC,Souza MFM. Evaluation of the impact of the Family Health Program on infant mortality in Brazil, 1990-2002. J Epidemiol Community Health. 2006; 60:1319. 
Manji KP, Massawe AW, Mgone JM. Birthweight and neonatal outcome at the Muhimbili Medical Center, Dar es Salaam, Tanzania. East Afr Med J. 1998; 75(7):382-7.

Mansano NH, Mazza VA, Soares VMN, Araldi MAR, Cabral VLM. Comitês de prevenção da mortalidade infantil no Paraná, Brasil: implantação e operacionalização. Cad Saúde Pública (Rio J). 2004; 20(1):109-18.

Mansour E, Eissa AN, Nofal LM, Kharboush I, Reda AA. Morbidity and mortality of low-birth-weight infants in Egypt. Eastn Mediterrn Health J. 2005; 11(4):723-31.

Maranha, LK. Condicionantes maternos e crescimento de crianças de baixo peso ao nascer: um estudo longitudinal [tese]. Campinas: Faculdade de Ciências Médicas, Universidade Estadual de Campinas, 2004.

Matijasevich A, Cesar JÁ, Santos IS, Barros AJD, Dode MASO, Barros FC, Victora CG. Hospitalizations during infancy in three population-based studies in Sourthern Brazil: trends and differentials. Cad Saúde Púplica (Rio J). 2008; 24(sup 3):S437-S443.

Mclntire DD, Bloom SL, Casey BM, Leveno KJ. Birth weight in relation to morbidity and mortality among newborn infants. N Engl J Med. 1999; 340(16):1234-8.

Mello RR, Dutra MVP, Lopes JMA. Morbidade respiratória no primeiro ano de vida de prematuros egressos de uma unidade pública de tratamento intensivo neonatal. J Pediatr. 2004; 80(6):503-10. 
Ministério da Saúde. AIDPI - Atenção Integrada às Doenças Prevalentes na Infância. Brasília: Ministério da Saúde. Disponível em <http://dtr2001.saude.gov.br/editora/produtos/livros/genero/livros.htm\#a>. Acesso em 10 jul 2005.

Ministério da Saúde. Secretaria de Vigilância em Saúde. Evolução da $\begin{array}{llll}\text { Mortalidade } & \text { Infantil no } & \text { Brasil. } & \text { Disponível }\end{array}$ em:<http://portal.saude.gov.br/portal/saude/visualizar_texto.cfm?idtxt=24437. Acesso 22 jul 2009.

Ministério da Saúde. Secretaria de Vigilância em Saúde. Saúde Brasil 2004 Uma análise da situação de saúde. Brasília: Ministério da Saúde, 2004.

Morris SS, Grantham-McGregor SM, Lira PIC, Assunção MAS, Ashworth A. Effect of breastfeeding and morbidity on the development of low birthweight term babies in Brazil. Acta Paediatr. 1999; 88(10):1101-6.

Motta MEFA, Silva GAP, Araujo OC, Lira PI, Lima MC. O peso ao nascer influencia o estado nutricional ao final do primeiro ano de vida? $J$ Pediatr (Rio J). 2005; 81:377-82.

Nascimento LFC, Marcitelli R, Agostinho FS, Gimenes C. Análise hierarquizada dos fatores de risco para pneumonia em crianças. J Bras Pneumol (São Paulo). 2004; 30(5):445-51.

Nascimento, LF. Análise hierarquizada dos fatores de risco para o baixo peso ao nascer. Rev Paul Pediatr. 2005; 23(2):76-82. 
Nobili V, Alisi A, Panera N, Agostoni C. Low birth weight and catch-up-growth associated with metabolic syndrome: a ten year systematic review. Pediatr Endocrinol Rev. 2008; 6(2):241-7.

OMS - Organização Mundial da Saúde. El estado físico: uso e interpretación de la antropometría. Informe de un comité de expertos de la OMS. (OMS, série de informes técnicos; n. 854). Genebra. 1995. 522 p.

OMS - Organização Mundial da Saúde. United Nations Children's Fund and World Health Organization, Low Birthweight: Country, regional and global estimates. New York: UNICEF, 2004.

OMS. Division of Diarrheal and Acute Respiratory Disease Control. Indicators for assessing breast-feeding practices: report of an informal meeting. Geneva, 1991.

OMS/UNICEF. Declaração de Innocenti. Breastfeeding in the 1990s: A Global Initiative"; 1990; Florença. Disponível em <bvsms.saude.gov.br/bvs/publicacoes/declaracao_innocenti.pdf>. Acesso em 10 nov 2009.

ONU - Organização das Nações Unidas. Declaração Mundial sobre a Sobrevivência, a Proteção e o Desenvolvimento da Criança. Nova lorque, set 1990 . 
Palma O, Cruz L, Ramos H, Baires A, Villatoro N, Pastor D, Oliveira LH, Kerin T, Bowen M, Gentsch J, Esposito DH, Parashar U, Tate J, Patel M. Effectiveness of rotavirus vaccination against childhood diarrhoea in $\mathrm{El}$ Salvador: case-control study. BMJ. 2010; 15(340):c2825.

Passini JR. Determinantes pré-gestacionais e gestacionais de Baixo Peso ao Nascer [dissertação]. Campinas: Faculdade de Medicina da Universidade Estadual de Campinas, 1992.

Perrin JM. Variations in pediatric hospitalization rates: Why do they occur? Pediatric Annals, 1994; 33:676-83.

Pinto EALC, Barros Filho AA, Barro, MBA. Fatores de risco para diarréia persistente em crianças hospitalizadas. Arq Gastroenterol. 1998; 35(2):126-31.

Pojda J, Kelley L (Ed.). Low birth weight. Geneva: ACC/SCN c/o WHO, 44 p. Nutricion Policy Paper n. 18, 2000.

Post CL, Victora CG, Barros FC, Horta BL, Guimarães PRV. Desnutrição e obesidade infantis em duas coortes de base populacional no Sul do Brasil: tendências e diferenciais. Cad Saúde Públ. (Rio J). 1996; 12(Supl.1):49-57.

Prefeitura Municipal de Sobral. A cidade de Sobras. Disponível em: <http://www.sobral.ce.gov.br/cidade/sobral.htm>. Acesso em 29 ago 2009. Prietsch SOM, Fischer GB, César JÁ, Cervo PV, Sangaletti LL, Wietzycoski RC, Zacca D, Santos FM. Fatores de risco para sibilância recorrente em menores de 13 anos no Sul do Brasil. Rev Panam Salud Publica. 2006; $20(5): 331-7$ 
Rahmanifar A, Kirksey A, Mc Cabe GP, Galal OM, Harrison GG, Jerome NW. Respiratory tract and diarrheal infections of breast-fed infants from birth to 6 months of age in household contexts of an Egyptian village. Eur L Clin Nutr. $1996 ; 50(10): 655-62$

Ribeiro AM, Guimarães MJ, Lima MC, Sarinho SW, Coutinho SB. Fatores de risco para mortalidade neonatal em crianças com baixo peso ao nascer. Rev. Saúde Pública (S Paulo). 2009; 43(2):

Rodrigues JC, Silva Filho LVRF. Pneumonias Agudas. In Schvartsman C, Reis AG, Farhat SCL. Pronto Socorro. Coleção Pediatria. Instituto da Criança. HC-FMUSP. Barueri: Manole, 2009:269-281.

Roncalli AG, Lima KC. Impacto do Programa Saúde da Família sobre indicadores de saúde da criança em municípios de grande porte da região Nordeste do Brasil. Ciên Saúde Coletiva. 2006; 11(3):713-24.

Rouquayrol MZ. Epidemiologia e saúde. 4aㅡ ed. Rio de Janeiro: Medsi; 1994.

Rugolo LMSS. Crescimento e desenvolvimento a longo prazo do prematuro extemo. J Pediatr (Rio J). 2005; 81(1 Supl):S101-110.

SCMS - Santa Casa de Misericórdia de Sobral. Disponível em <http://www.stacasa.com.br/>. Acesso em 15 jan 2010.

Sena MCF, Silva EF, Pereira MG. Prevalência de aleitamento materno nas capitais brasileiras. Rev AMB. 2007; 53(6):520-4. 
Sgroi JCL. Relação de fatores de risco na gestação e peso ao nascer em crianças atendidas no Centro de Saúde Escola do Butantã, cidade de São Paulo [dissertação]. São Paulo: Universidade de São Paulo, 2008.

Sharma P, McKay K, Rosenkrantz TS, Hussain N. Comparisons of mortality and pre-discharge respiratory outcomes in small-for-gestacional-age and appropriate-for-gestacional-age premature infants. BMC Pediatr. 2004. Disponível em: <http://www.biomedcentral.com/1471-2431/4/9>. Acesso 11 out 2007.

Silva AC. O impacto do Programa de Saúde da Família no município de Sobral - Ceará: uma análise da evolução da saúde das crianças menores de cinco anos de idade no período de 1995-2002 [tese]. São Paulo: Faculdade de Medicina da Universidade de São Paulo, 2003.

Simon Jr H, Preto MM, Miszputen PT. Afecções de vias aéreas superiores. In Schvartsman C, Reis AG, Farhat SCL. Pronto Socorro. Coleção Pediatria. Instituto da Criança. HC-FMUSP. Barueri: Manole, 2009: 237-54.

Starfield B. Atenção primária: equilíbrio entre necessidades de saúde, serviços e tecnologia. Brasília: UNESCO, Ministério da Saúde, 2002.

Stoll BJ, Adams-Champman I. The high-risk infant. In Behrman ER, Kliegman RM, Arwin AM, Nelson WE. Nelson Textbook of pediatrics. $18^{\mathrm{a}}$ ed. New York: Saunders. 2007:701-10.

Strauss RS, Dietz WH. Effects of intrauterine growth retardation in premature infants on early childhood growth. J Pediatr 1997;130:95-102. 
Susin LRO, Giugliani ERJ, Kummer SC, Maciel M, Benjamin ACW, Machado DB, Barcaro $M$, Draghetti V. Uma estratégia simples que aumenta os conhecimentos das mães em aleitamento materno e melhora as taxas de amamentação. J Pediatr (Rio J). 1998; 74:368-75.

Vasconcelos MJOB. Prevalência, demandas ambulatoriais e hospitalização por diarréia em crianças, segundo variáveis nutricionais e fatores sócioambientais, no estado de Pernambuco [dissertação]. Recife: Universidade Federal de Pernambuco, 2006.

Venâncio SI; Escuder MML; Kitoko P; Rea MF; Monteiro CA. Freqüência e determinantes do aleitamento materno em municípios do Estado de São Paulo. Rev Saúde Pública (S. Paulo). 2002; 36(3):313-8.

Victora CG, Smith PG, Vaughan JP, Nobre LC, Lombardi C, Teixeira AM, Fuchs SM, Moreira LB, Gigante LP, Barros FC. Evidence for protection by breastfeeding against infant deaths from infectious diseases in Brazil. Lancet. $1987 ; 2: 319-22$.

Wilcox, A.J. On the importance - And the unimportance - Of birthweight. Int $J$ Epidemiol. 2001; 30:1233-41.

Xavier CC, Jorge SM, Gonçalves AL. Prevalência do aleitamento materno em recém-nascidos de baixo peso Rev Saúde Publ (S. Paulo). 1991; 25(5):381-7.

Young PC, Glasgow T, Li X, Guest-Warnick G, Stoddard G. Mortality of latepreterm (near-term) newborns in Utah. Pediatr. 2007; 119:659-65. 